\title{
Design, Synthesis and Evaluation of Inhibitors for Severe Acute Respiratory Syndrome 3C-like Protease Based on Phthalimidoketones or Heteroaromatic Esters
}

Jianmin Zhang, ${ }^{a}$ Hanna I. Pettersson, ${ }^{a}$ Carly Huitema, ${ }^{b}$ Chunying Niu, ${ }^{c}$ Jiang Yin, ${ }^{c}$ Michael N. G. James, ${ }^{\dagger c}$ Lindsay D. Eltis ${ }^{b}$ and John C. Vederas $*{ }^{\S a}$

${ }^{a}$ Department of Chemistry, University of Alberta, Edmonton, Alberta, Canada T6G 2G2.

${ }^{b}$ Departments of Microbiology and Biochemistry, University of British Columbia, Vancouver, British Columbia, Canada, V6T 1 Z3.

${ }^{c}$ Department of Biochemistry, University of Alberta, Edmonton, Alberta, Canada T6G $2 \mathrm{H} 7$.

*Canada Research Chair in Bioorganic and Medicinal Chemistry

${ }^{\dagger}$ Canada Research Chair in Protein Structure and Function

${ }^{\S}$ To whom correspondence should be addressed: Department of Chemistry, University of Alberta, Edmonton, Alberta, Canada T6G 2G2. Tel: +1-780-492-5475; Fax: +1-780-4922134; Email: john.vederas@ualberta.ca

Table of Contents

Page Numbers

90 carboxylic acids

2

HPLC spectra of crude and purified products by HPLC-MS 3

${ }^{1}$ HNMR spectra of crude and purified products by HPLC-MS 4-5

ESI-MS of complexes of $3 \mathrm{CL}^{\text {pro }}$ with inhibitors $35, \mathbf{4 8}, \mathbf{5 1} 6-7$ 


\section{A library of 90 carboxylic acids in the parellel synthesis.}

Part 1: Pyridinyl esters were obtained for the following 72 carboxylic acids.

$$
\text { (n) }
$$

Part 2: Pyridinyl esters were not obtained for the following 18 carboxylic acids. 

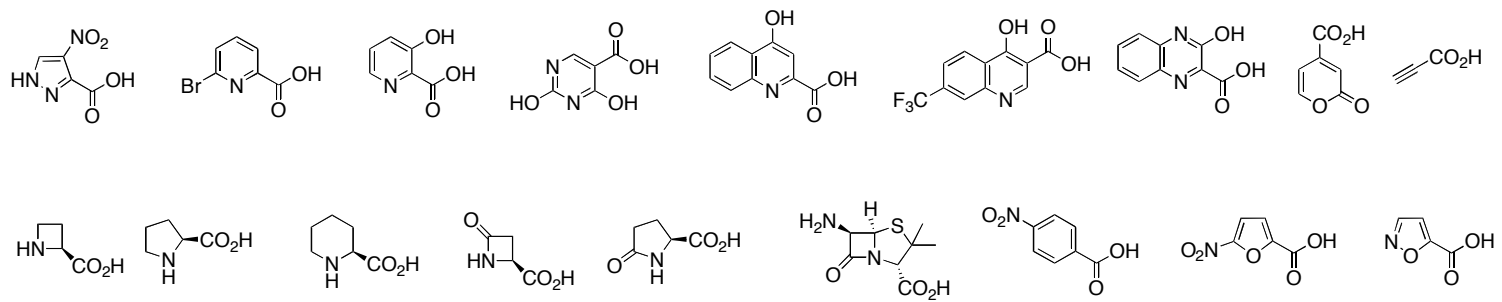

HPLC spectrum of the crude reaction mixture for 5-Chloropyridin-3-yl-3methylthiophene-2-carboxylate (Method A) through semi-prep column.

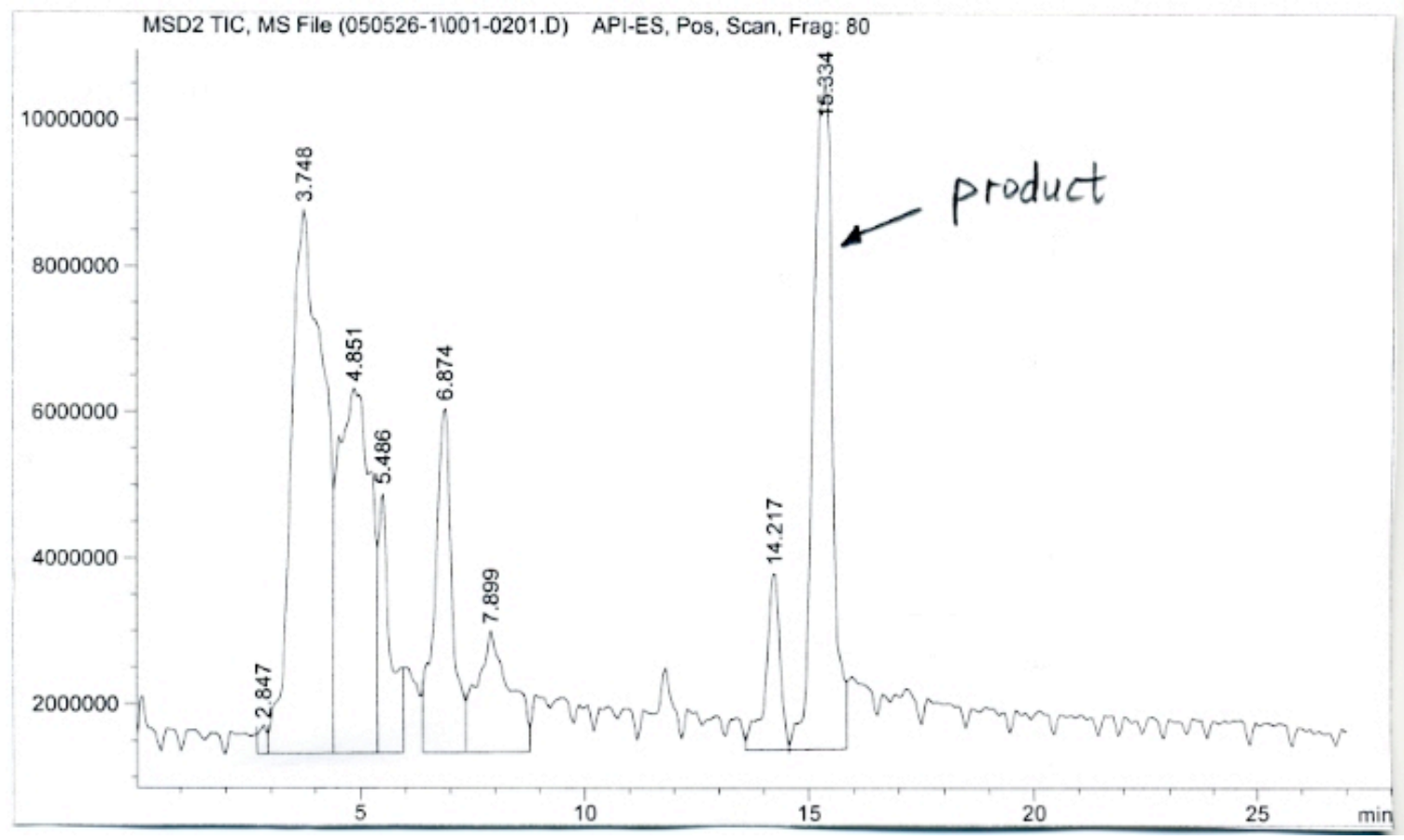

HPLC spectrum of the purified 5-Chloropyridin-3-yl-3-methylthiophene-2carboxylate by re-injection through analytic column.

SB 


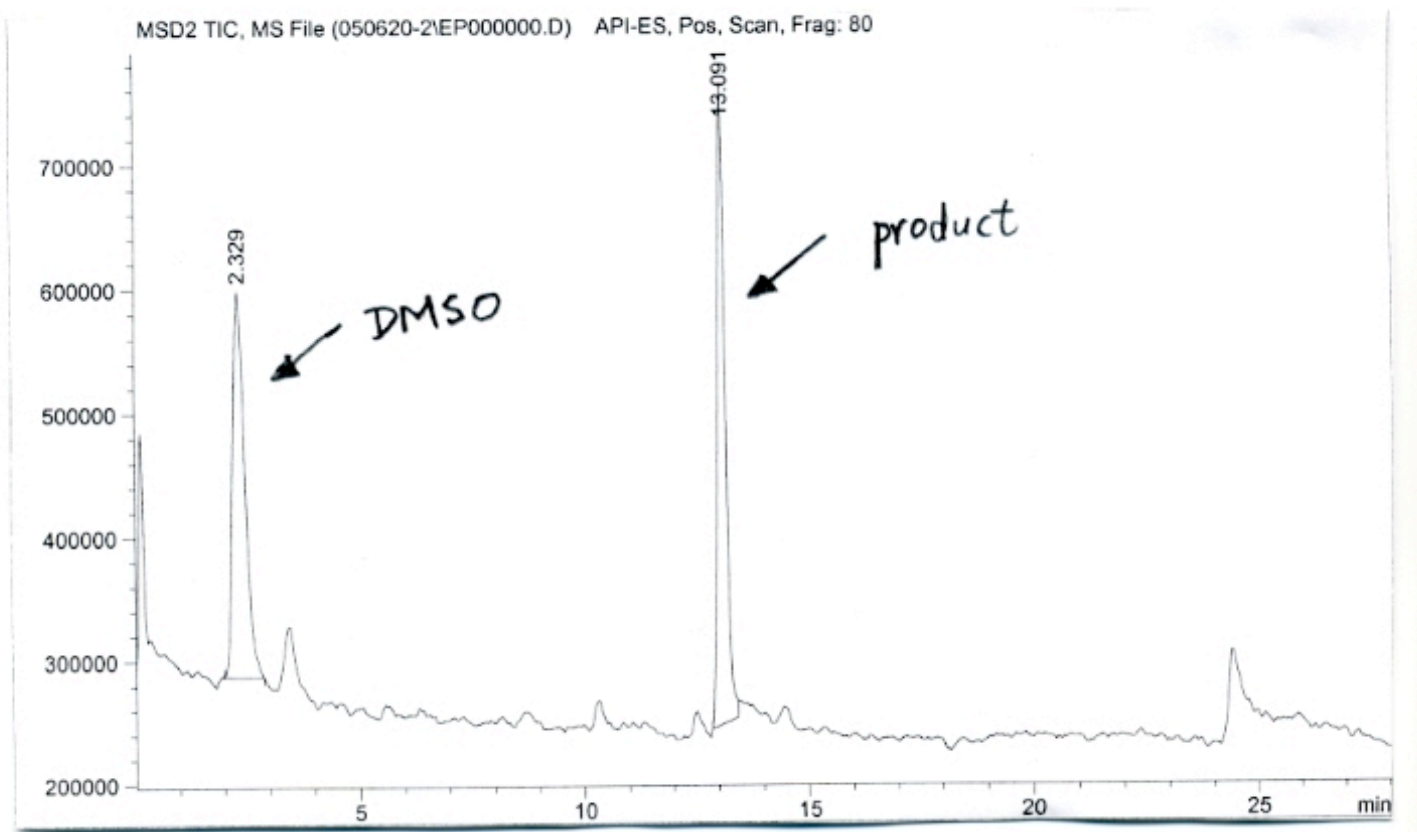

${ }^{1}$ HNMR spectrum of the crude reaction mixture for 5-Chloropyridin-3-yl-3methylthiophene-2-carboxylate (Method A). 


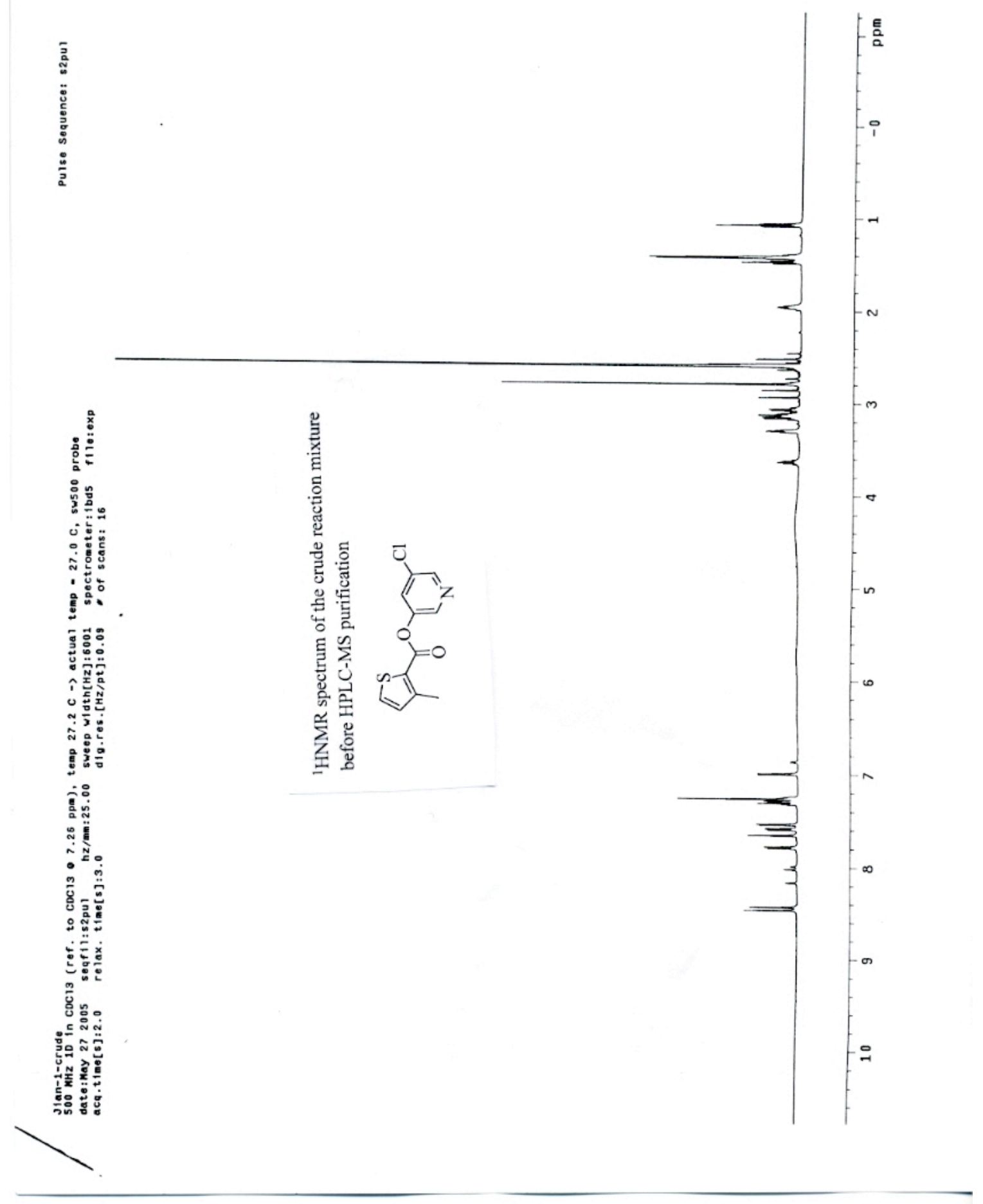

${ }^{1}$ HNMR spectrum of the purified 5-Chloropyridin-3-yl-3-methylthiophene-2carboxylate through HPLC-MS. 


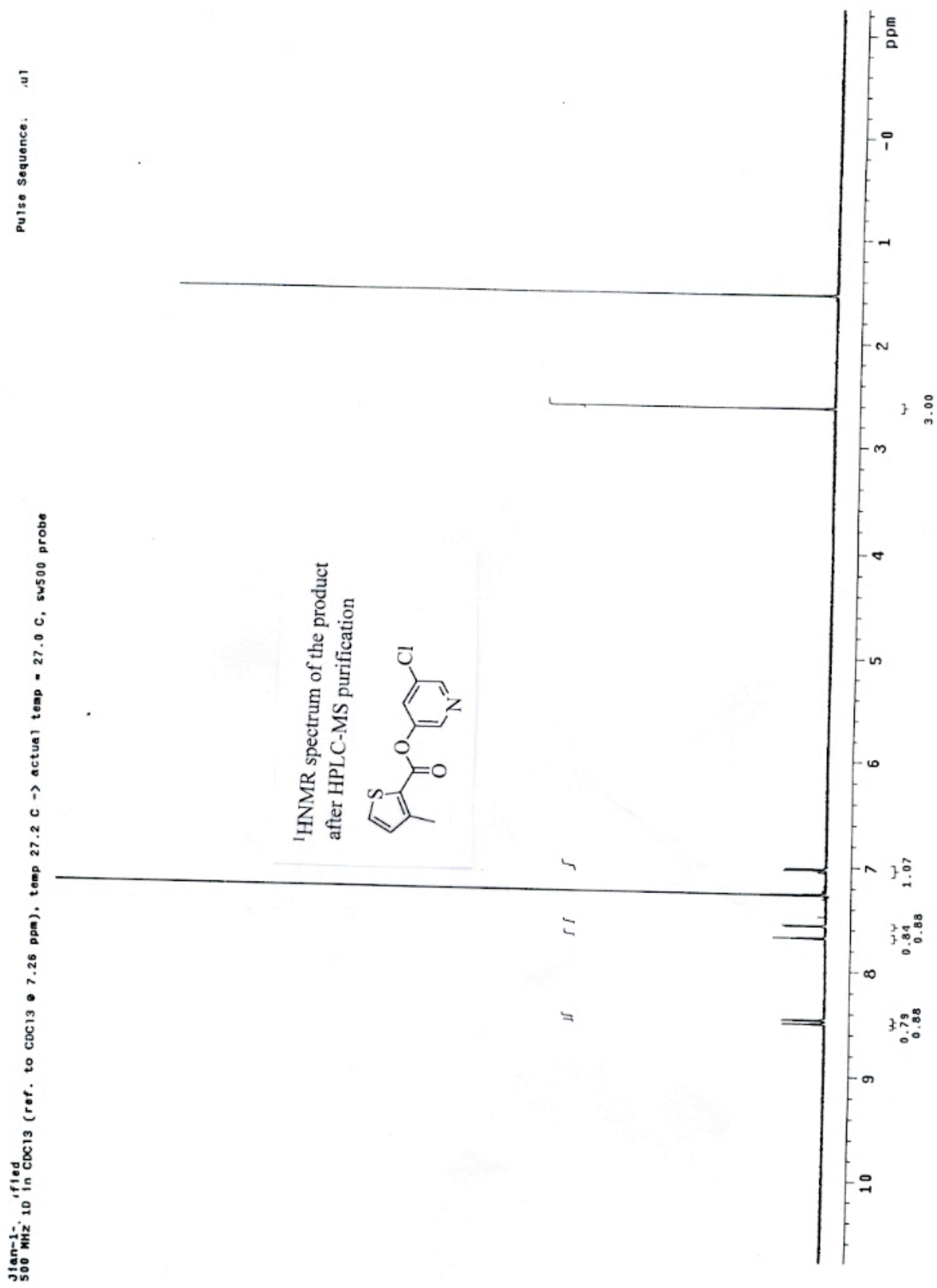

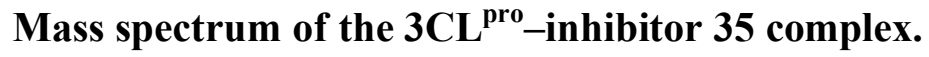




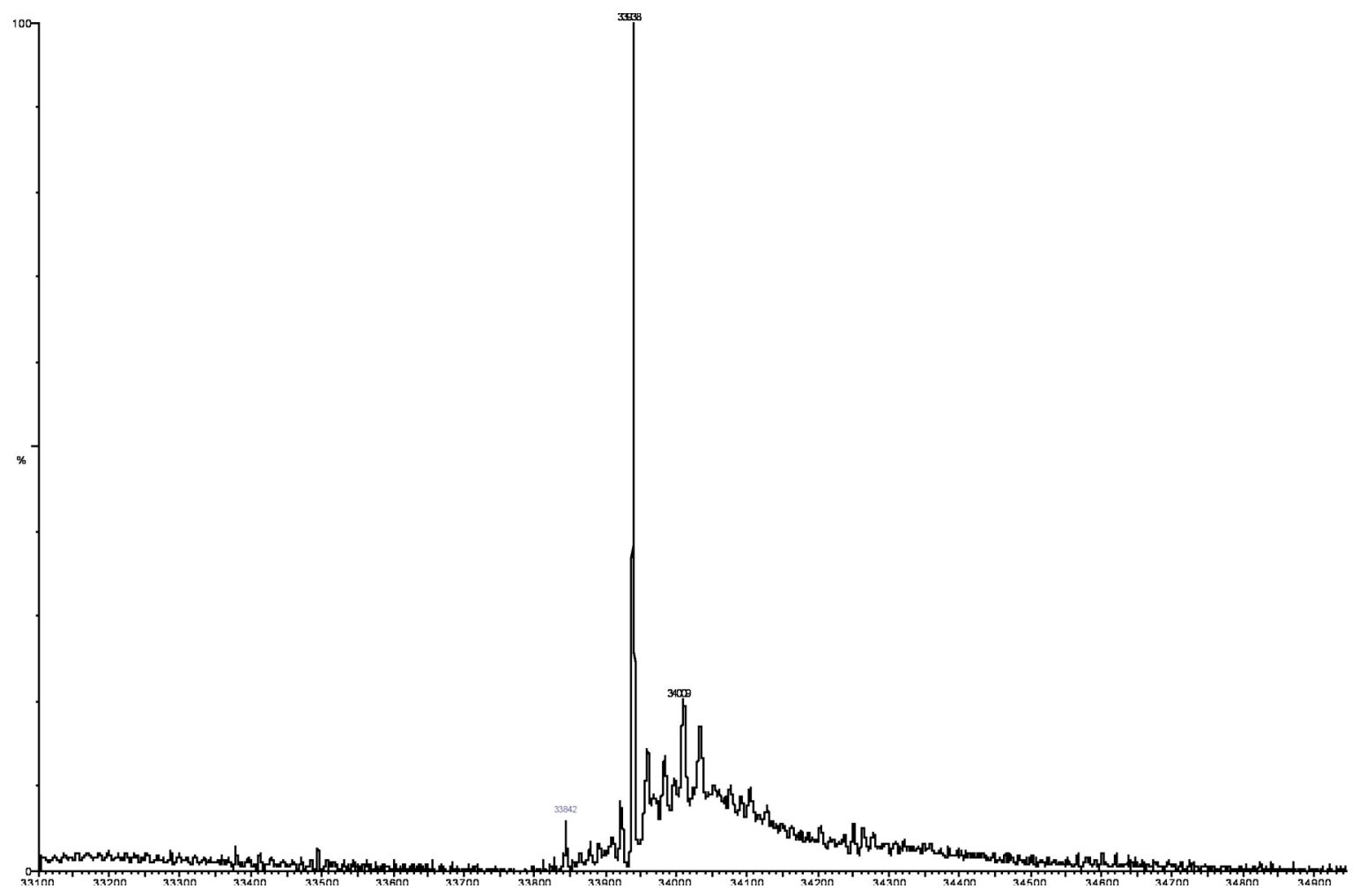

Mass spectrum of the $3 C L^{\text {pro }}$-inhibitor 48 complex.

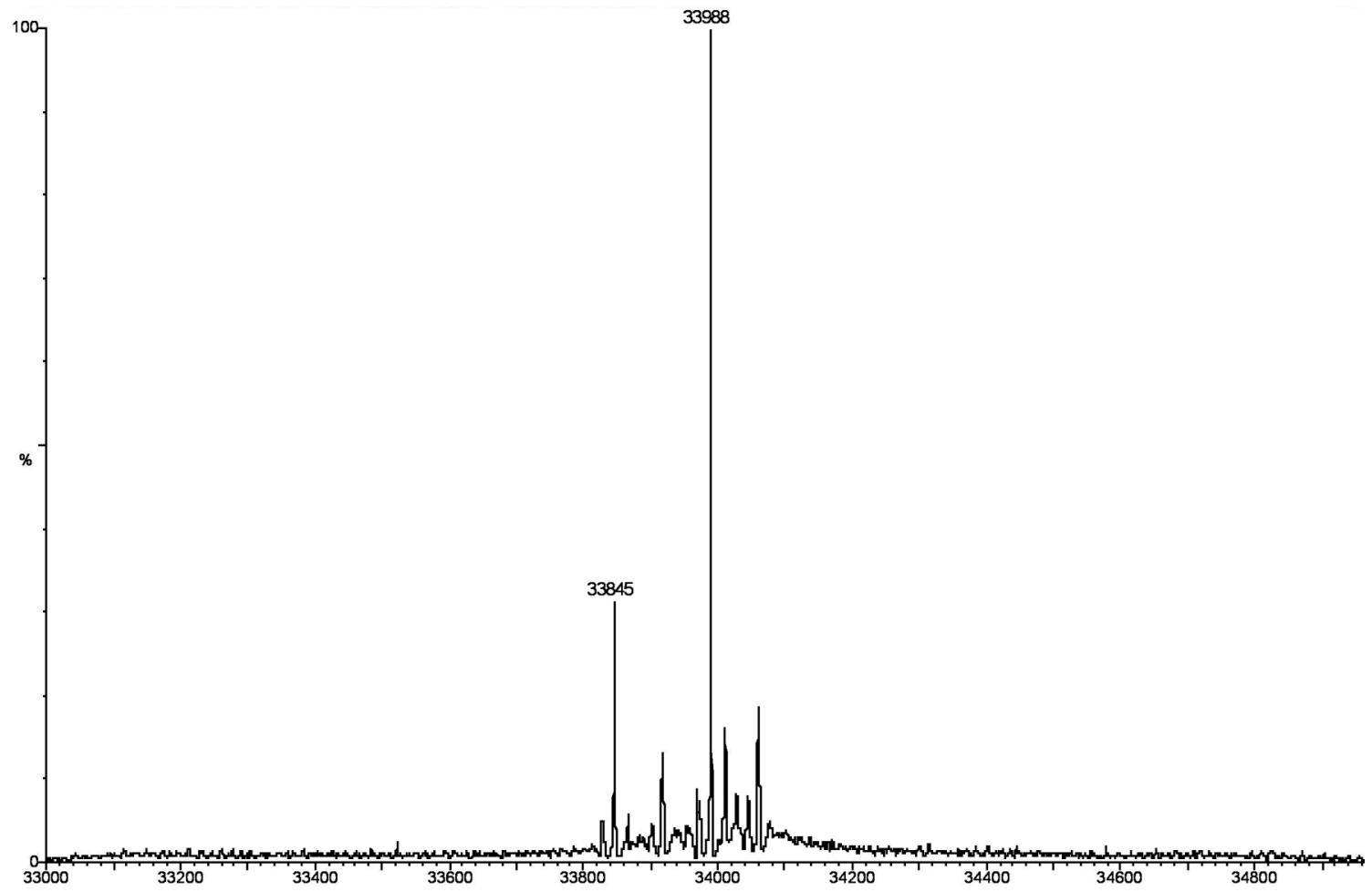

Mass spectrum of the $3 C L^{\text {pro }}$-inhibitor 51 complex. 


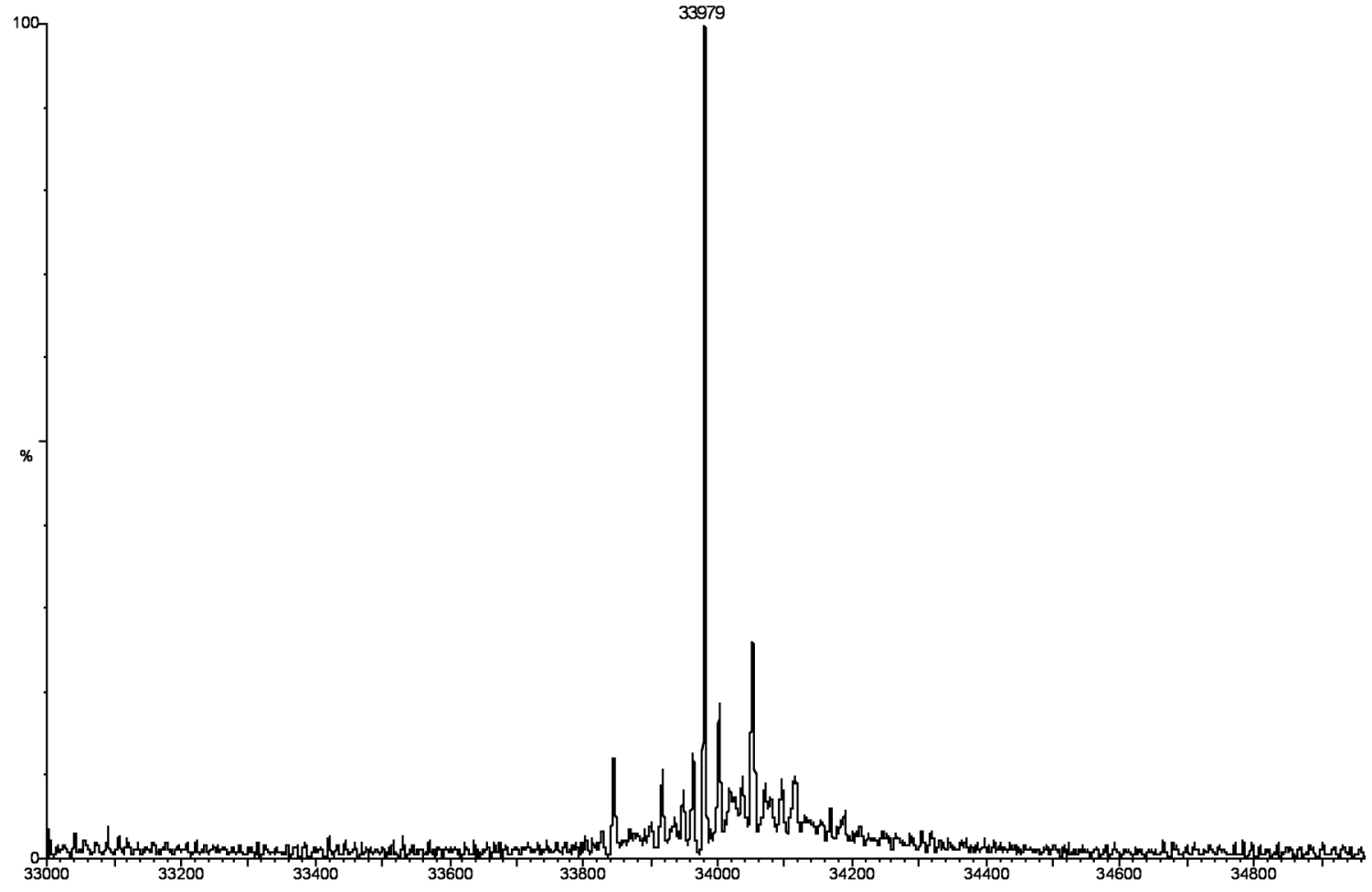




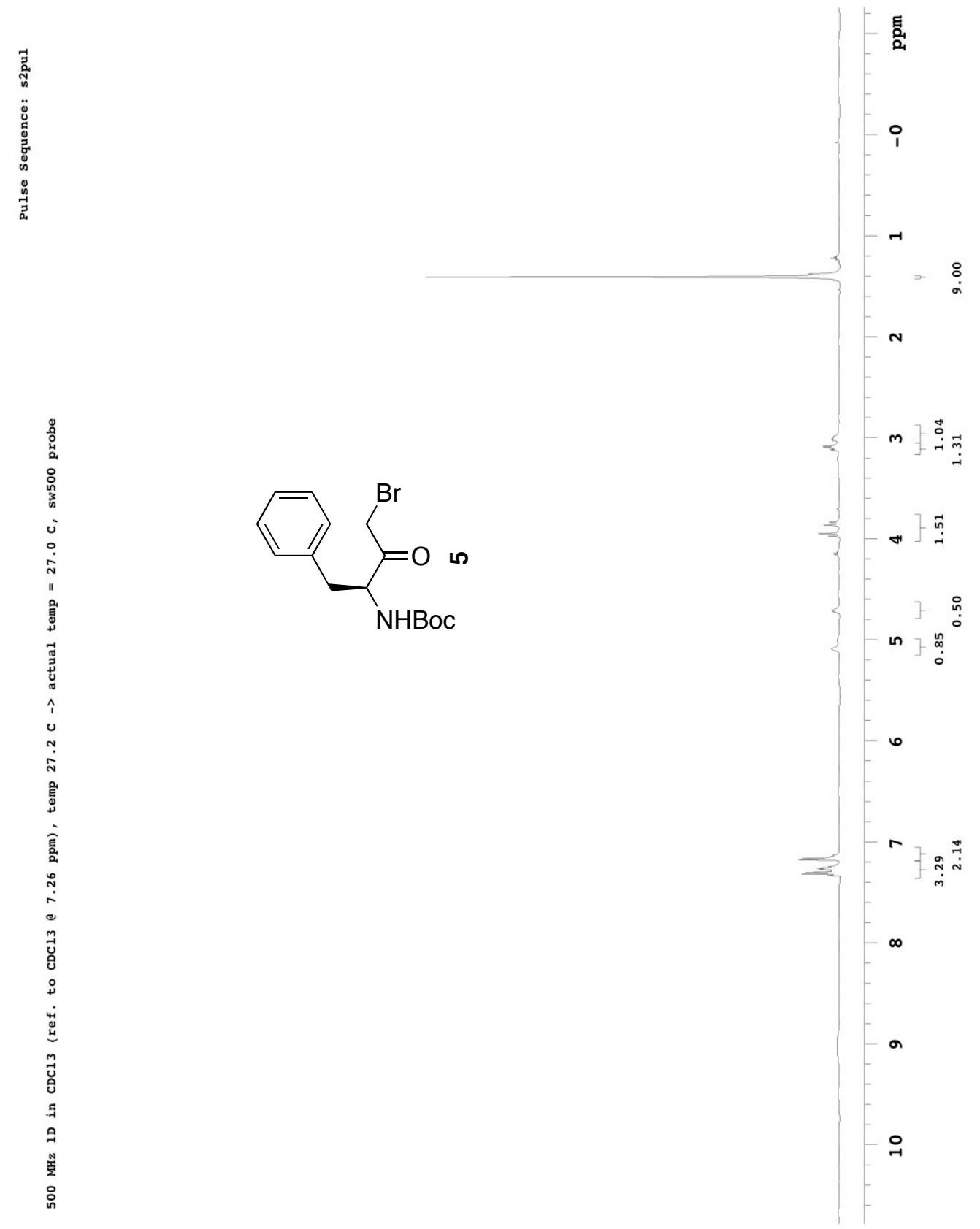




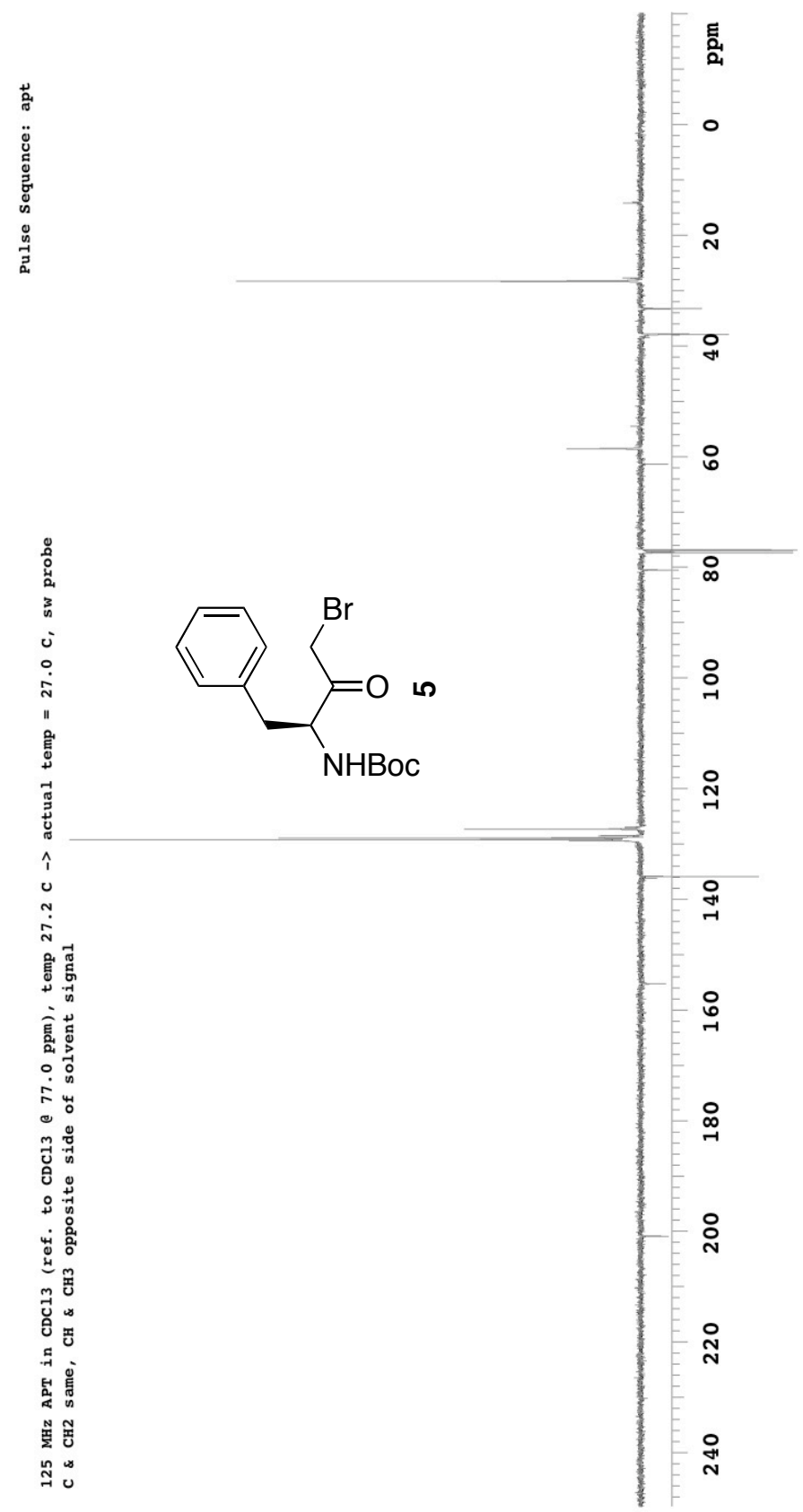




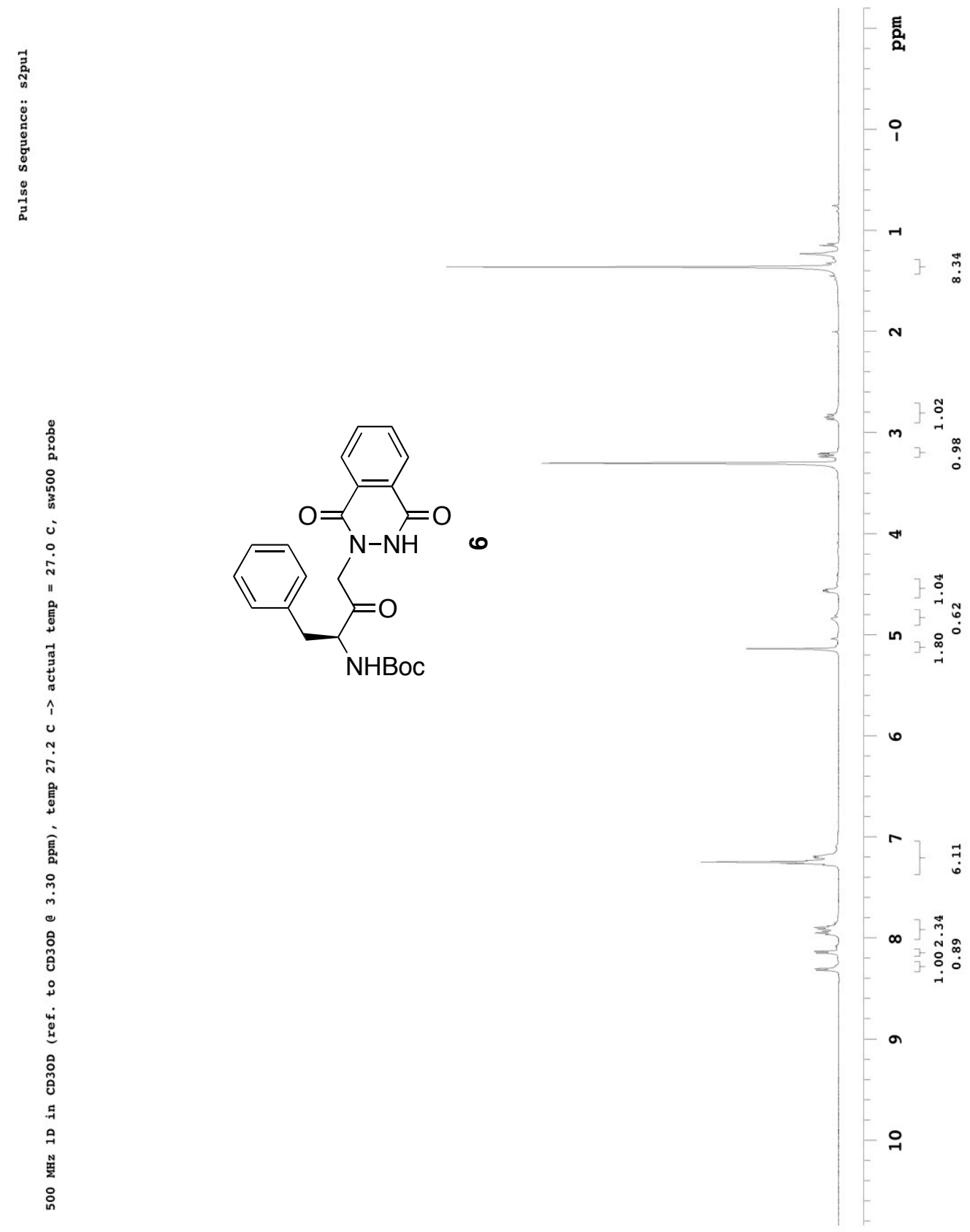




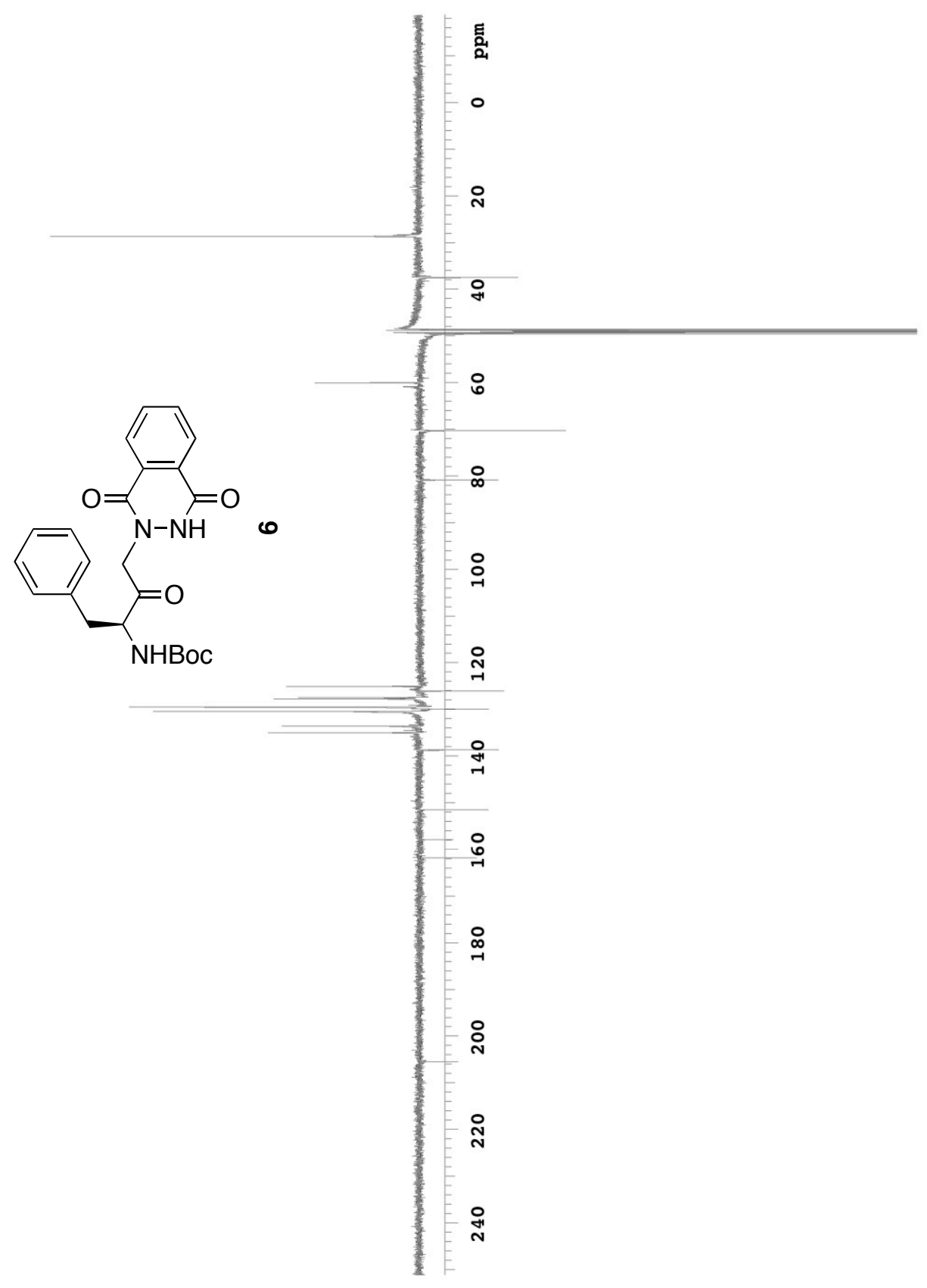




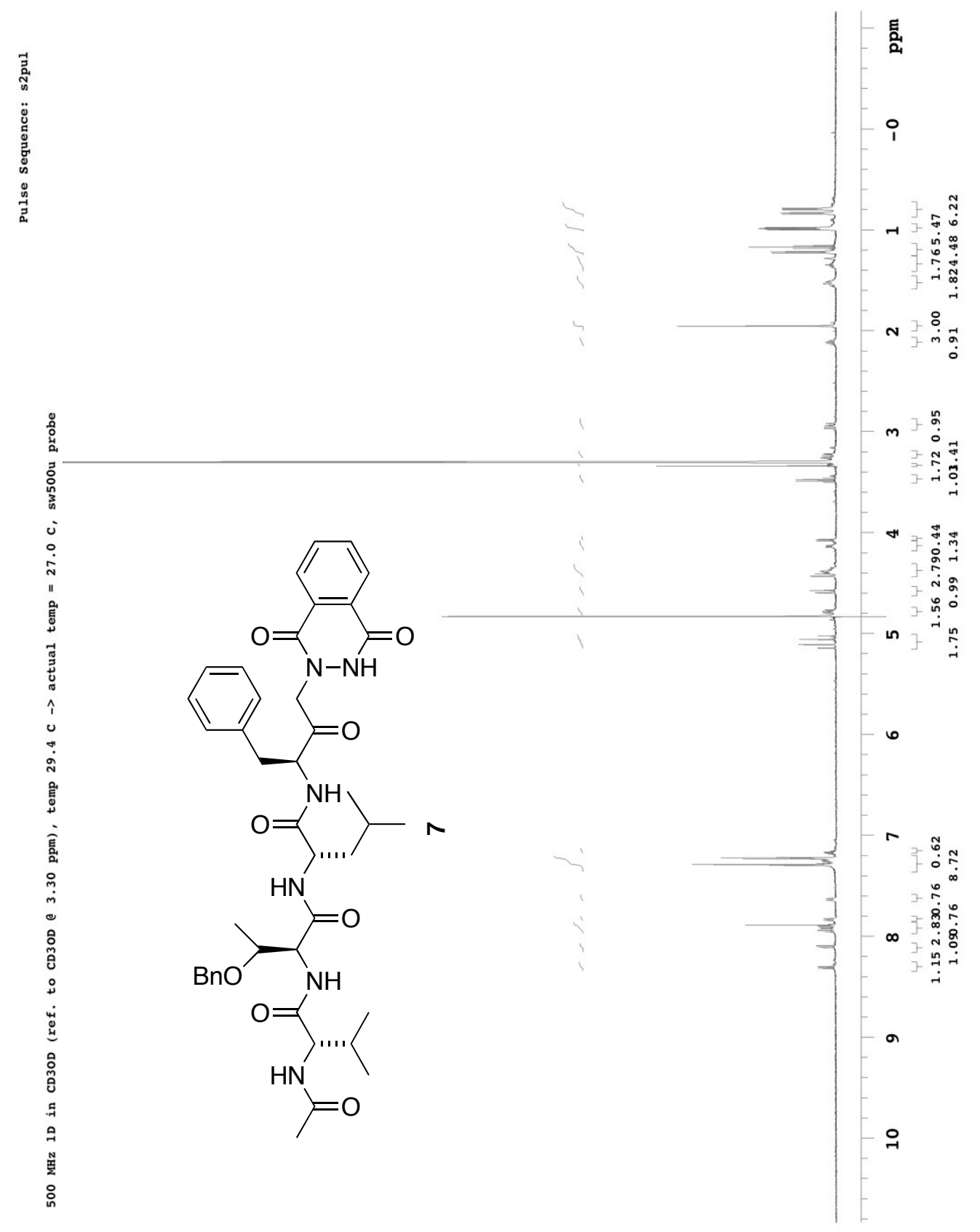




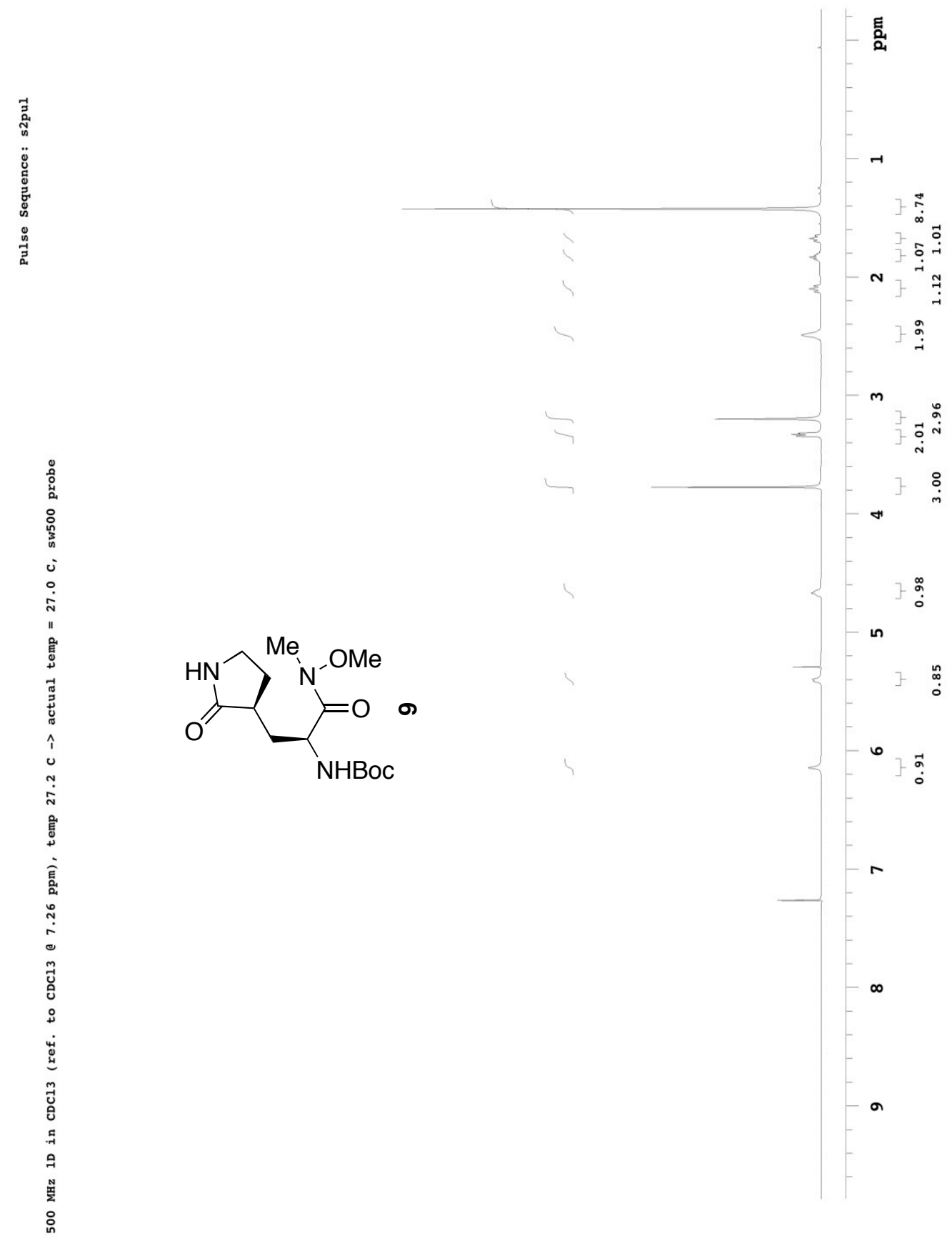




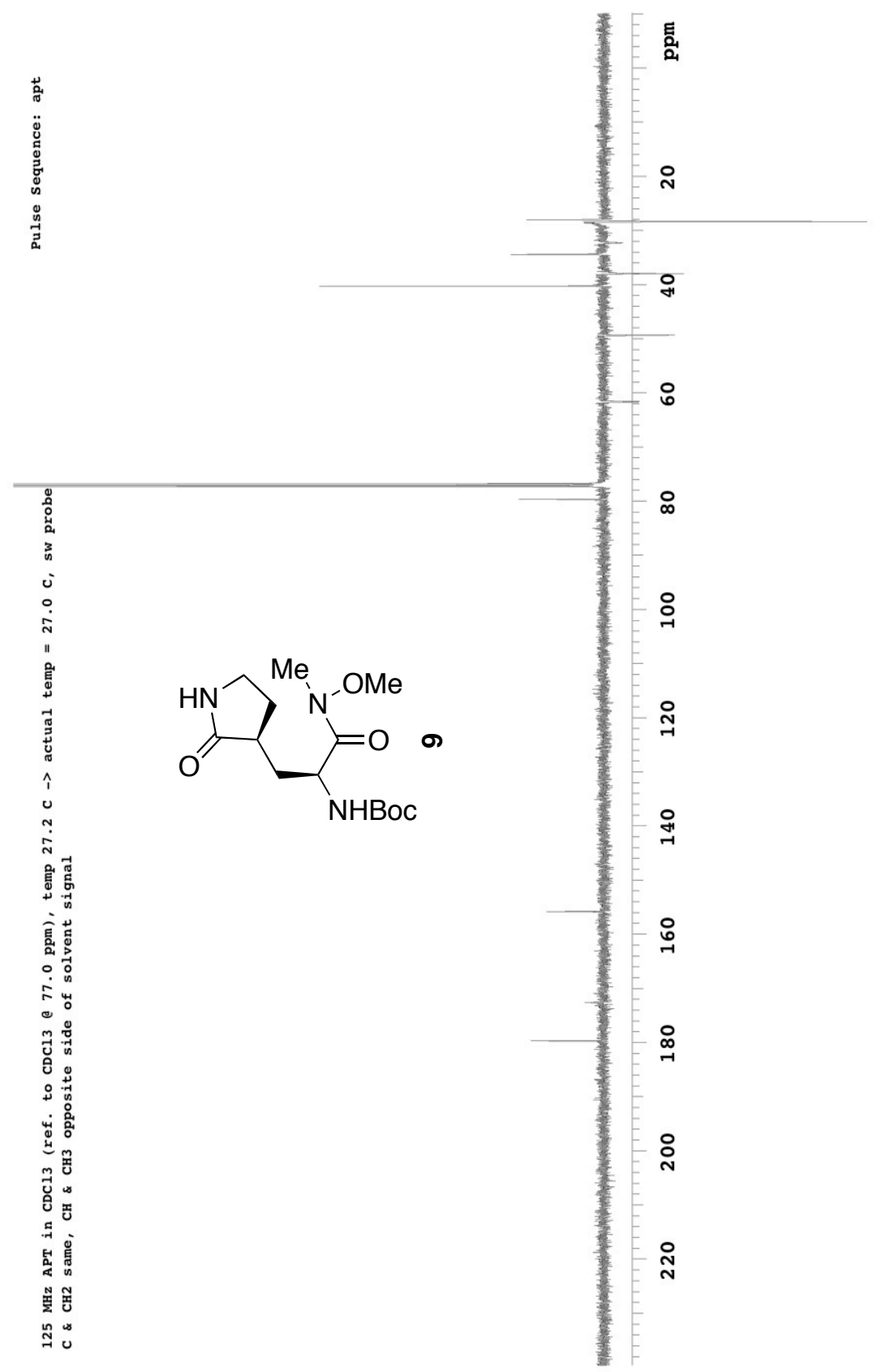




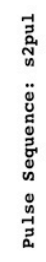

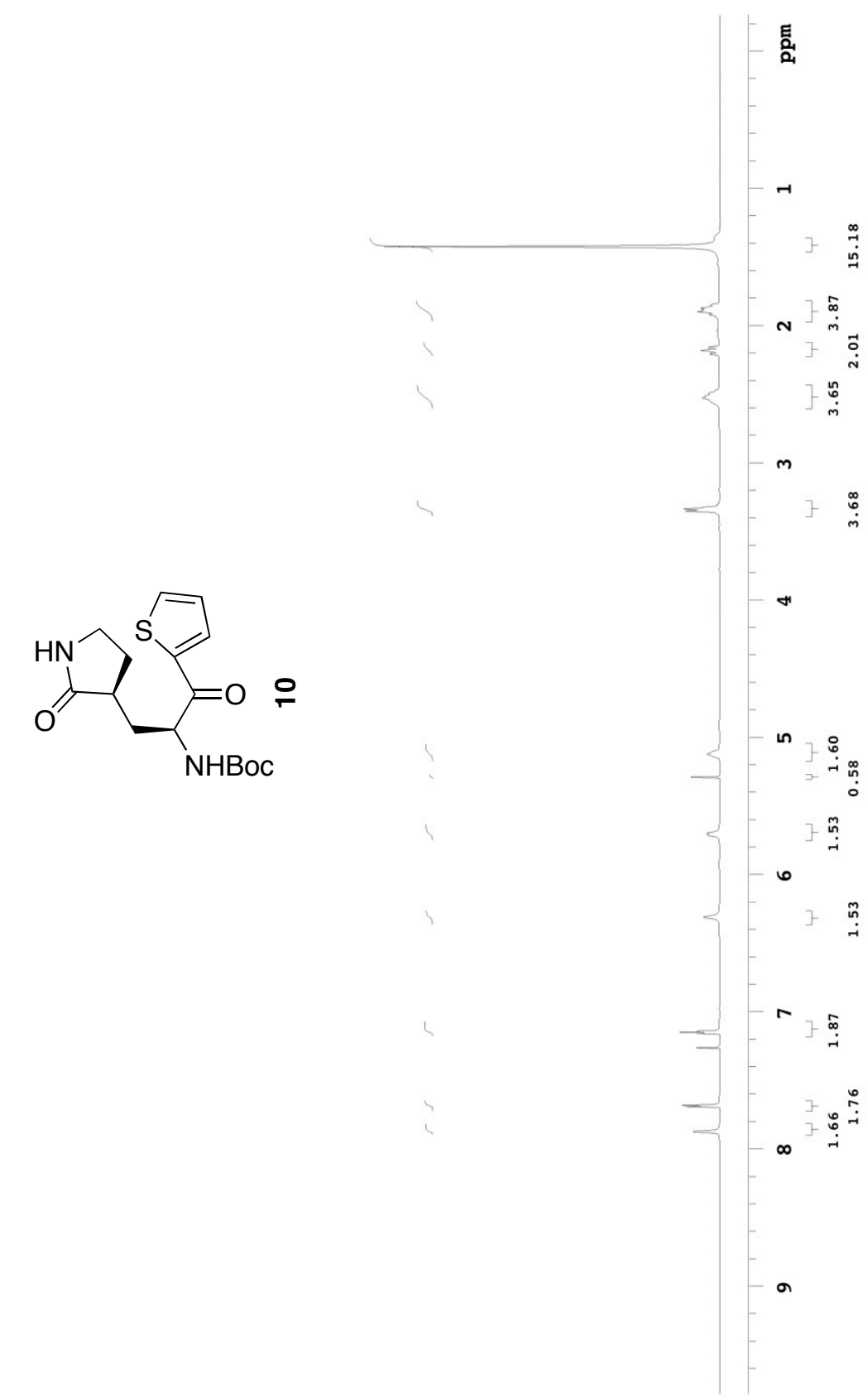




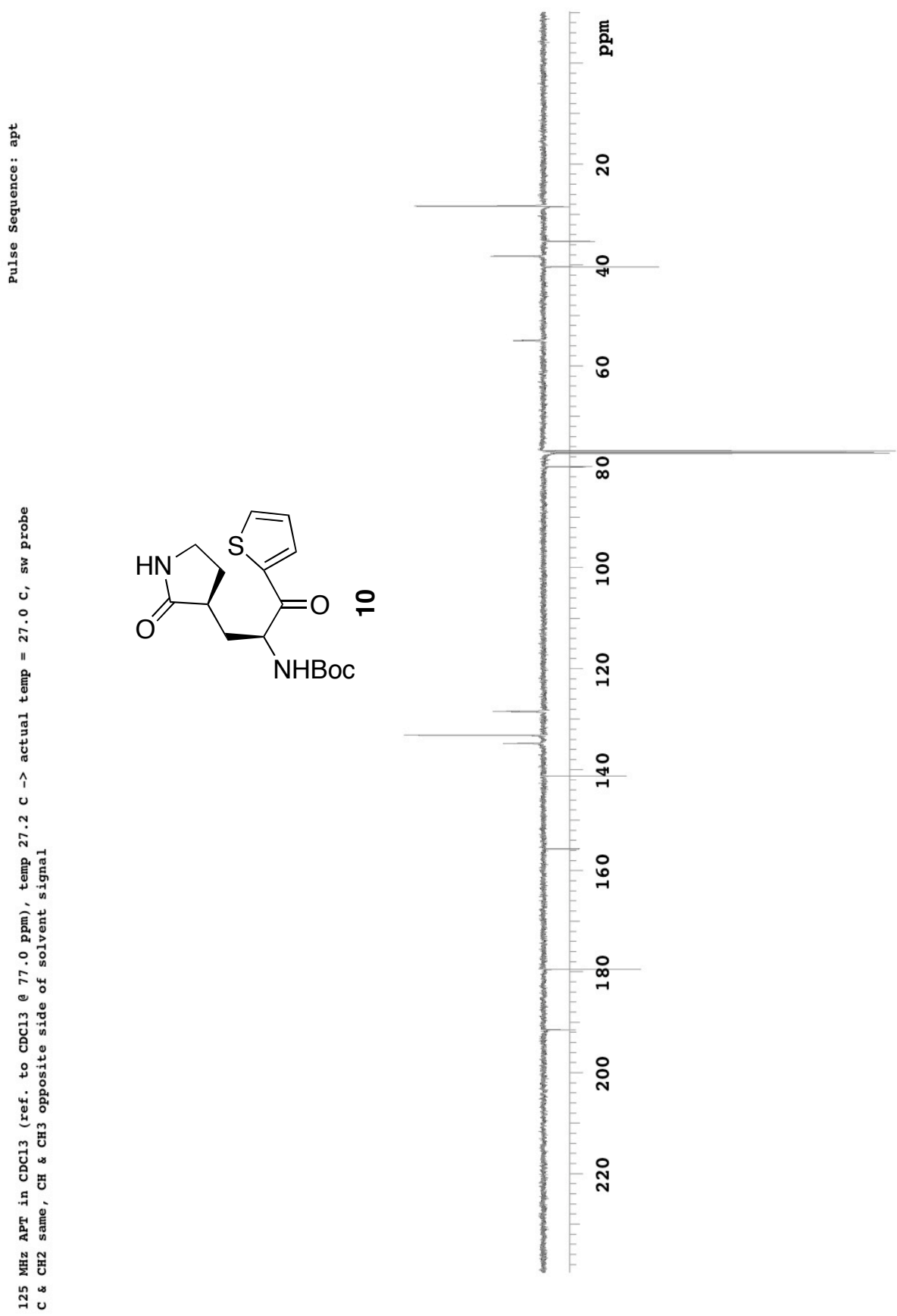




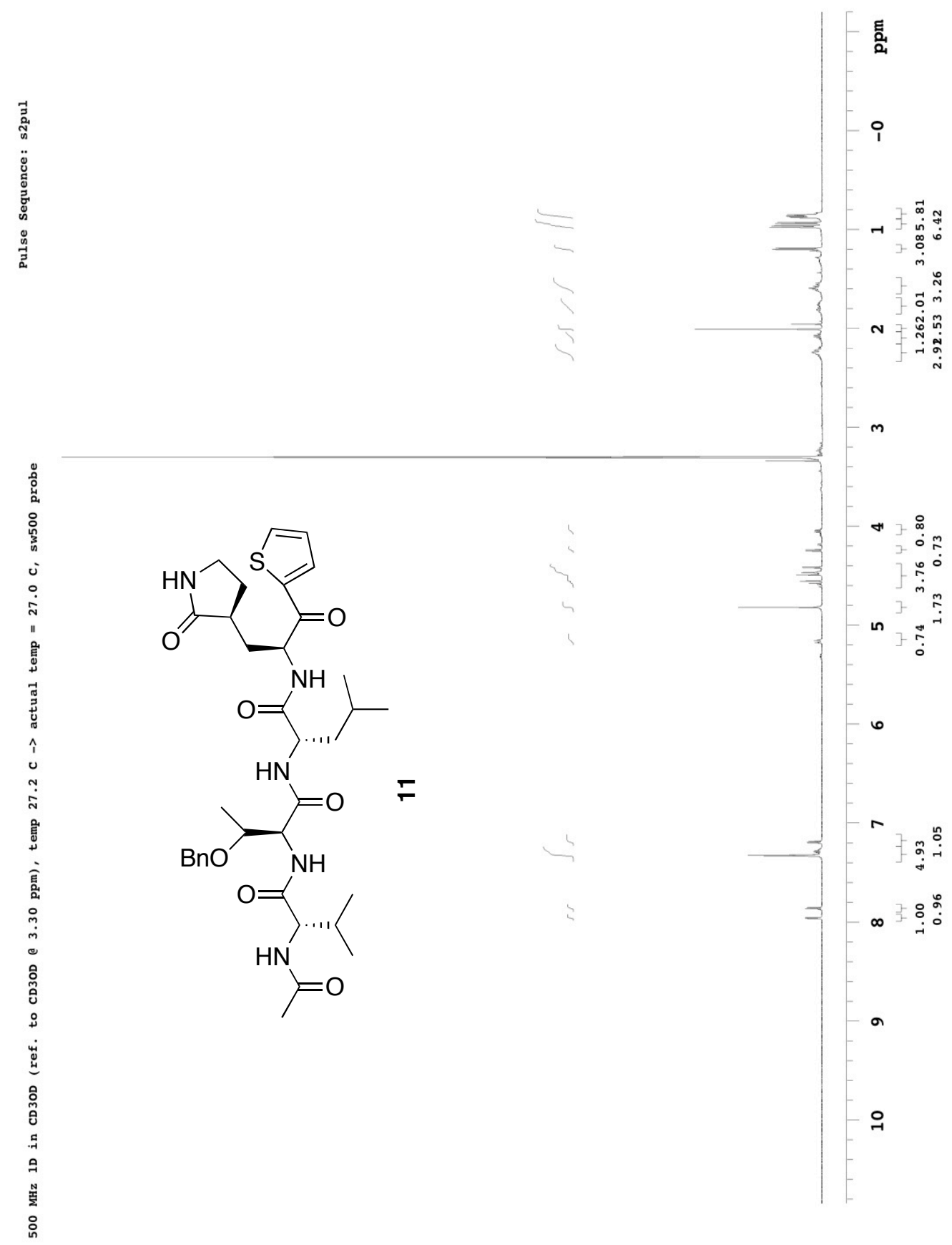




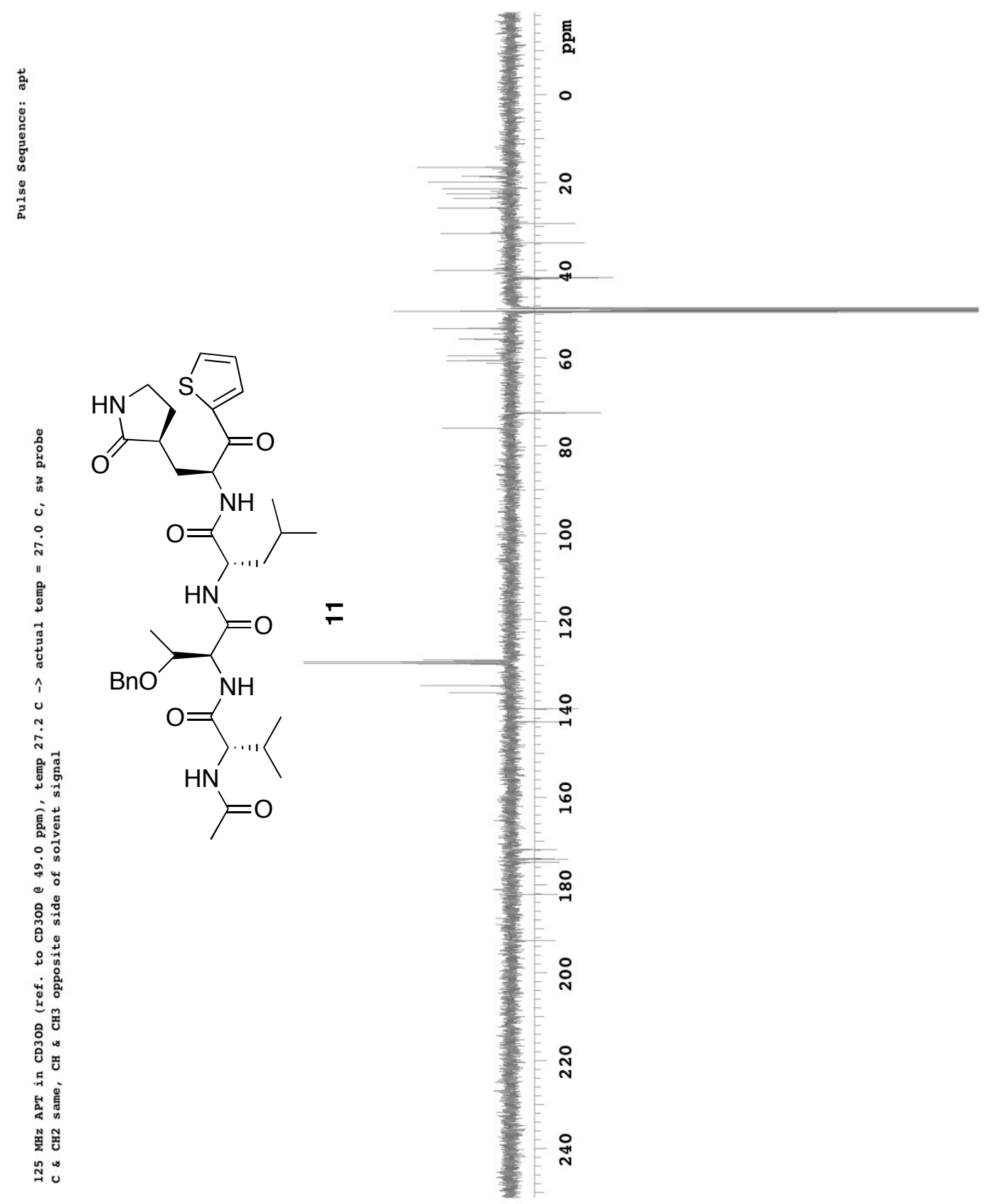




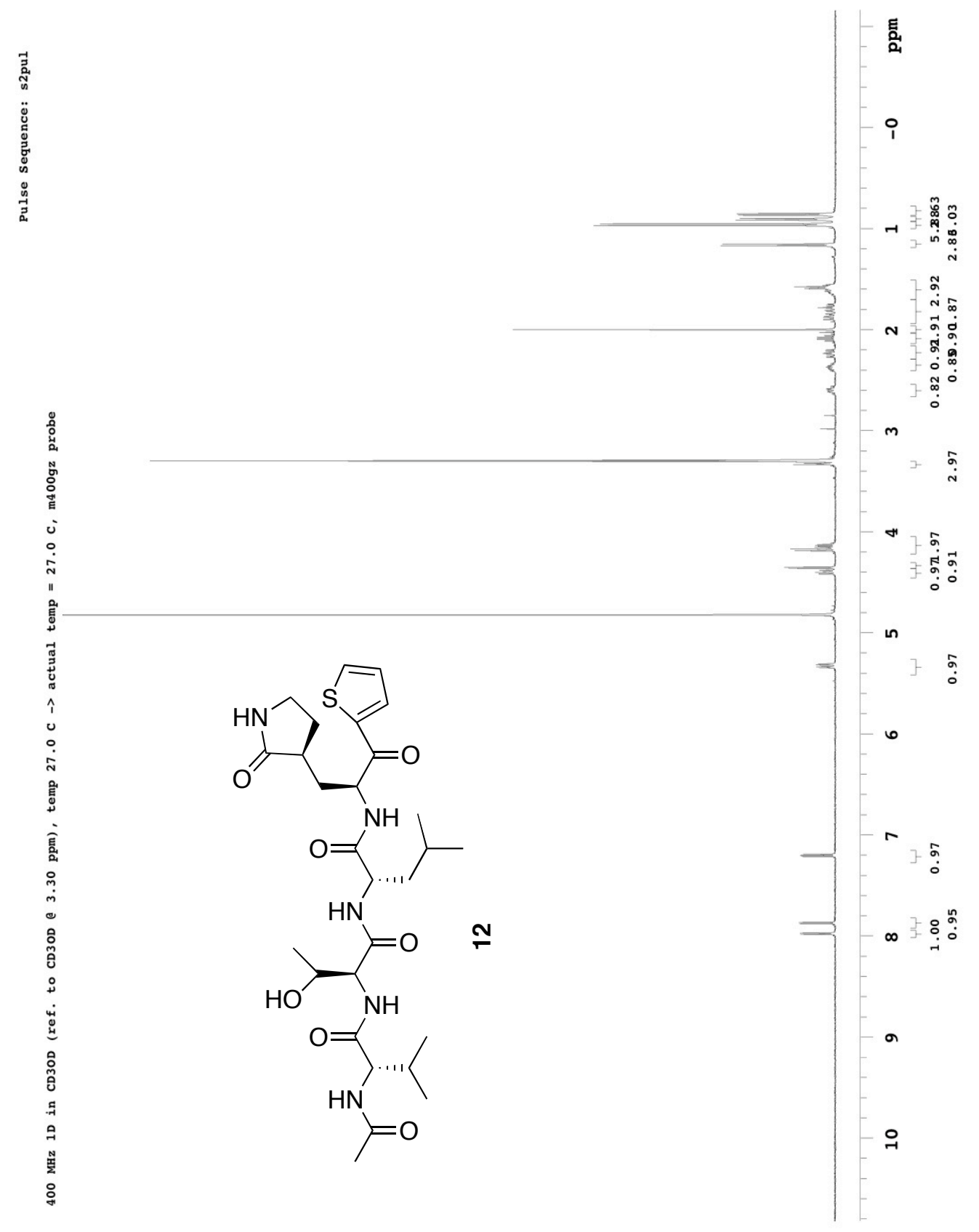




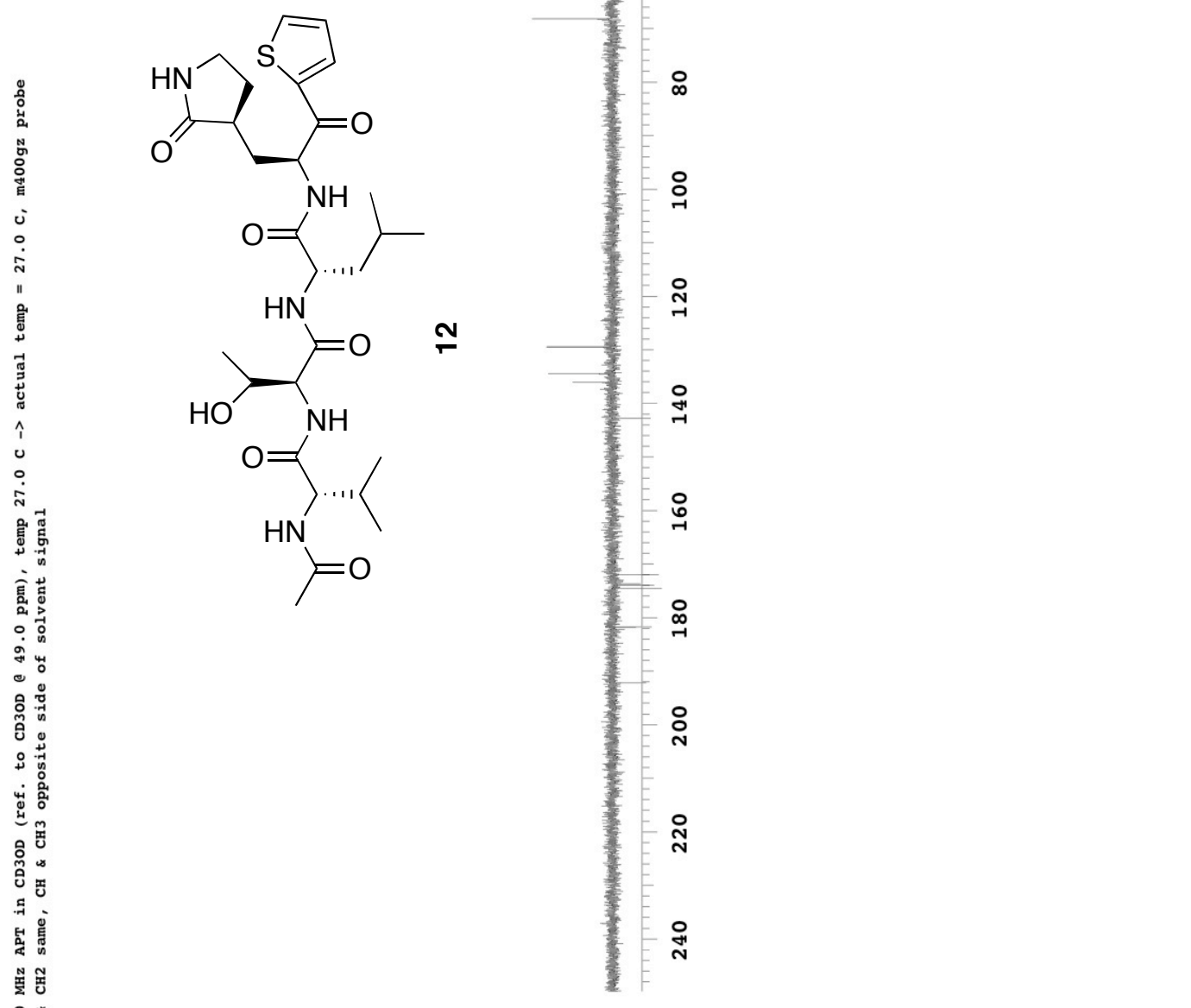




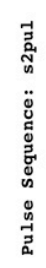

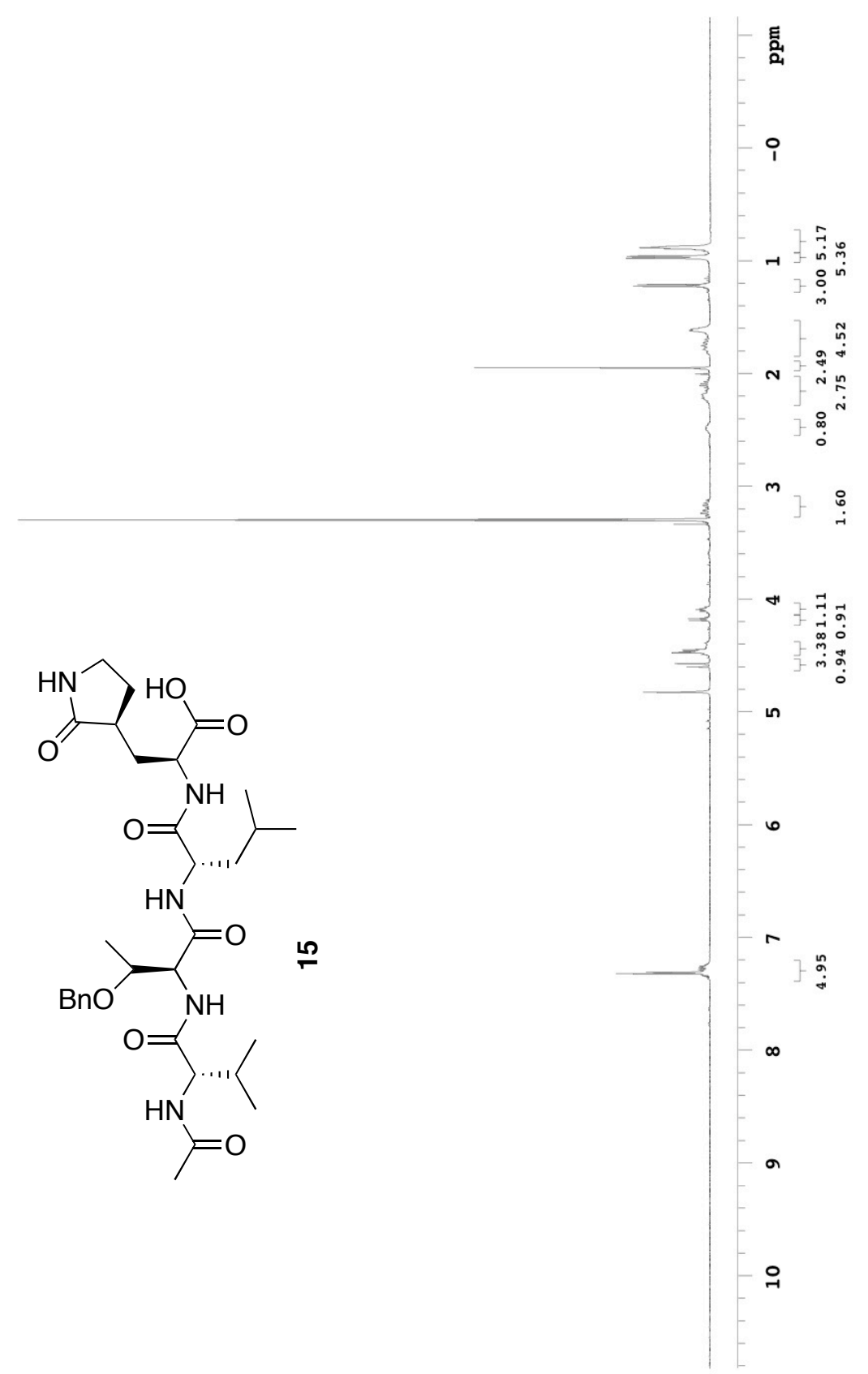




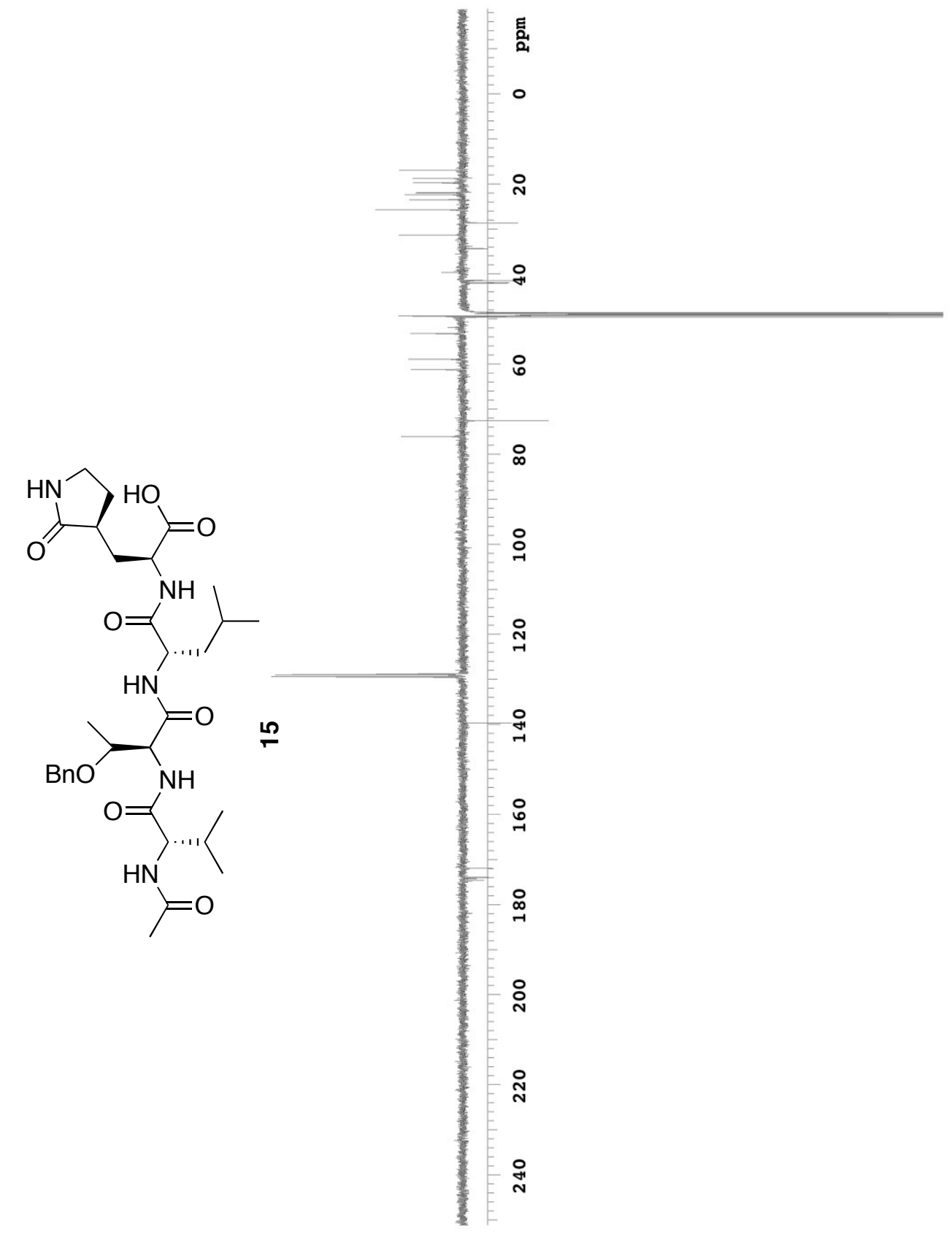




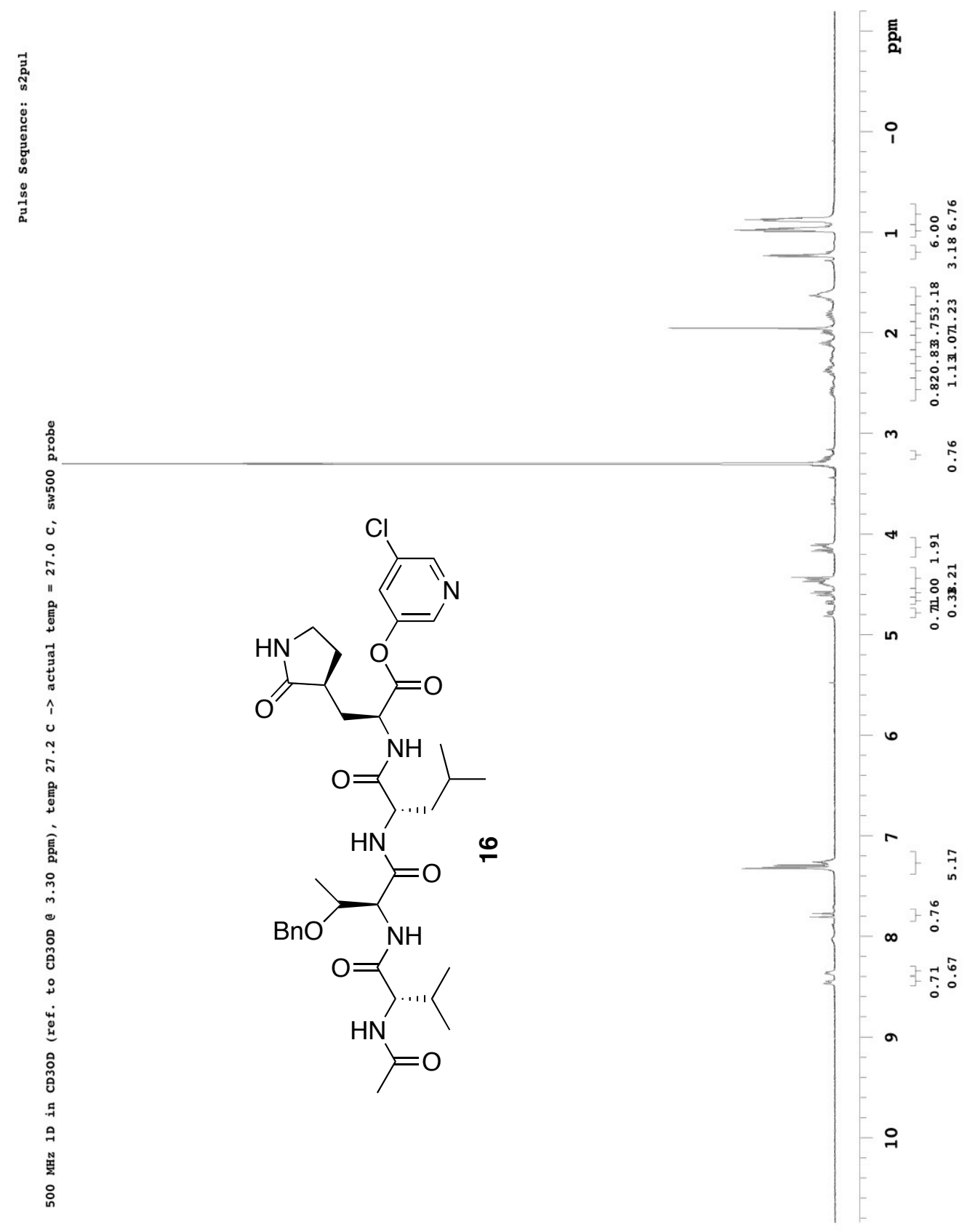




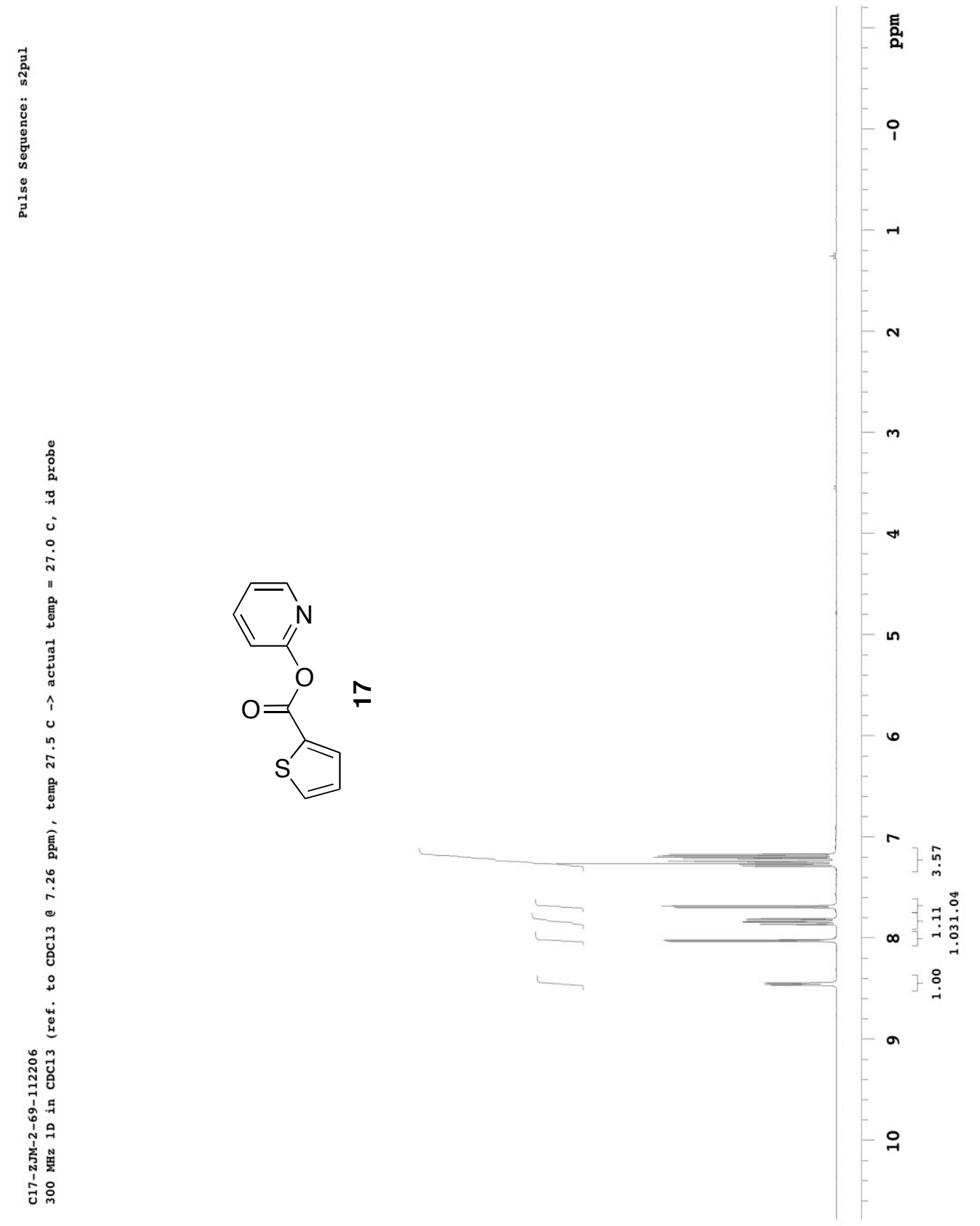




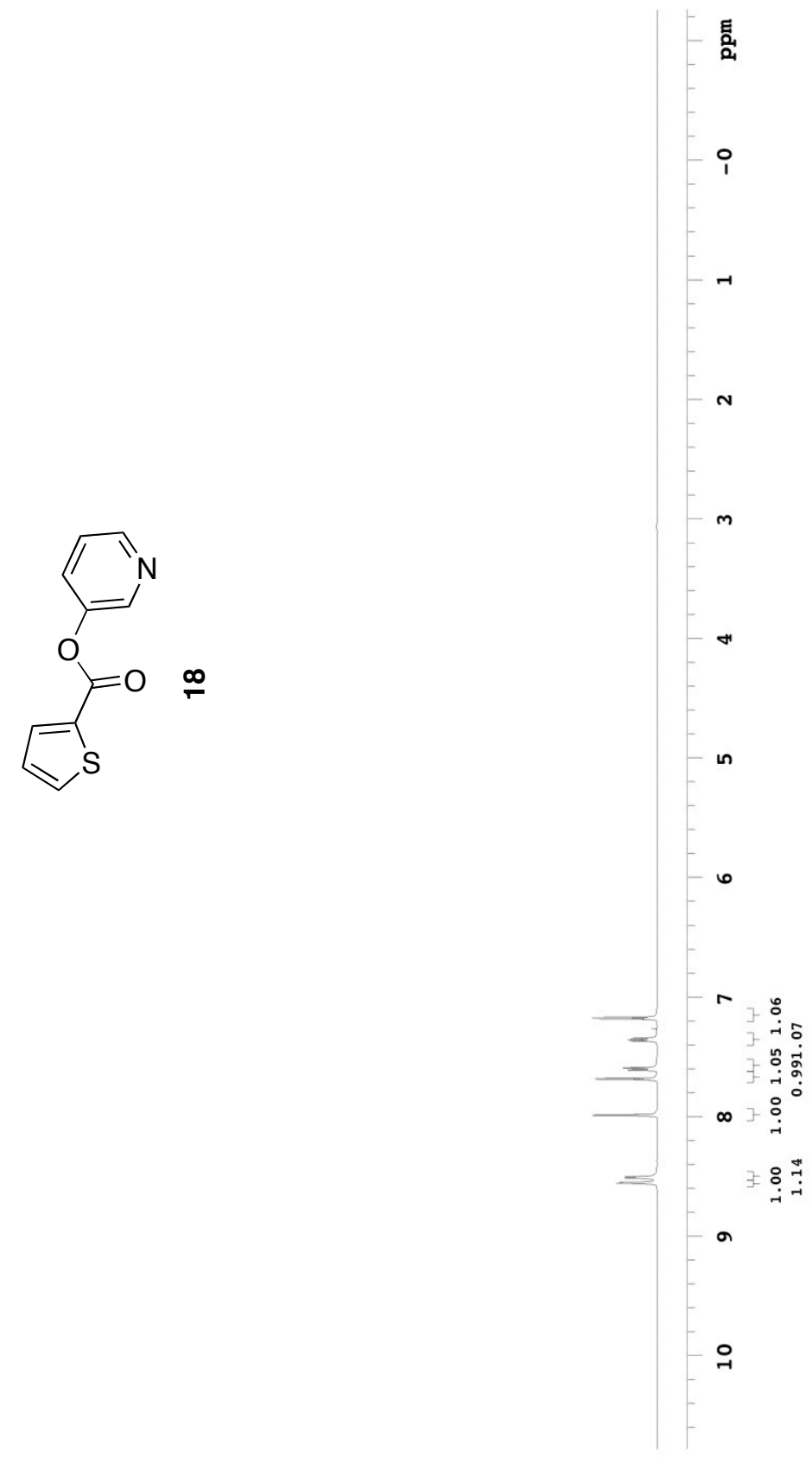



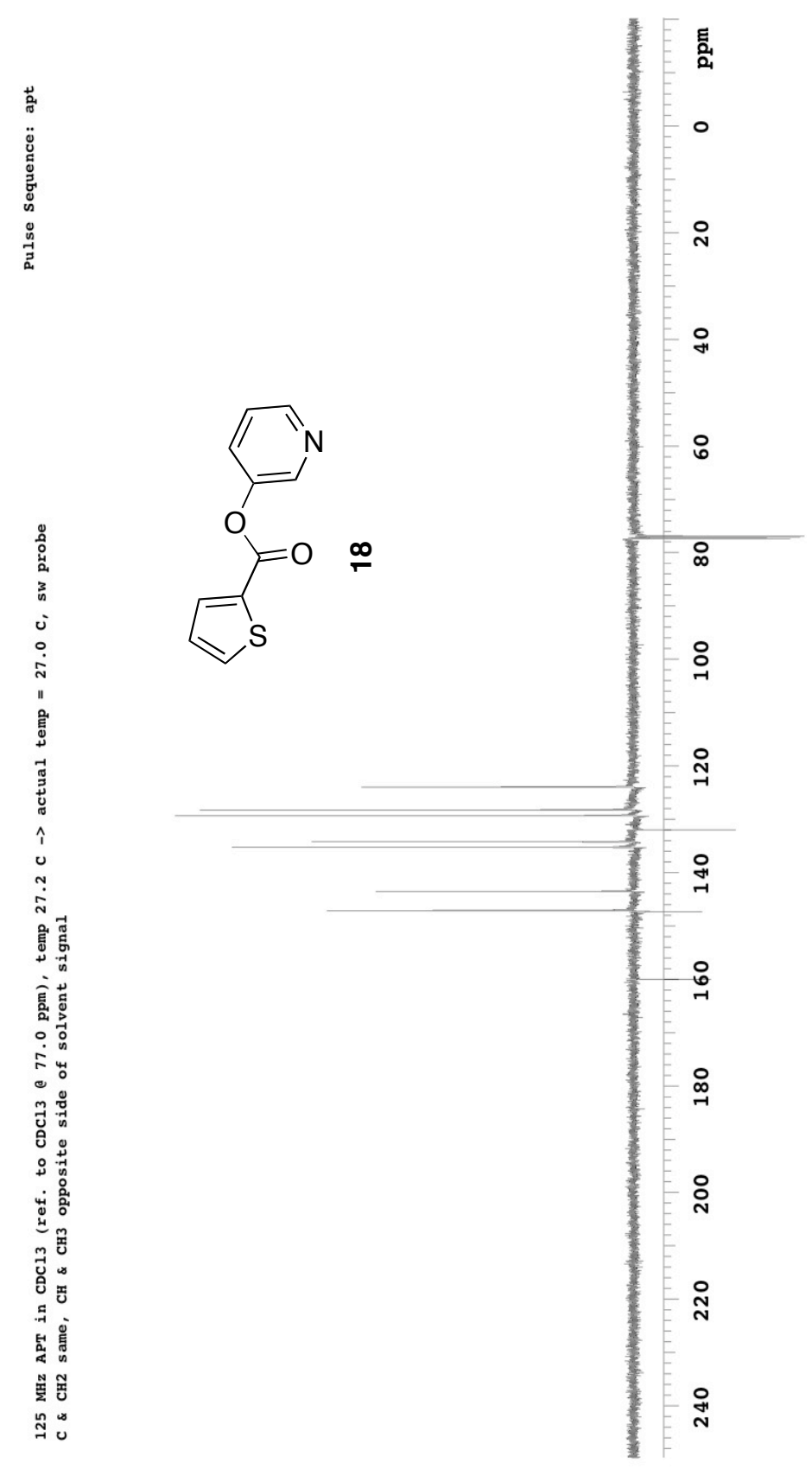


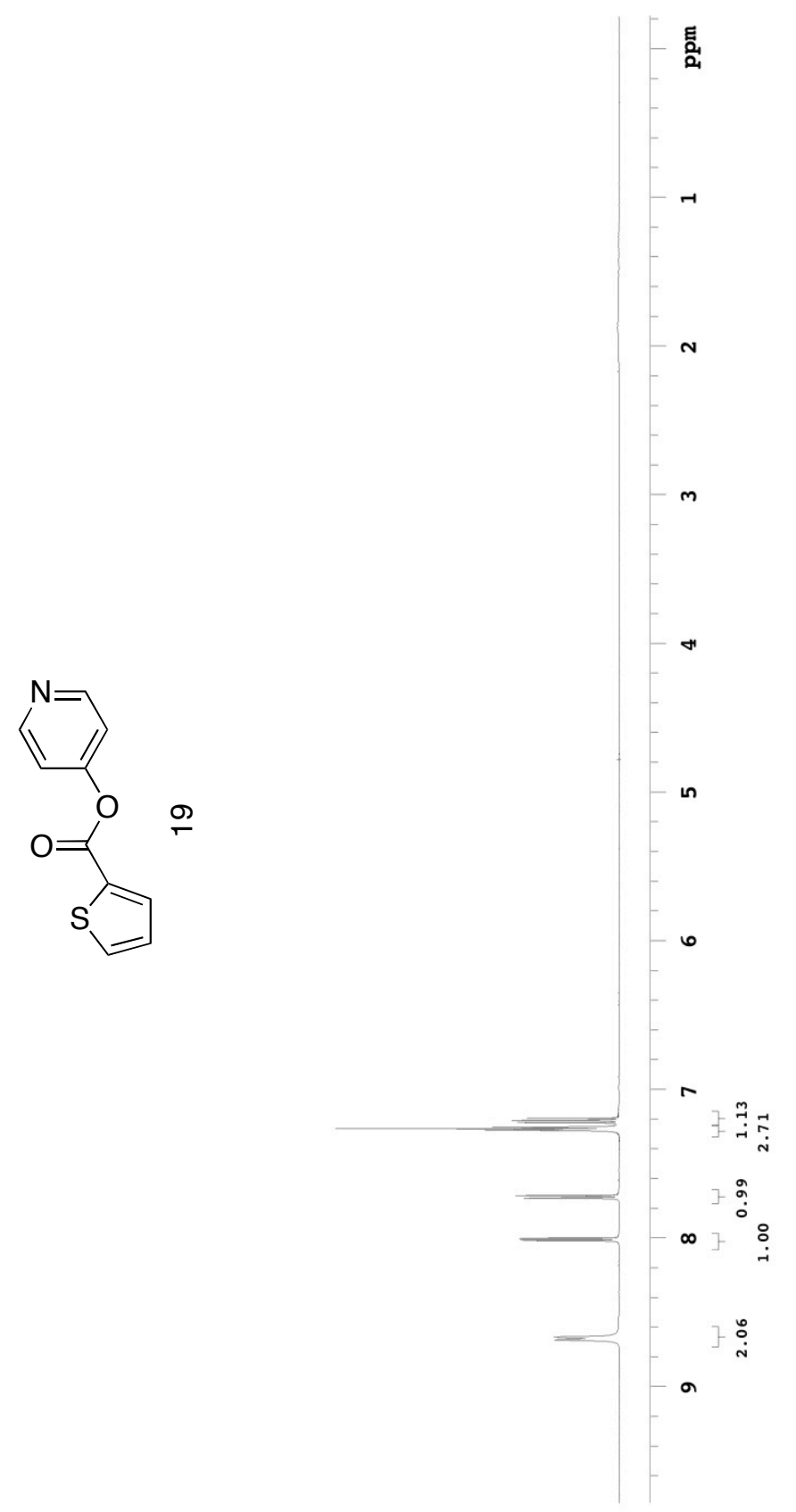




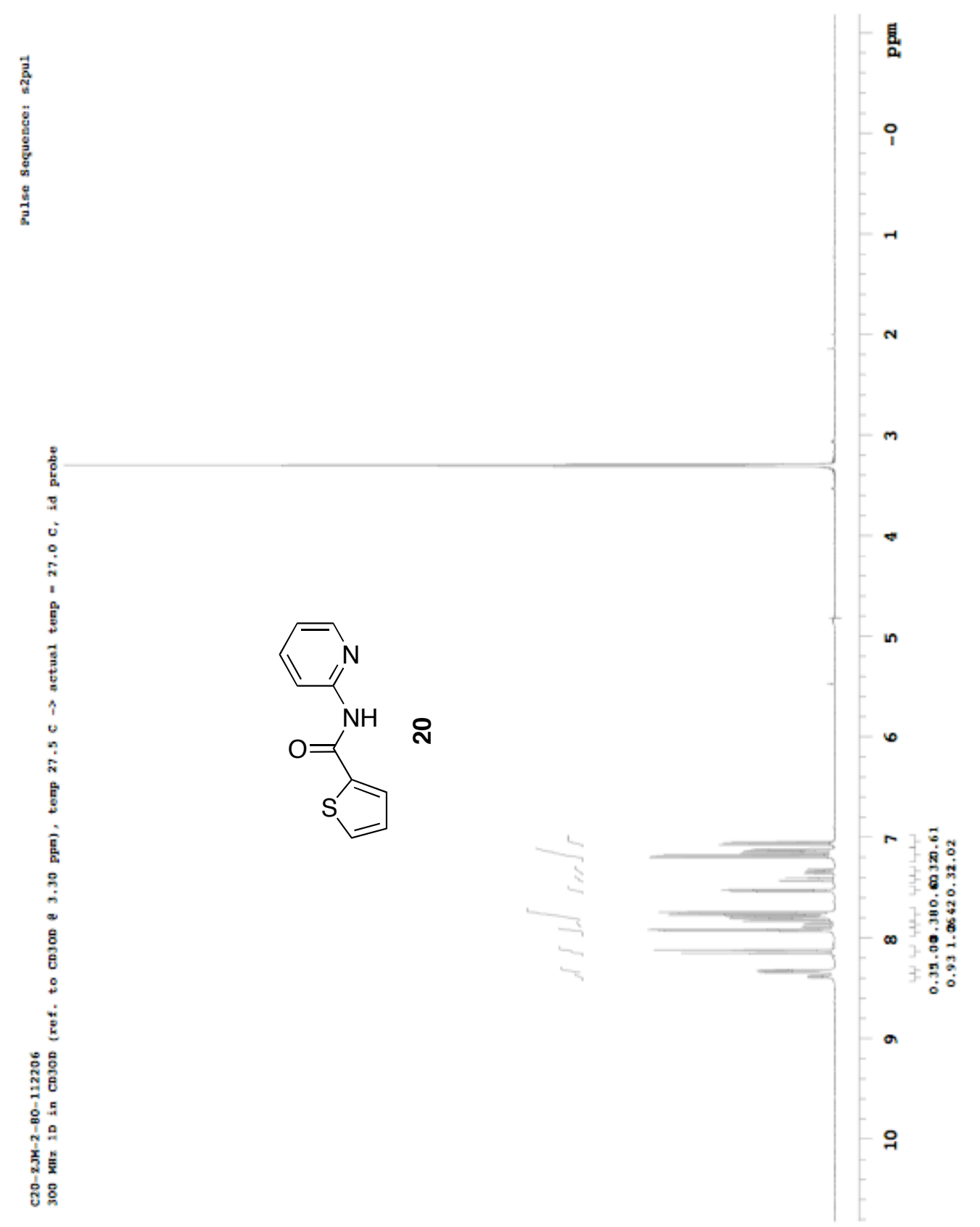




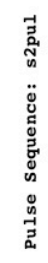

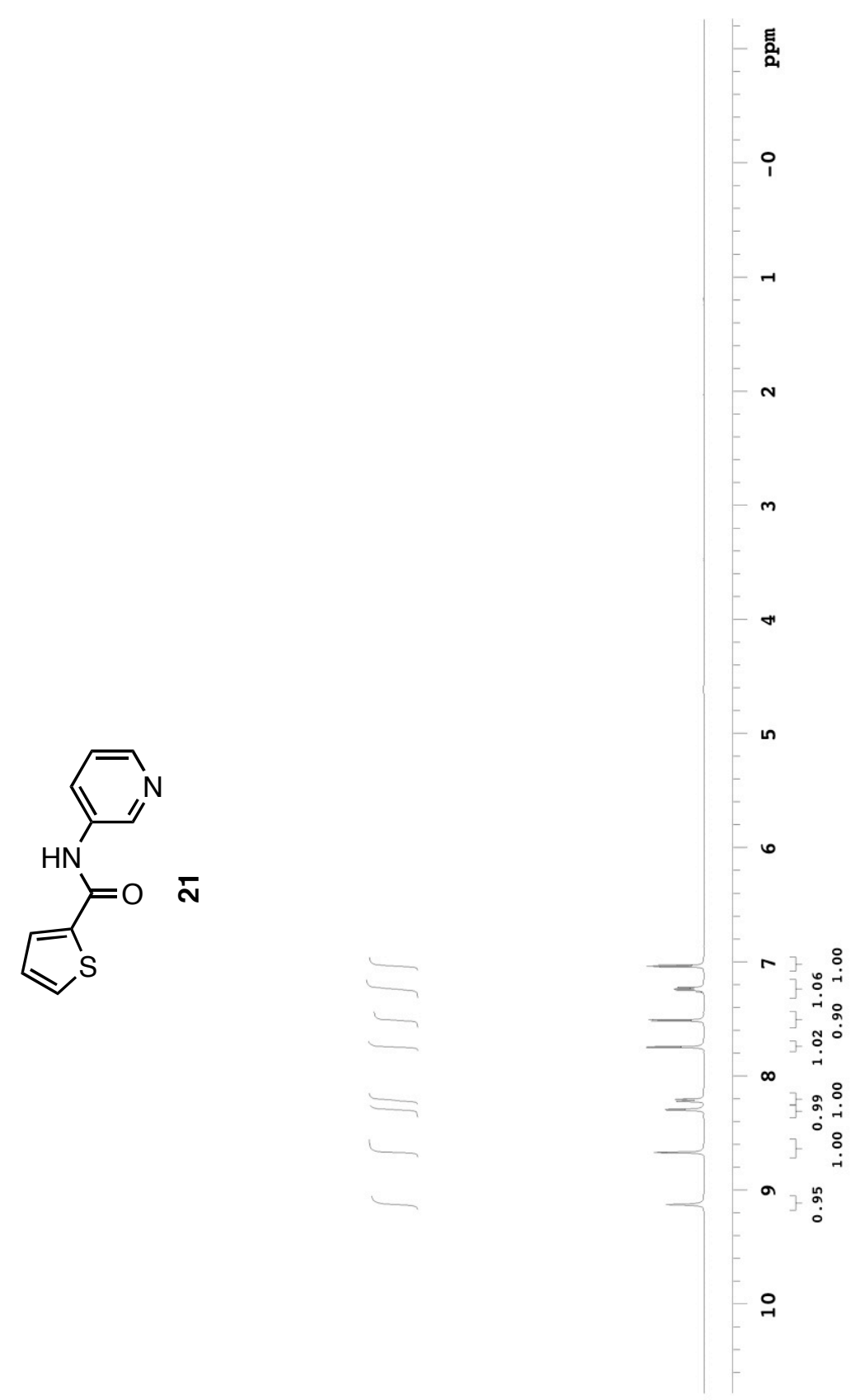




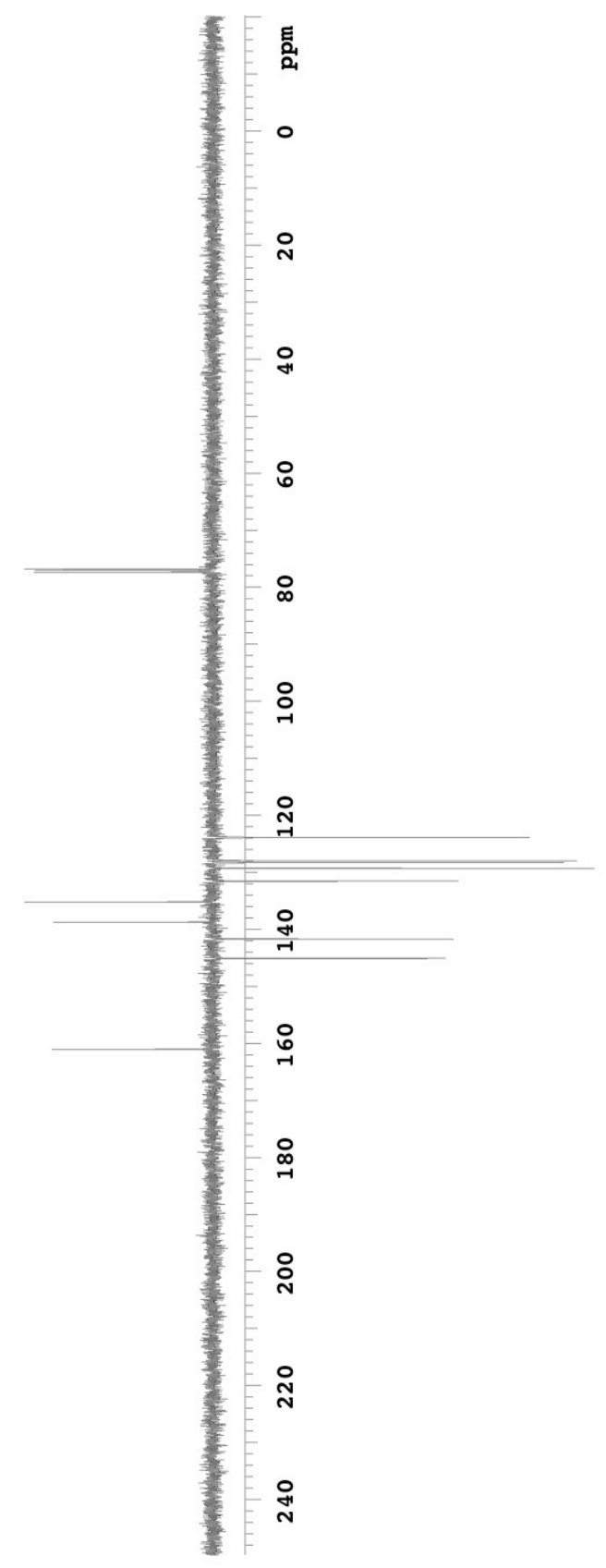




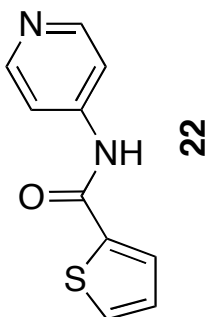




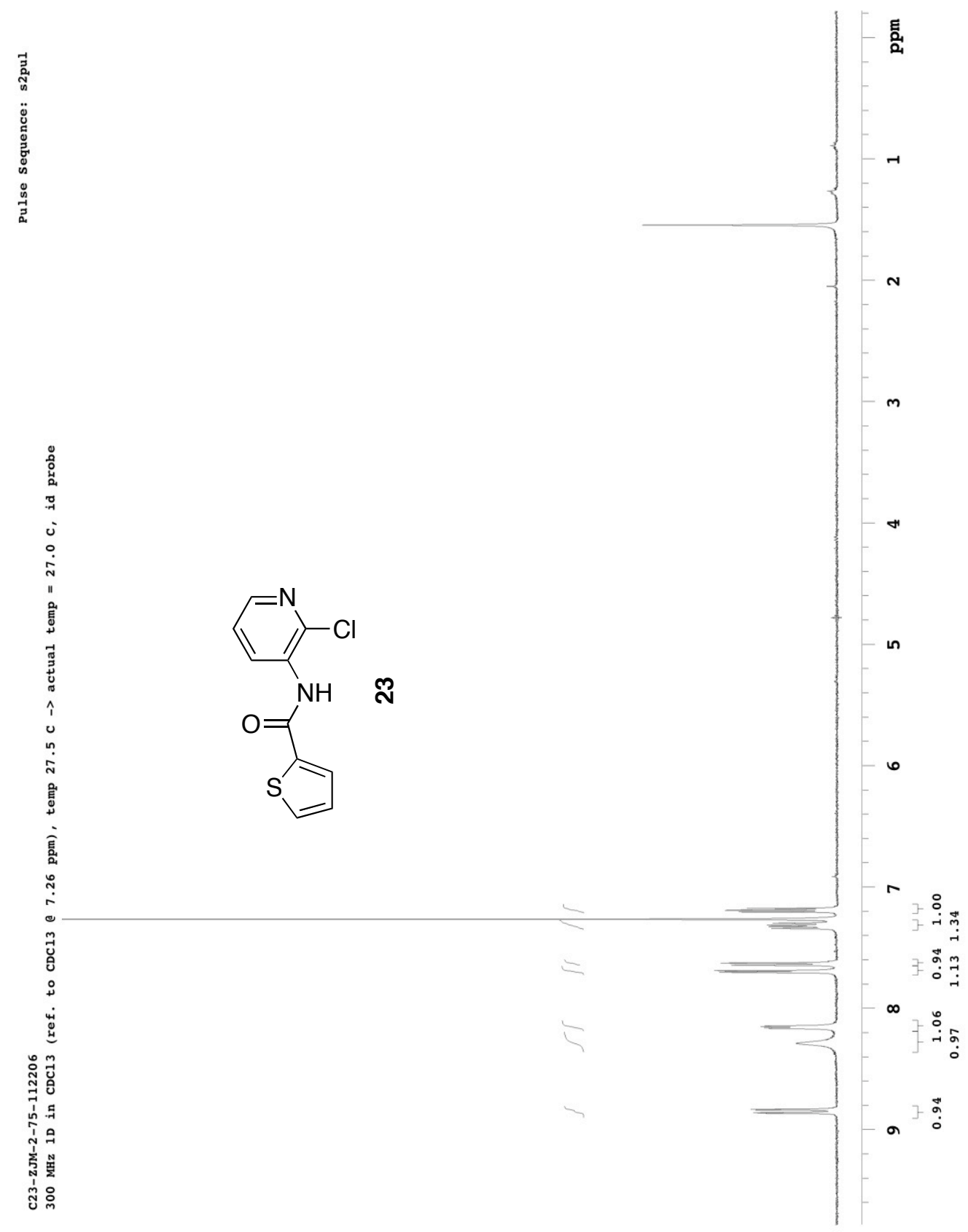




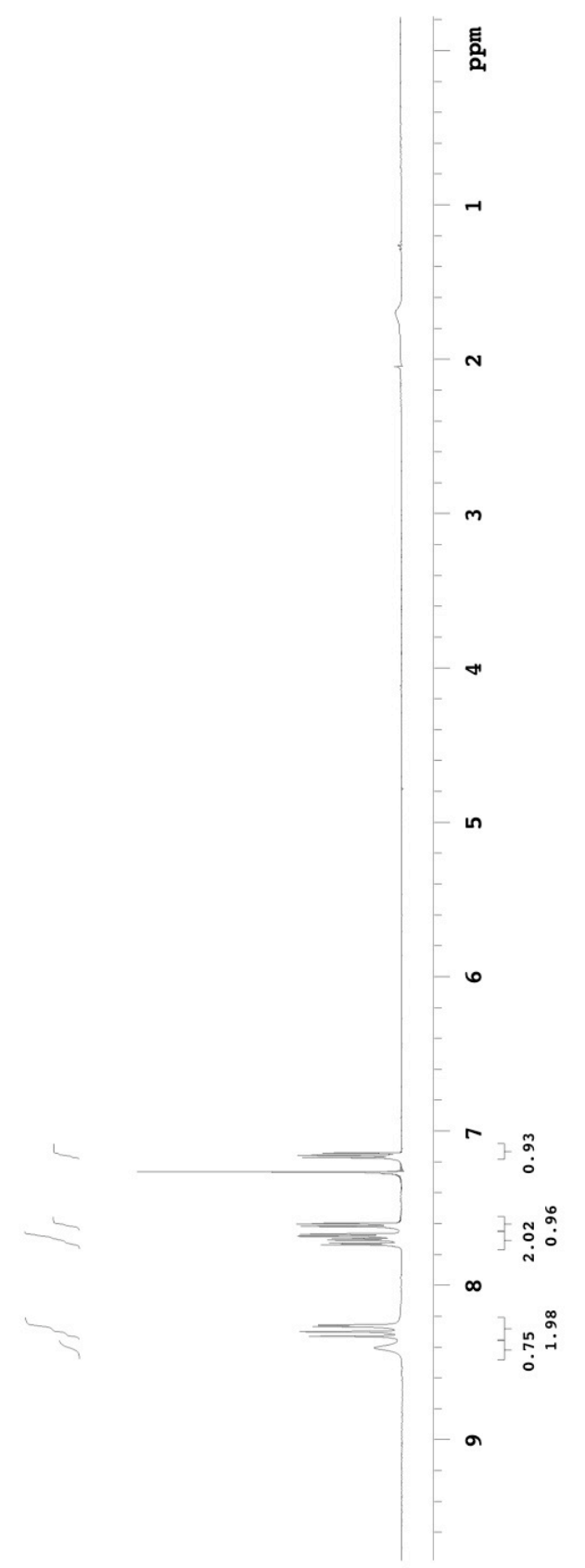




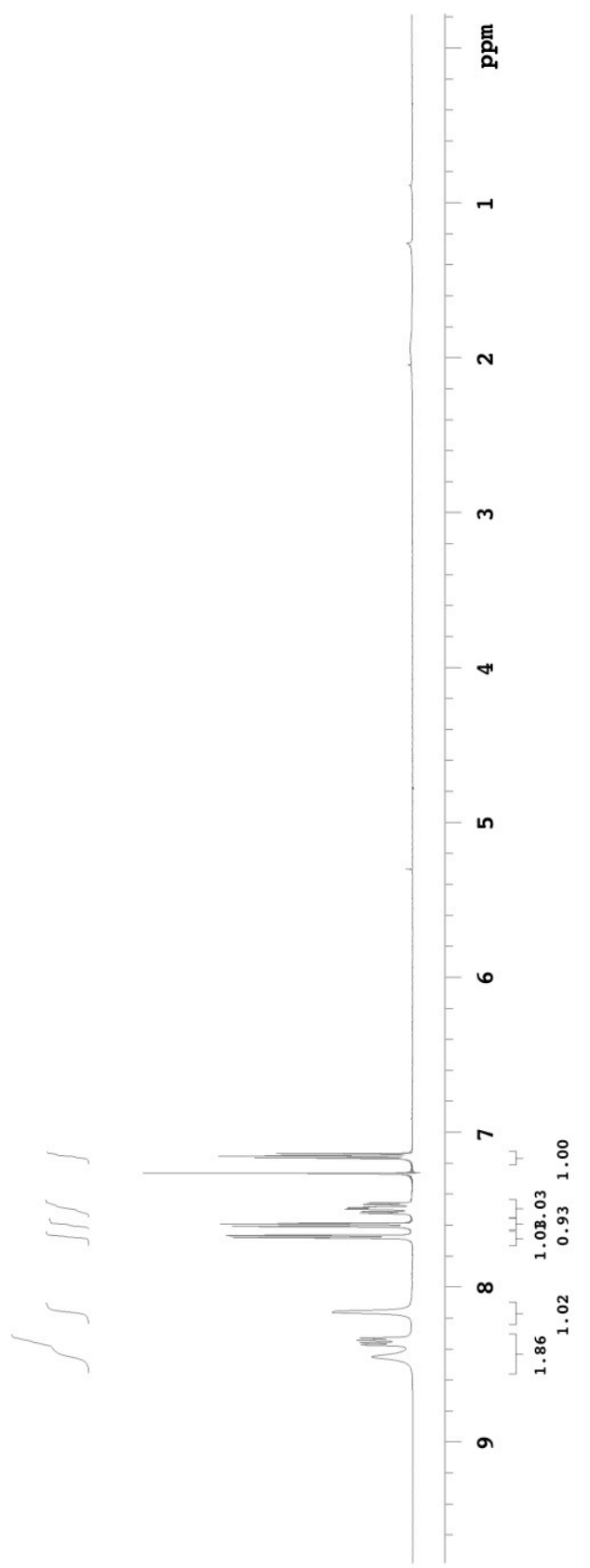




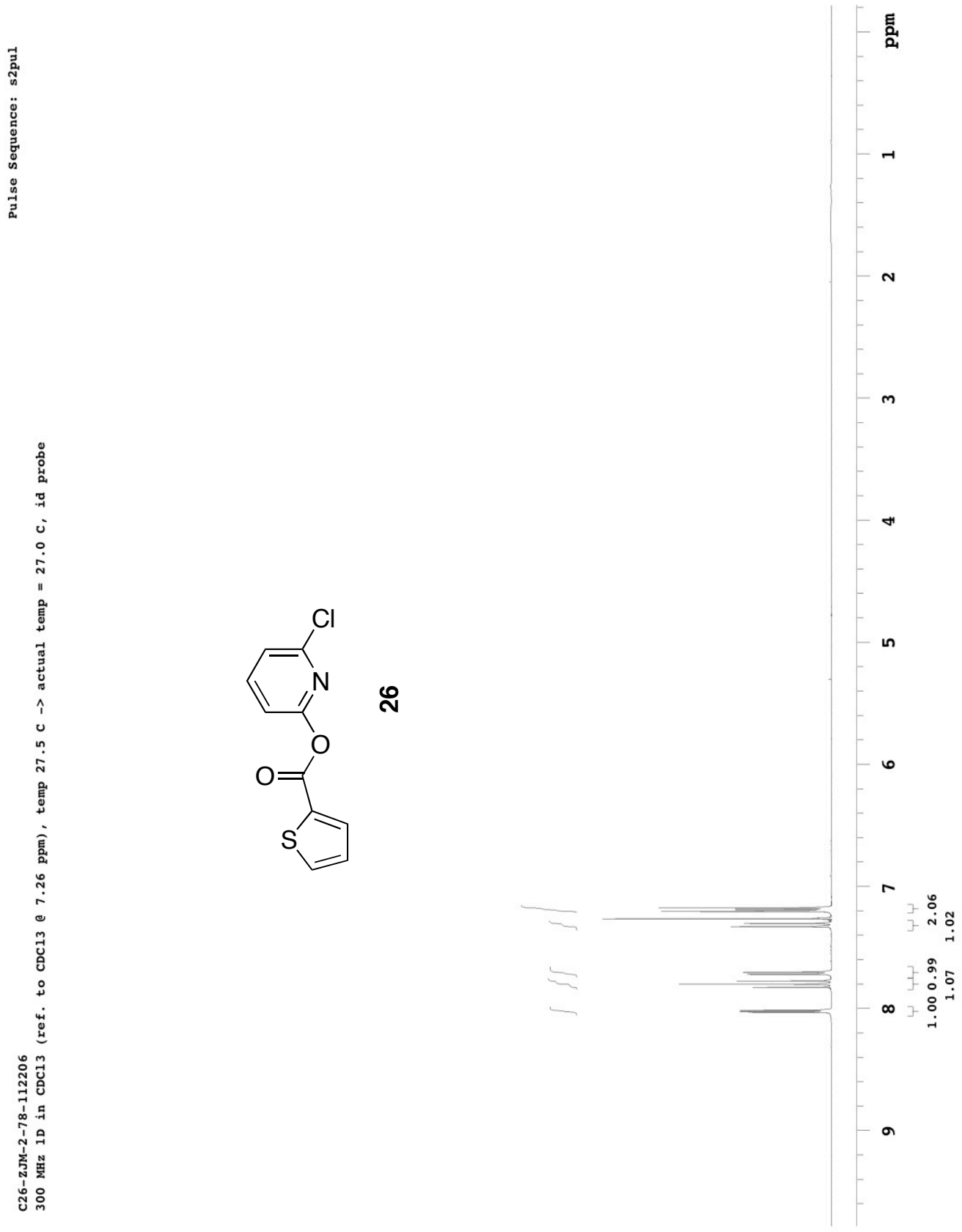



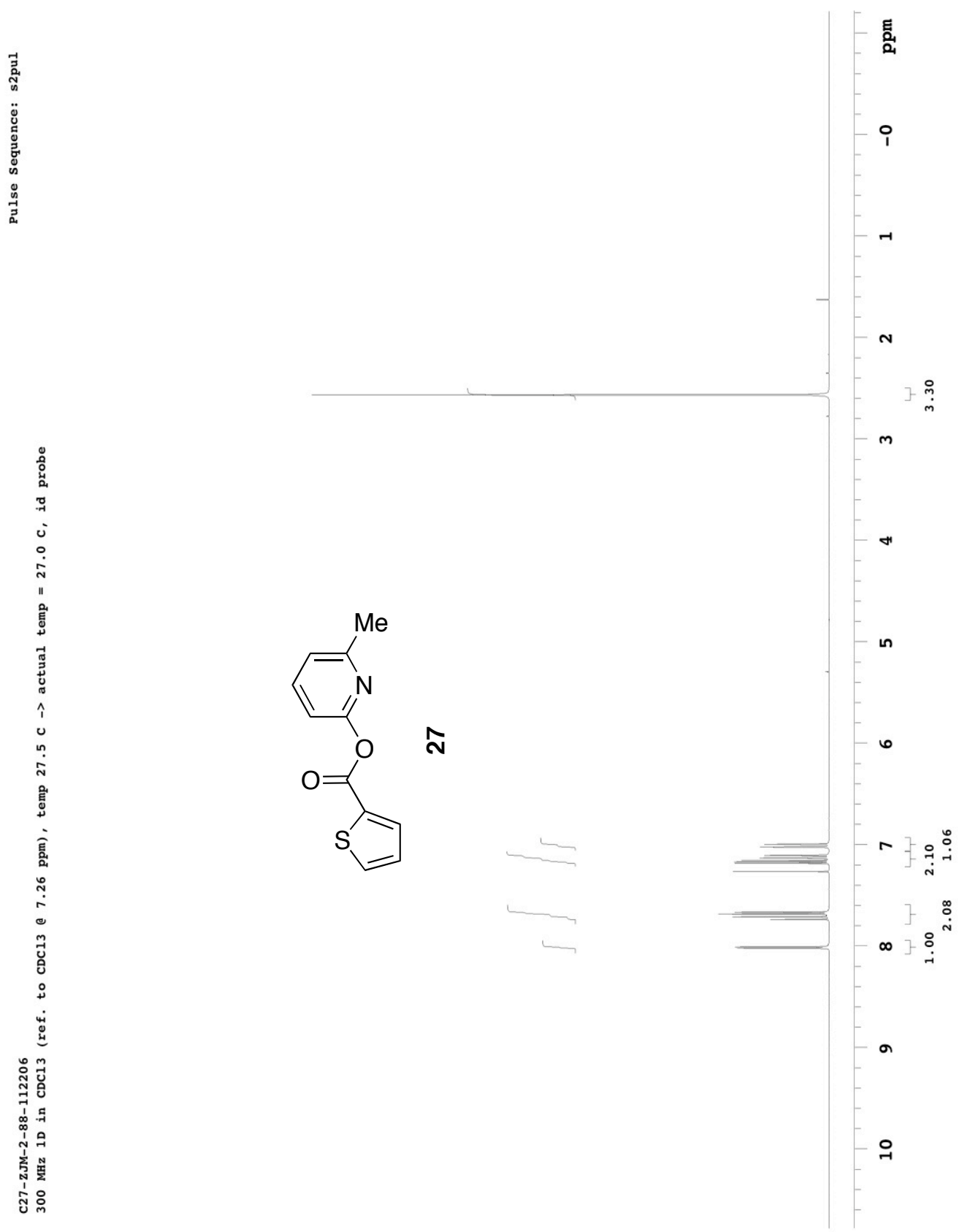

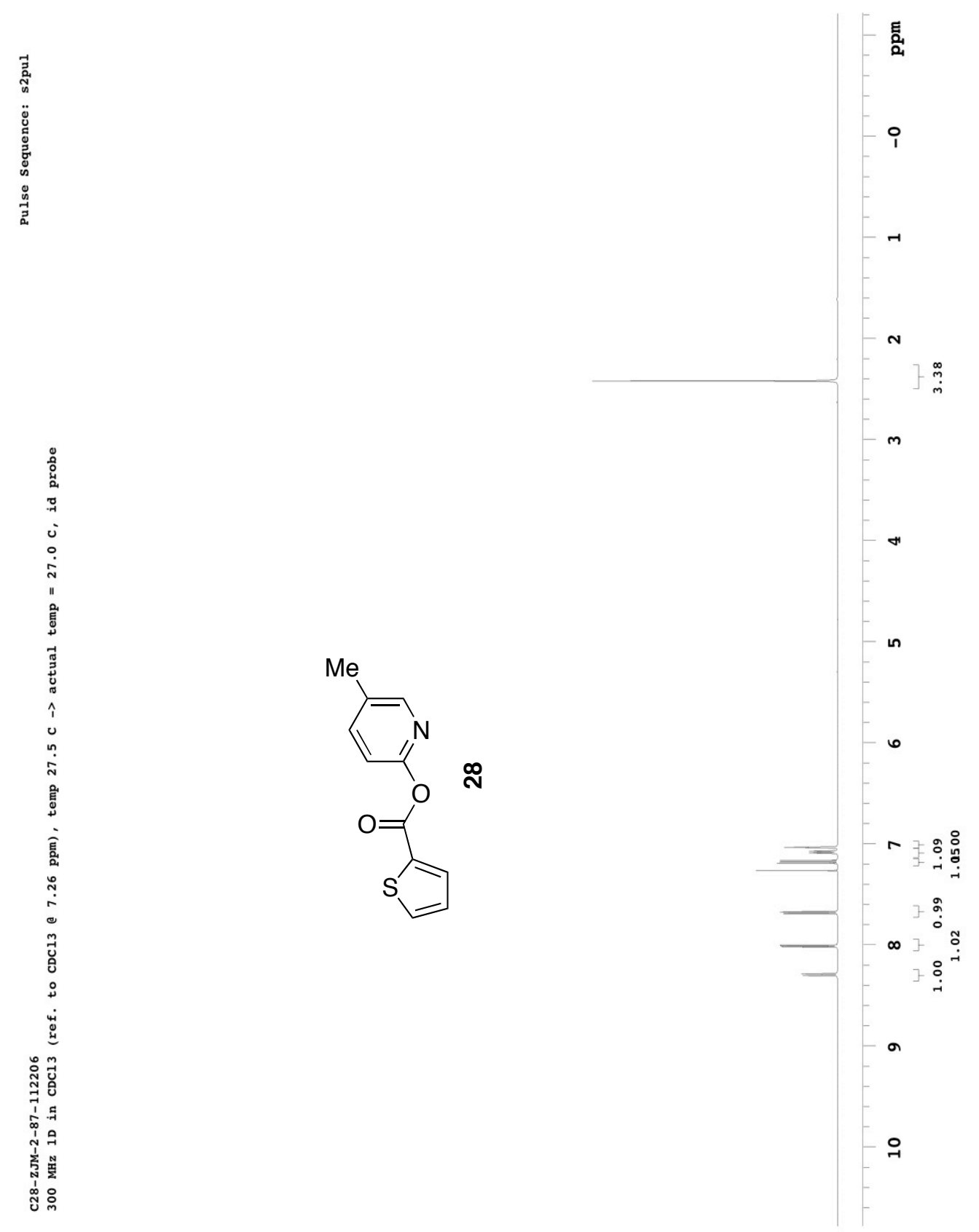


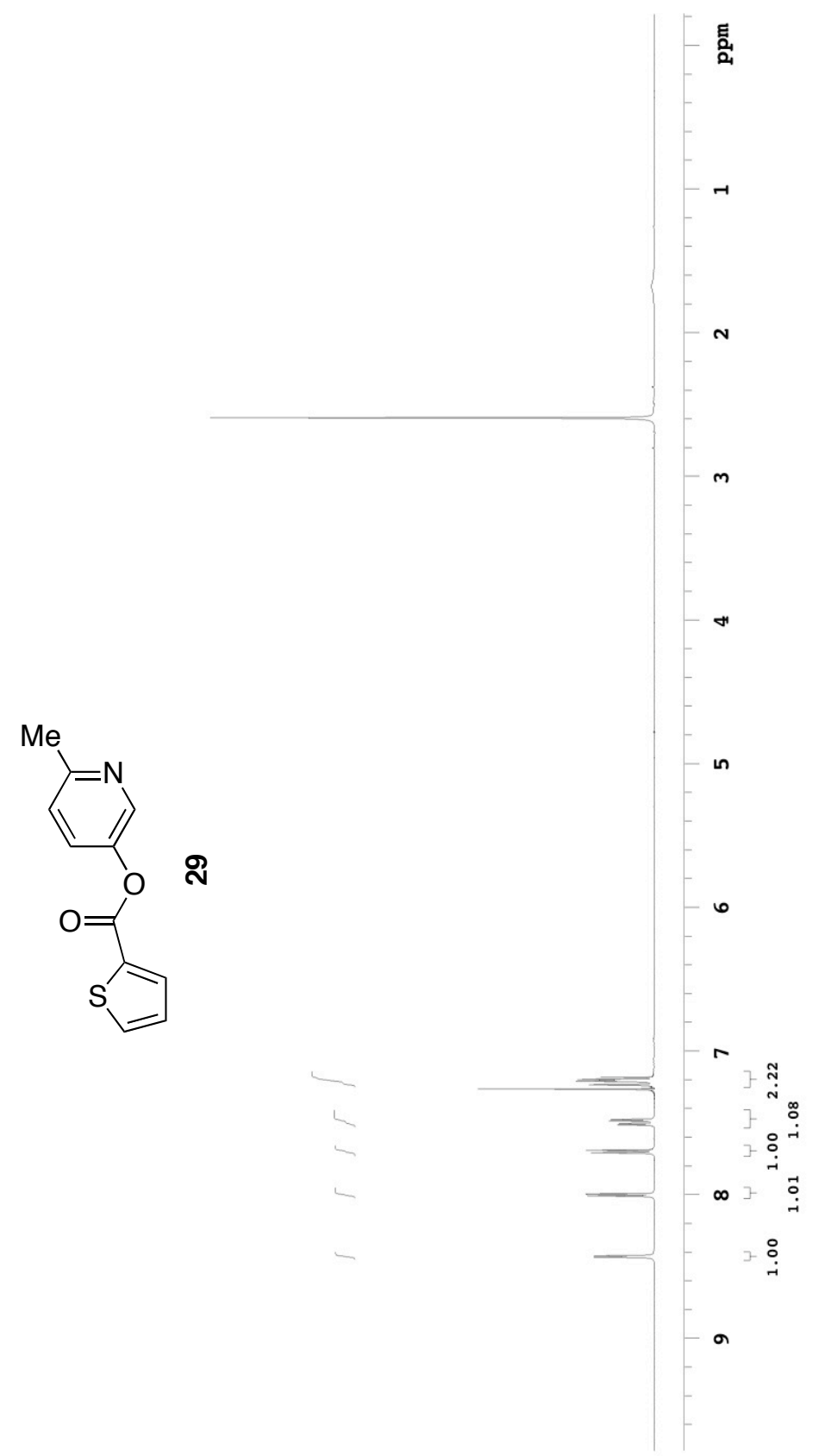




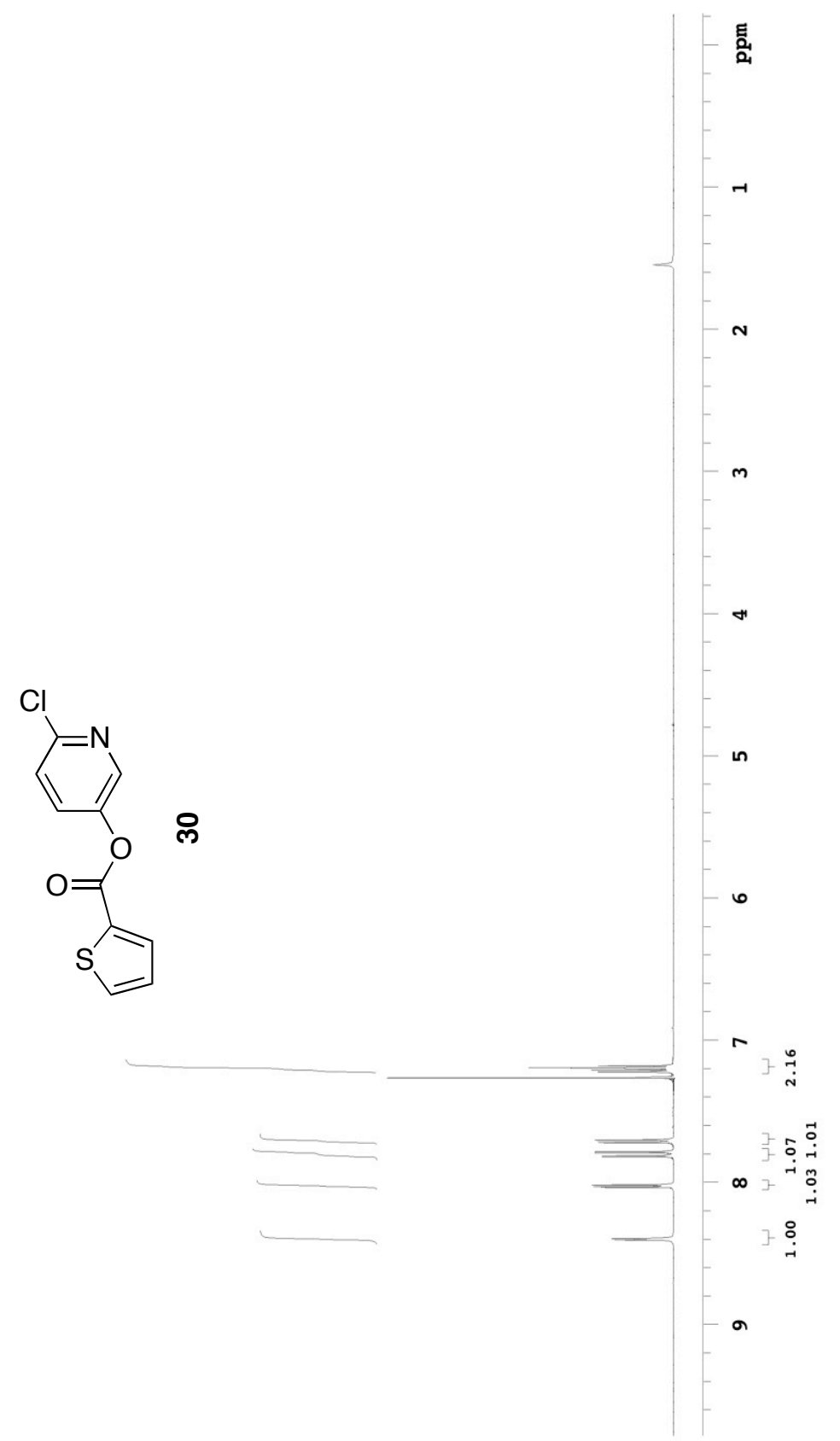




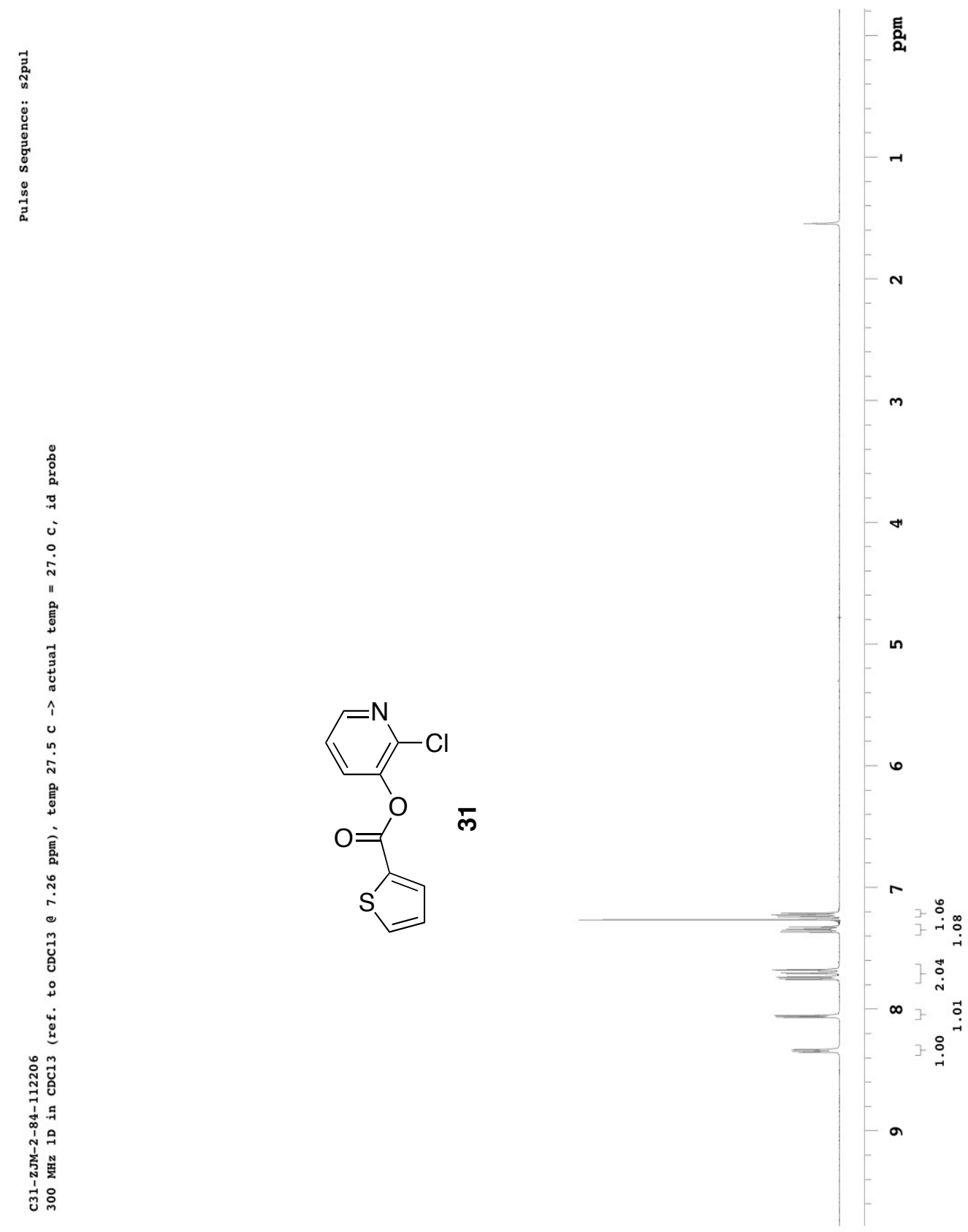




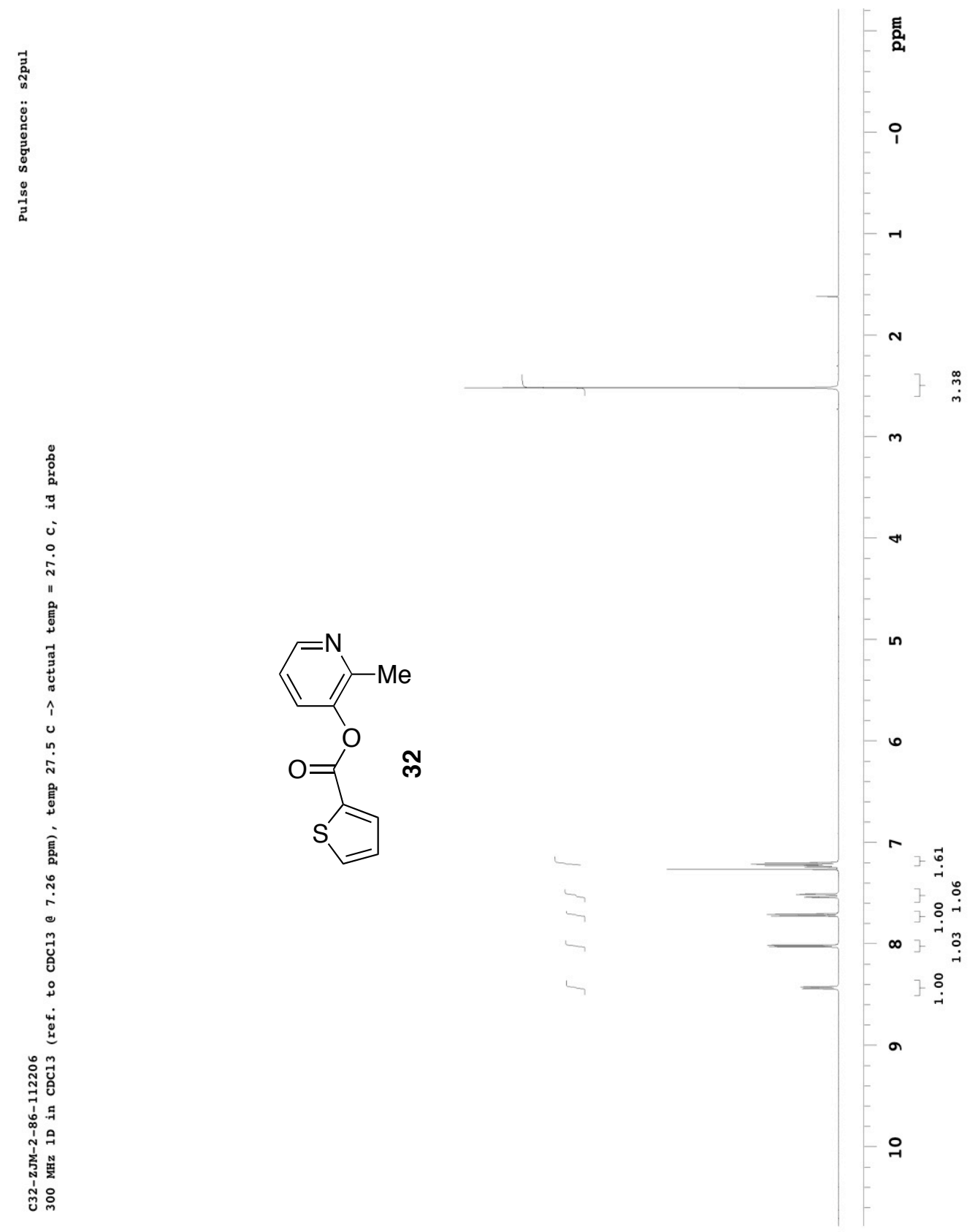




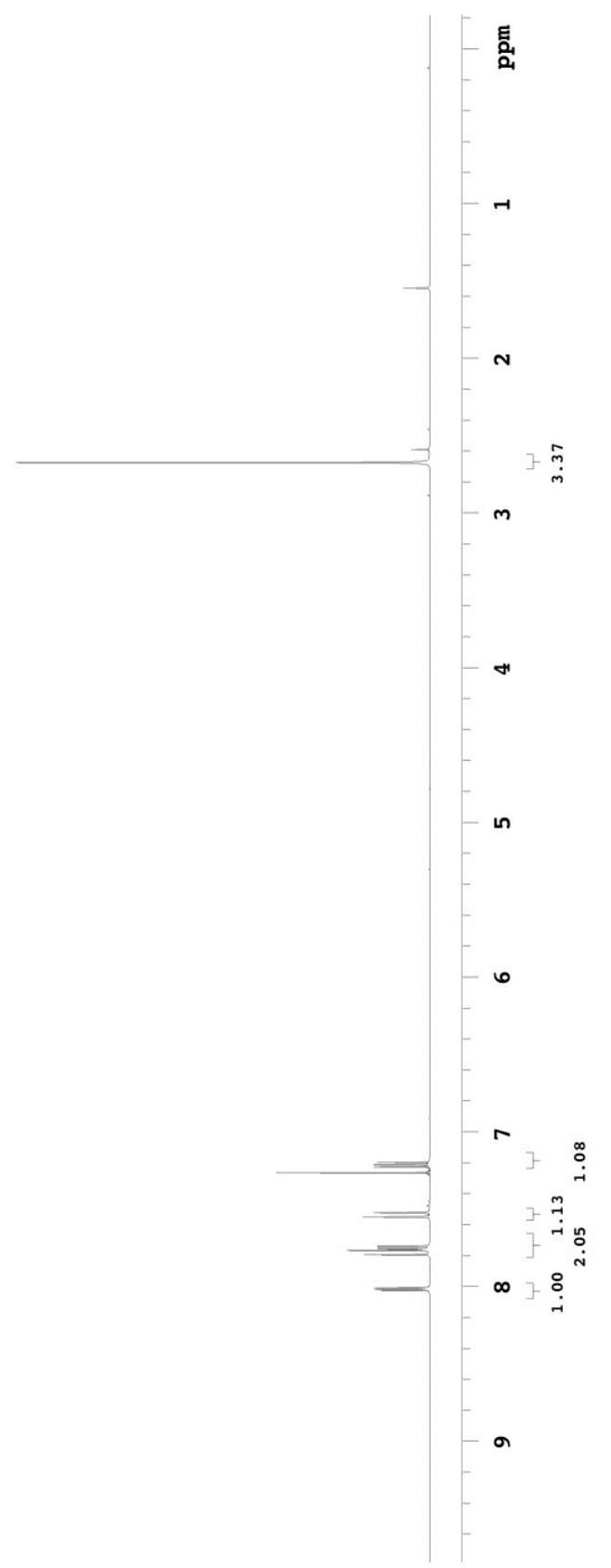



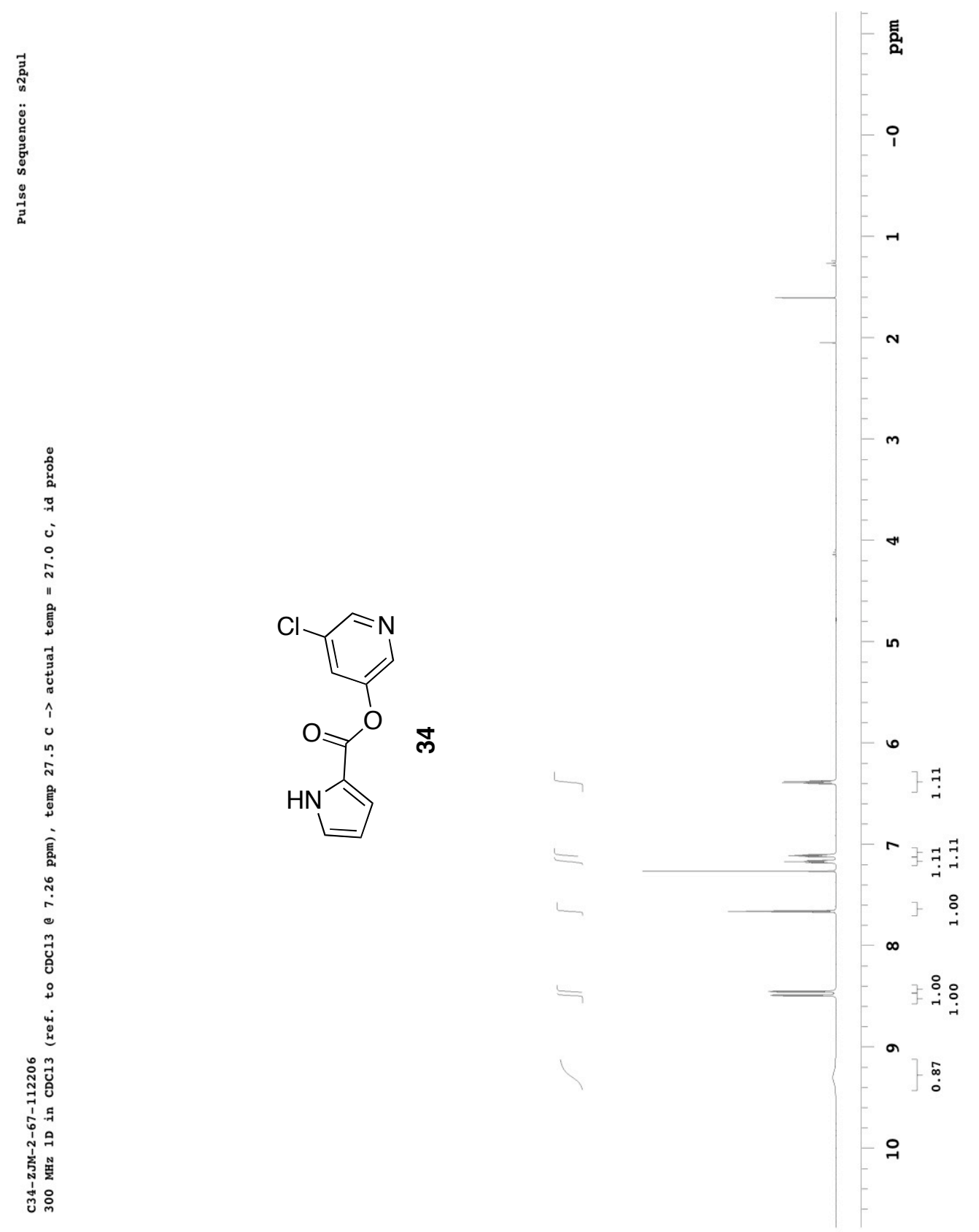


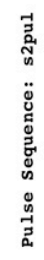

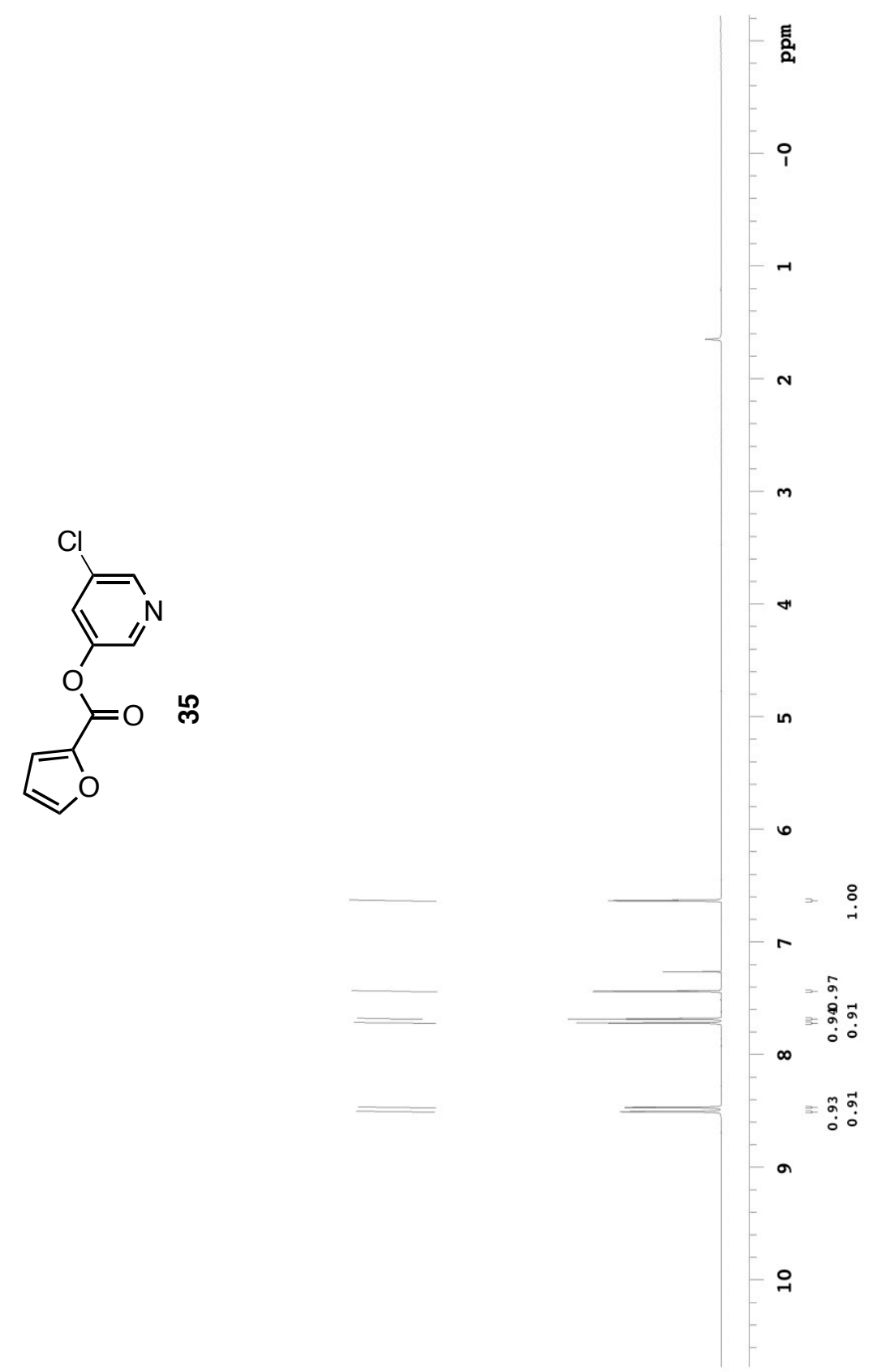




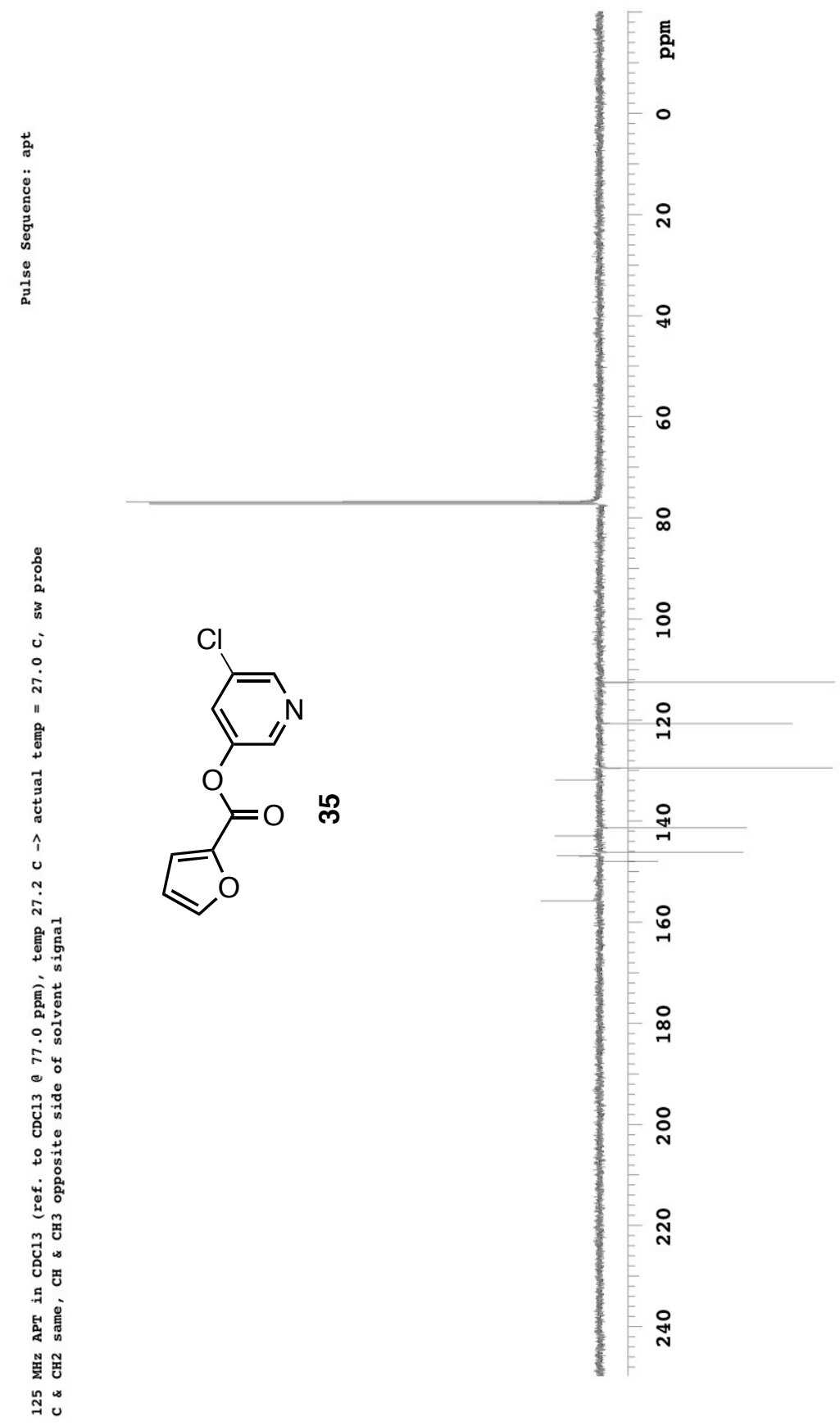




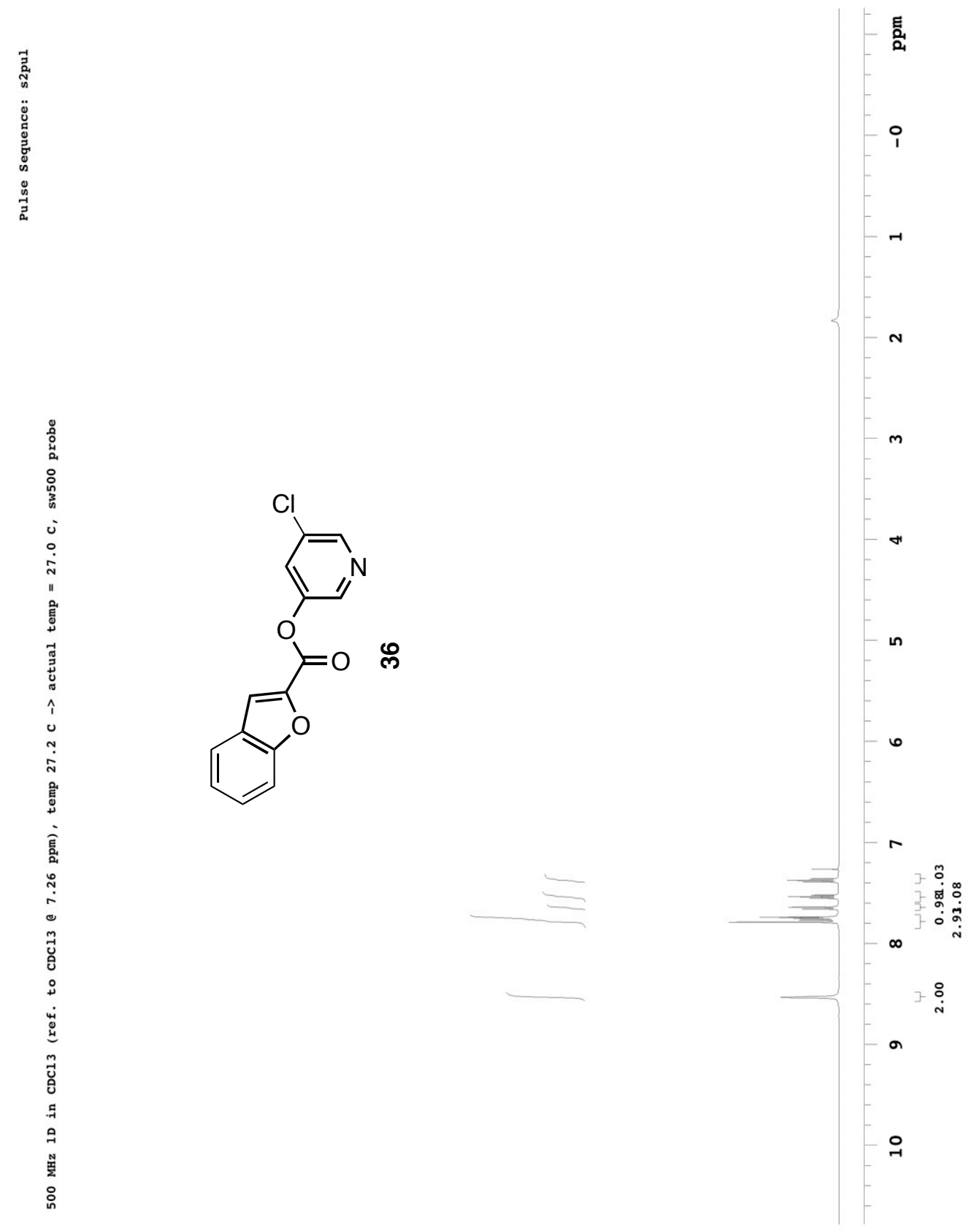




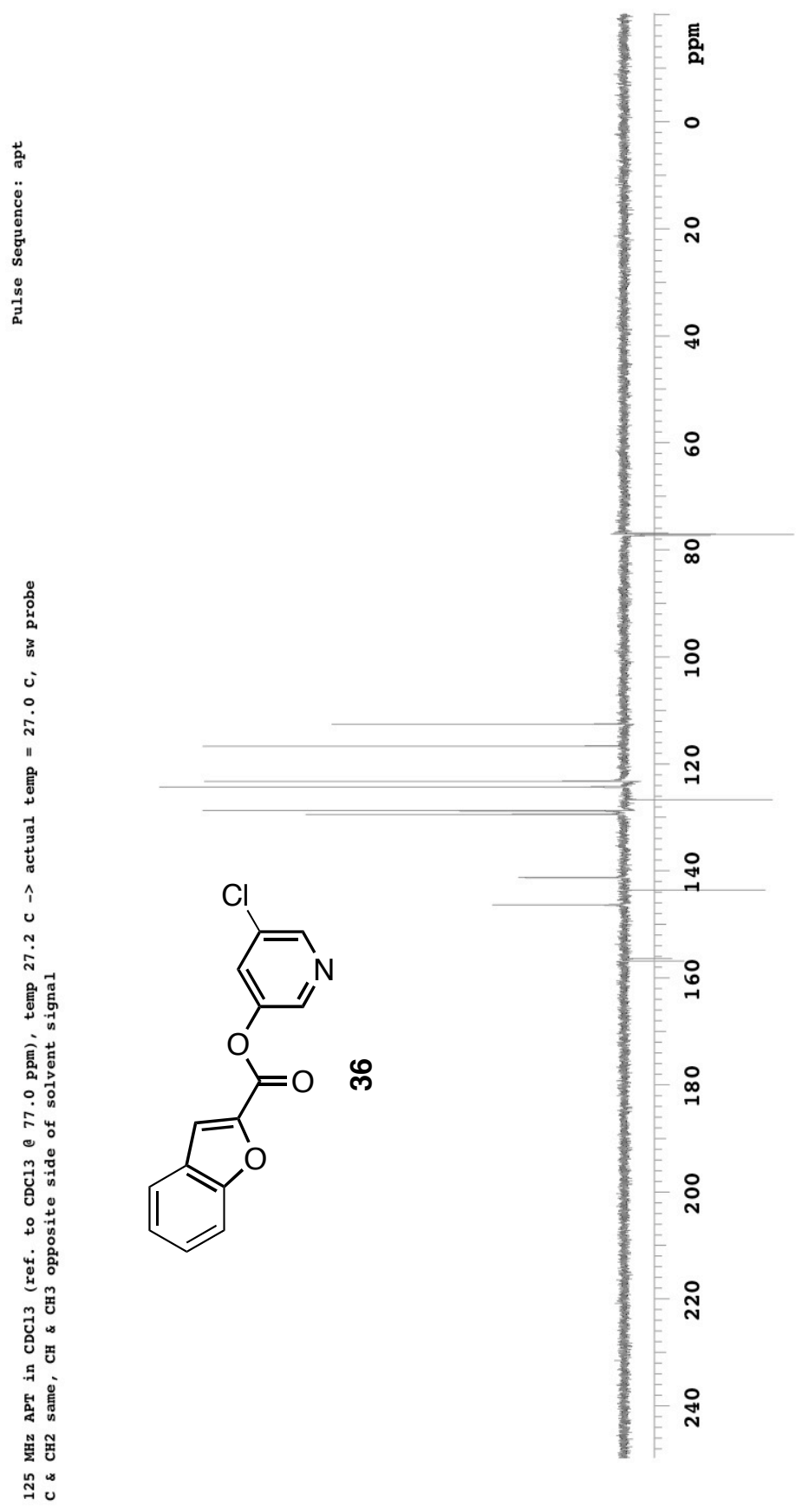




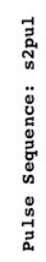

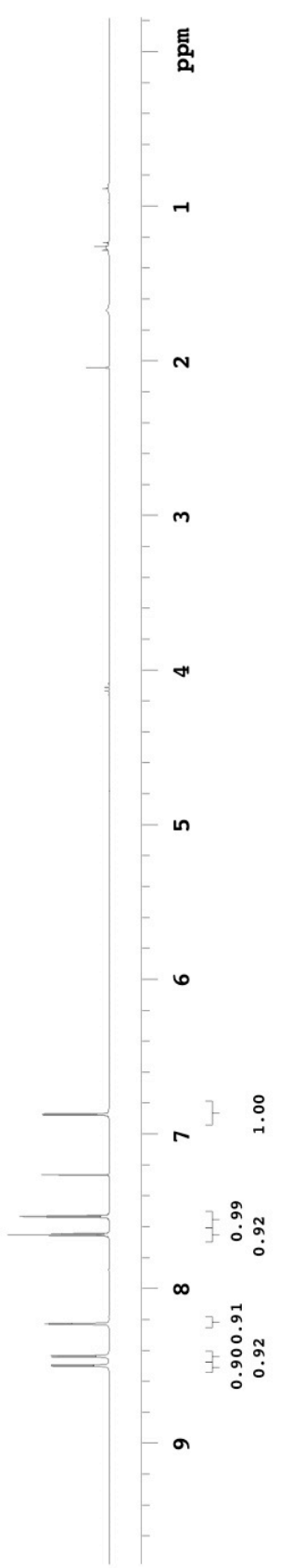




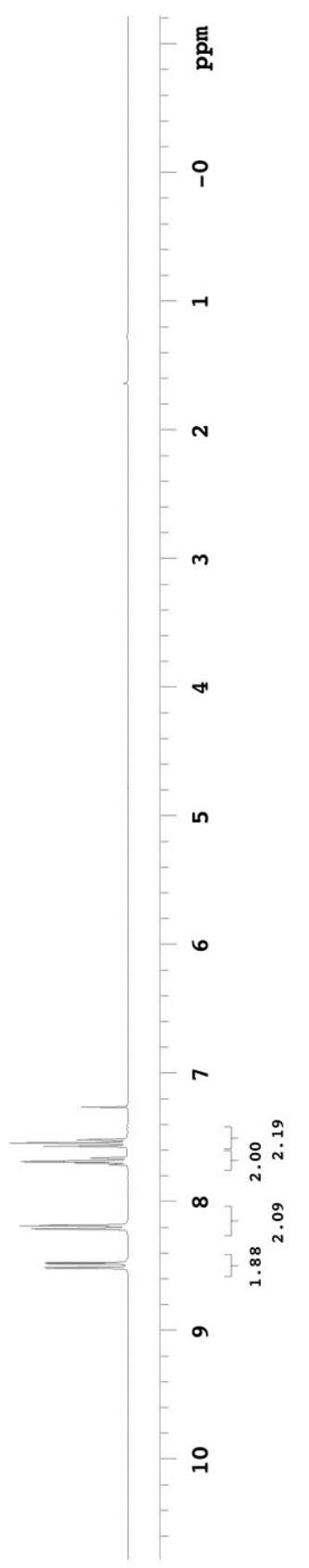




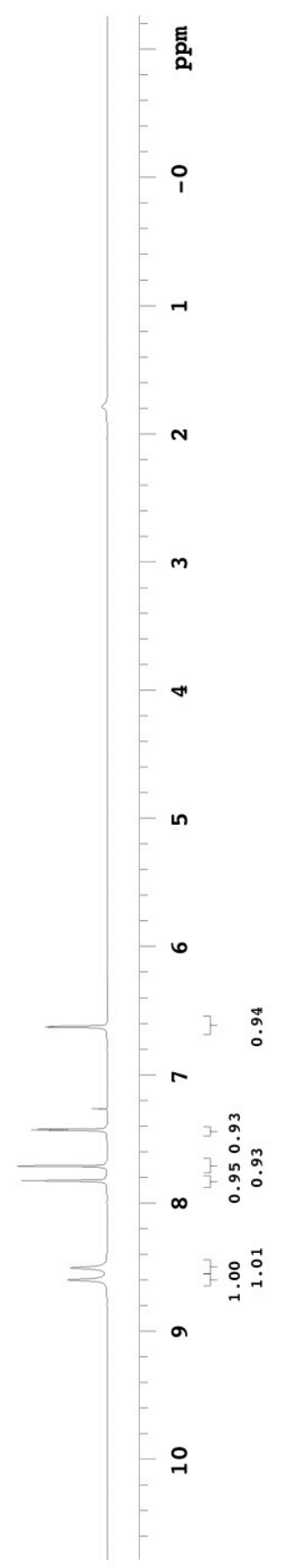




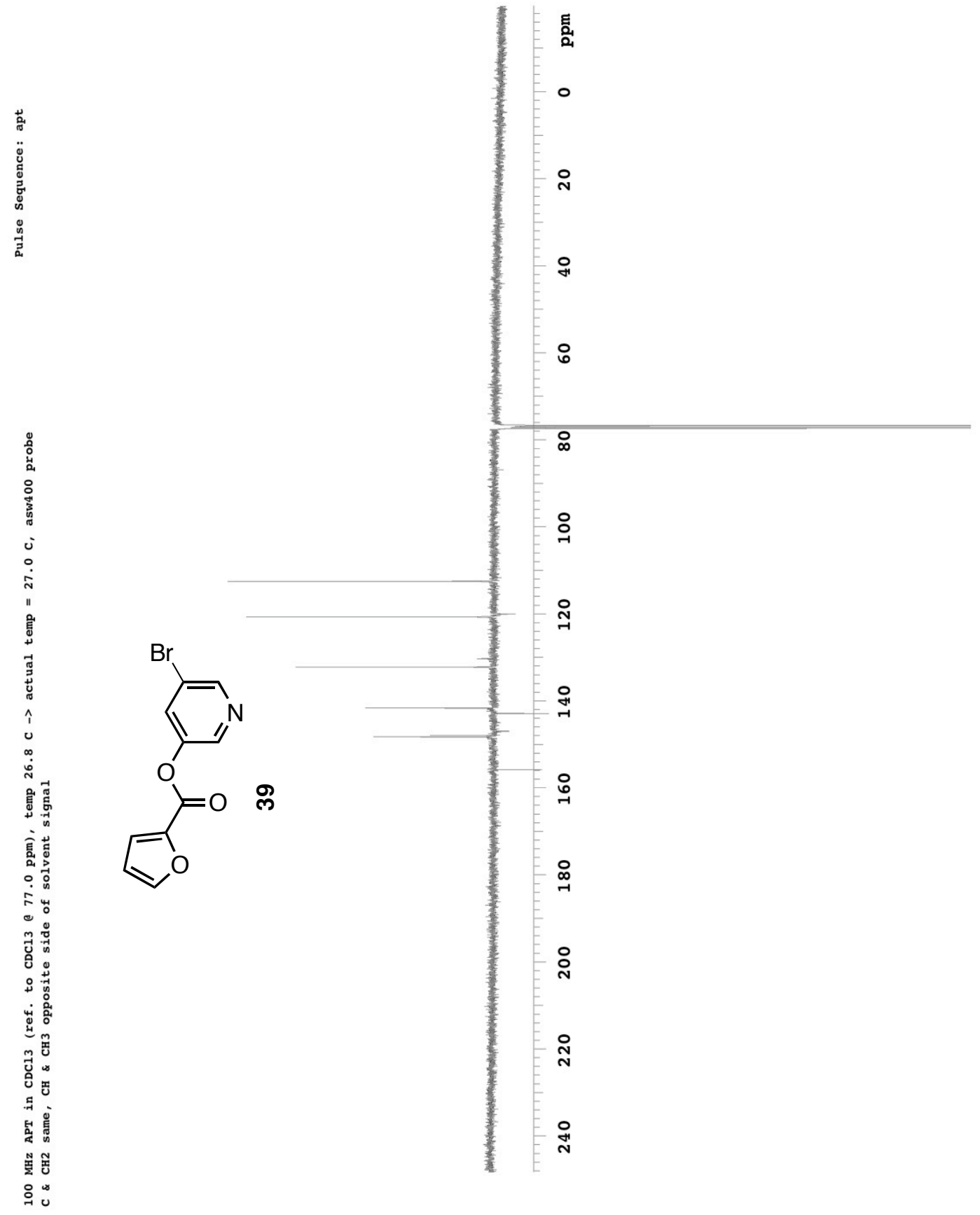




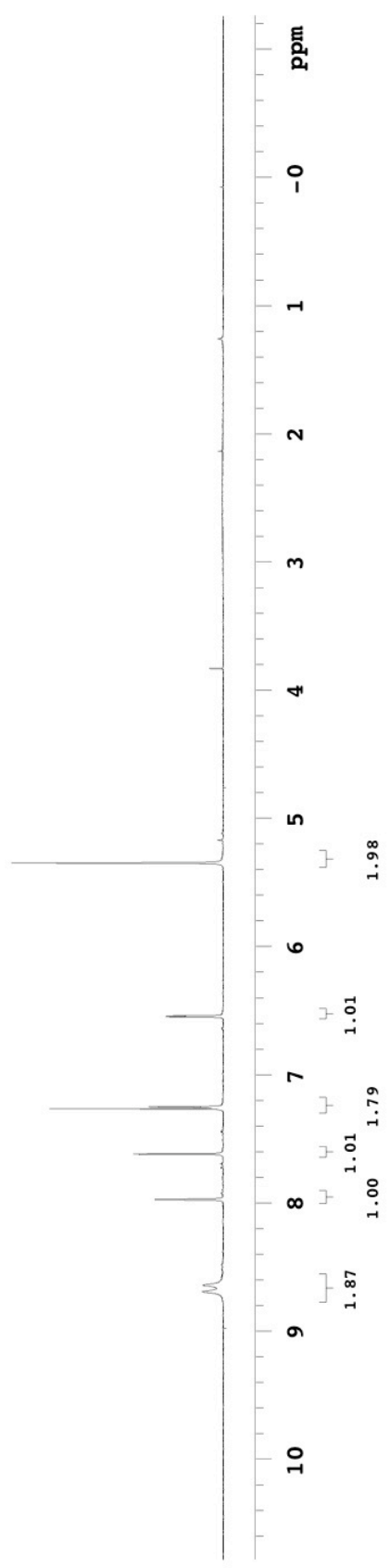




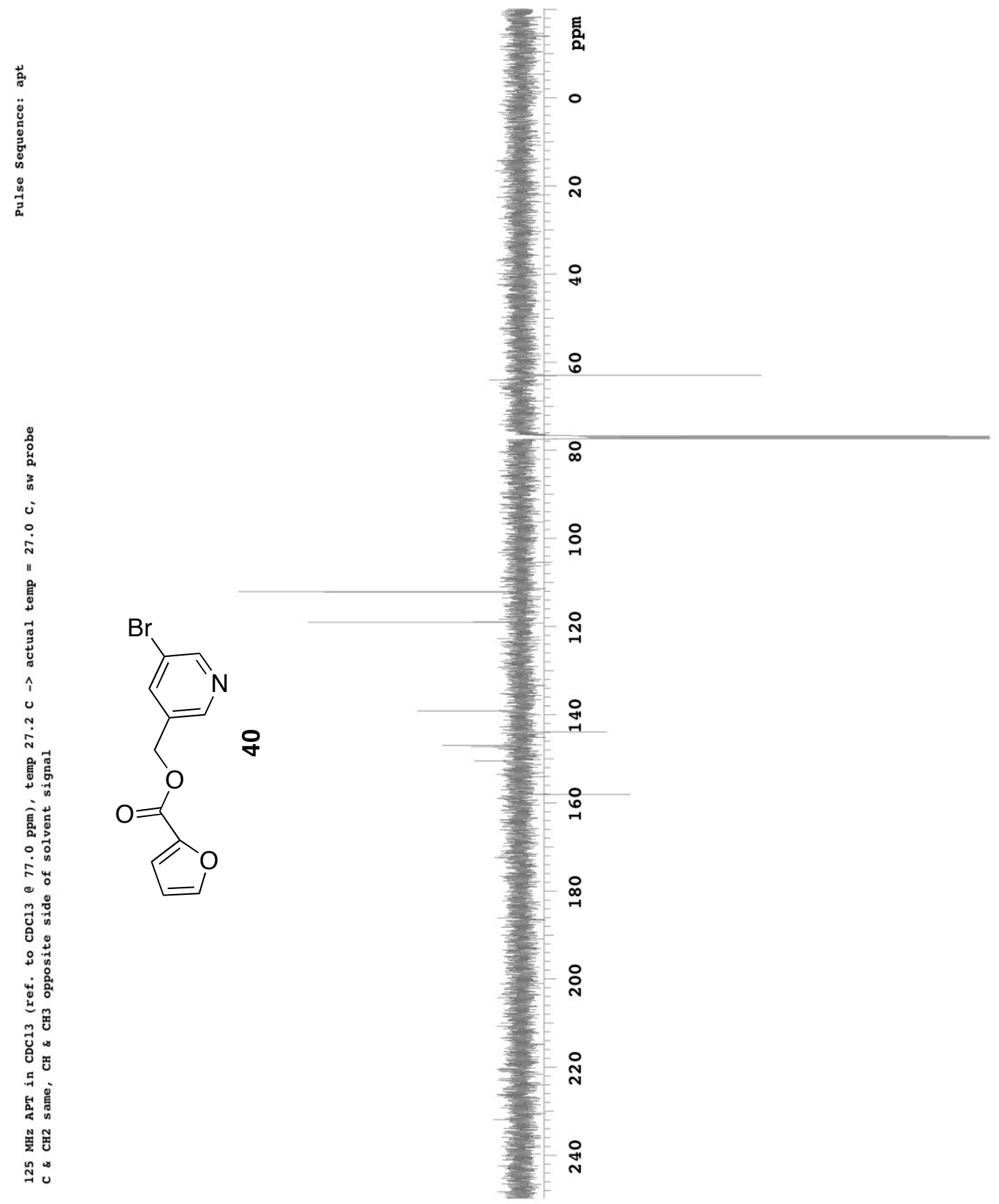



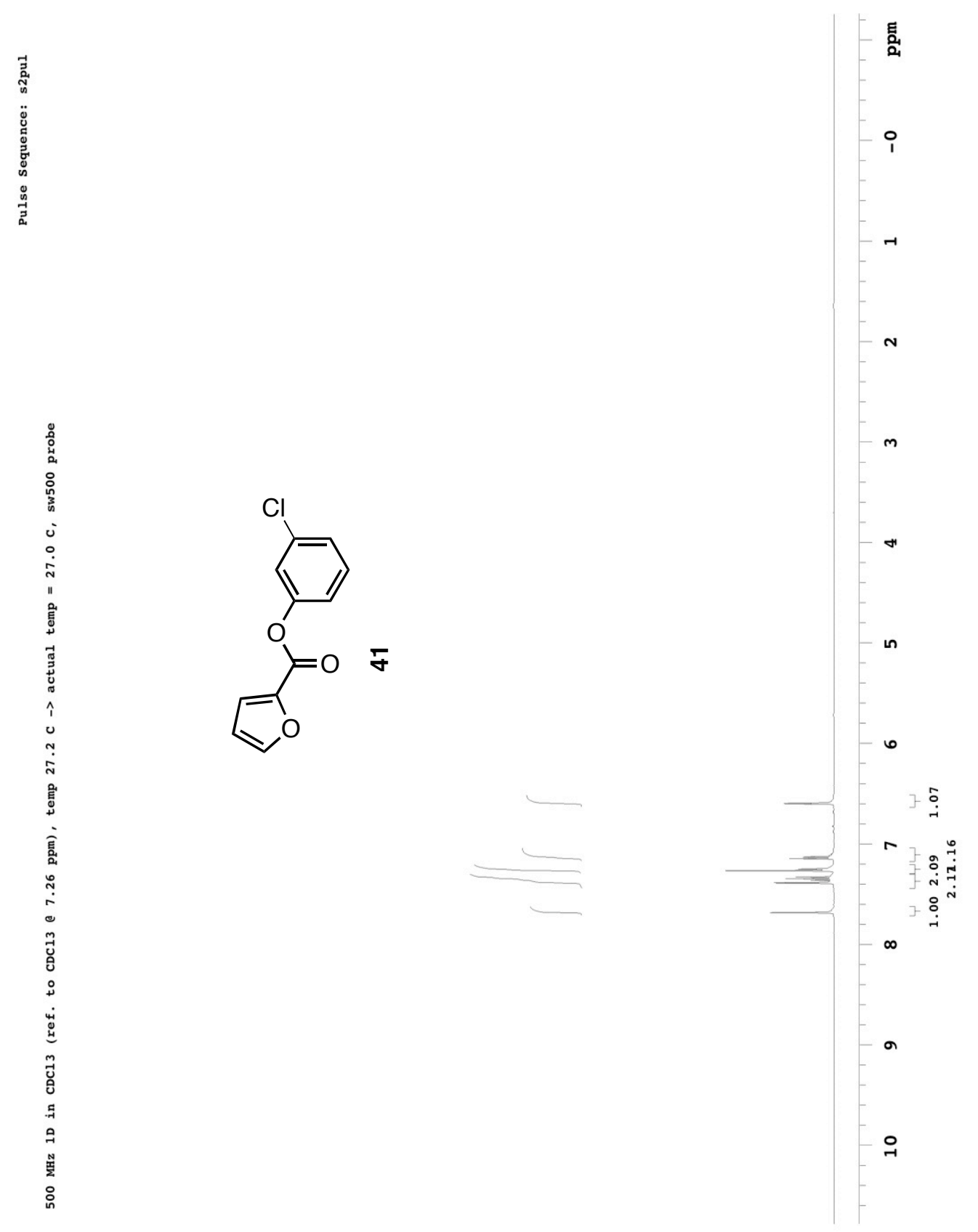


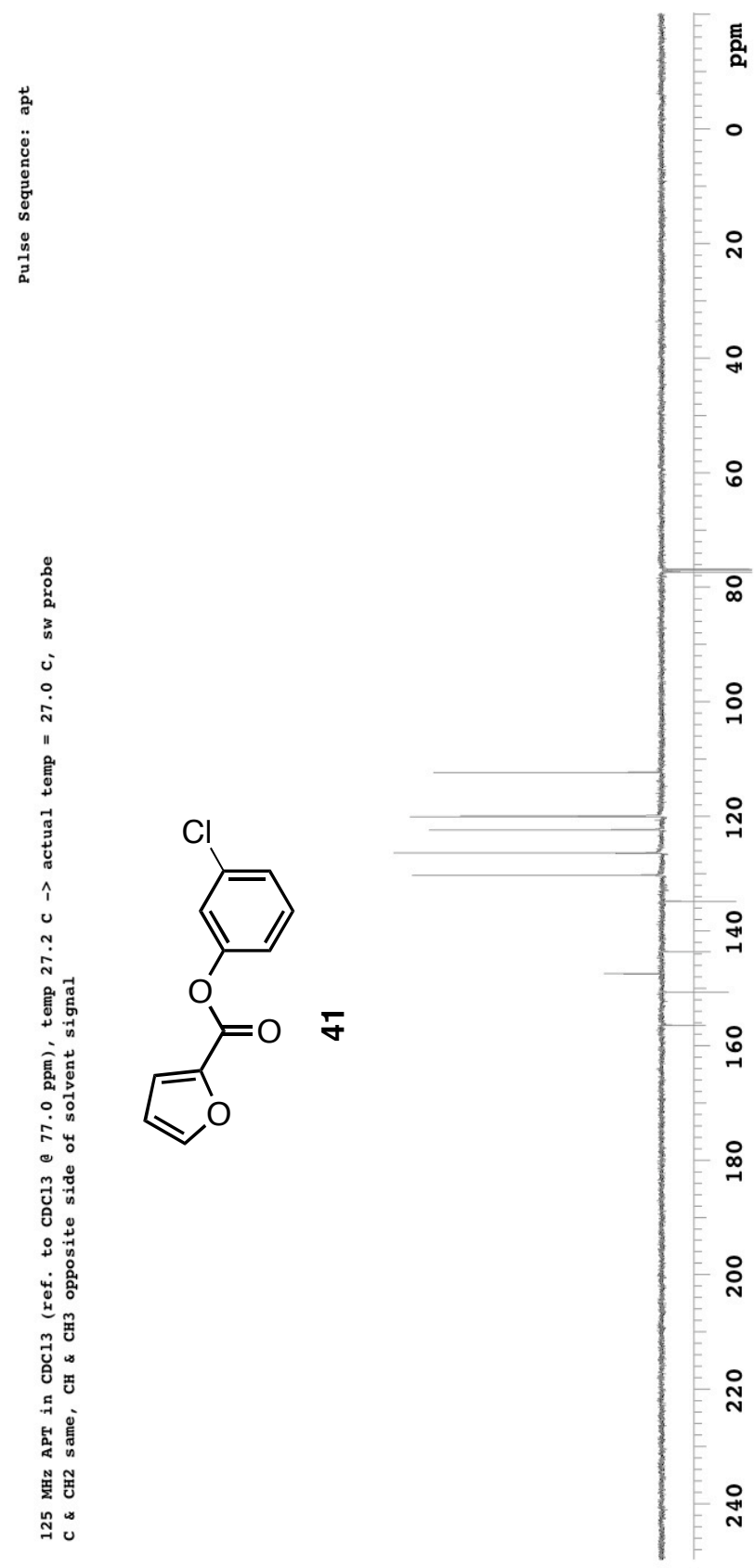




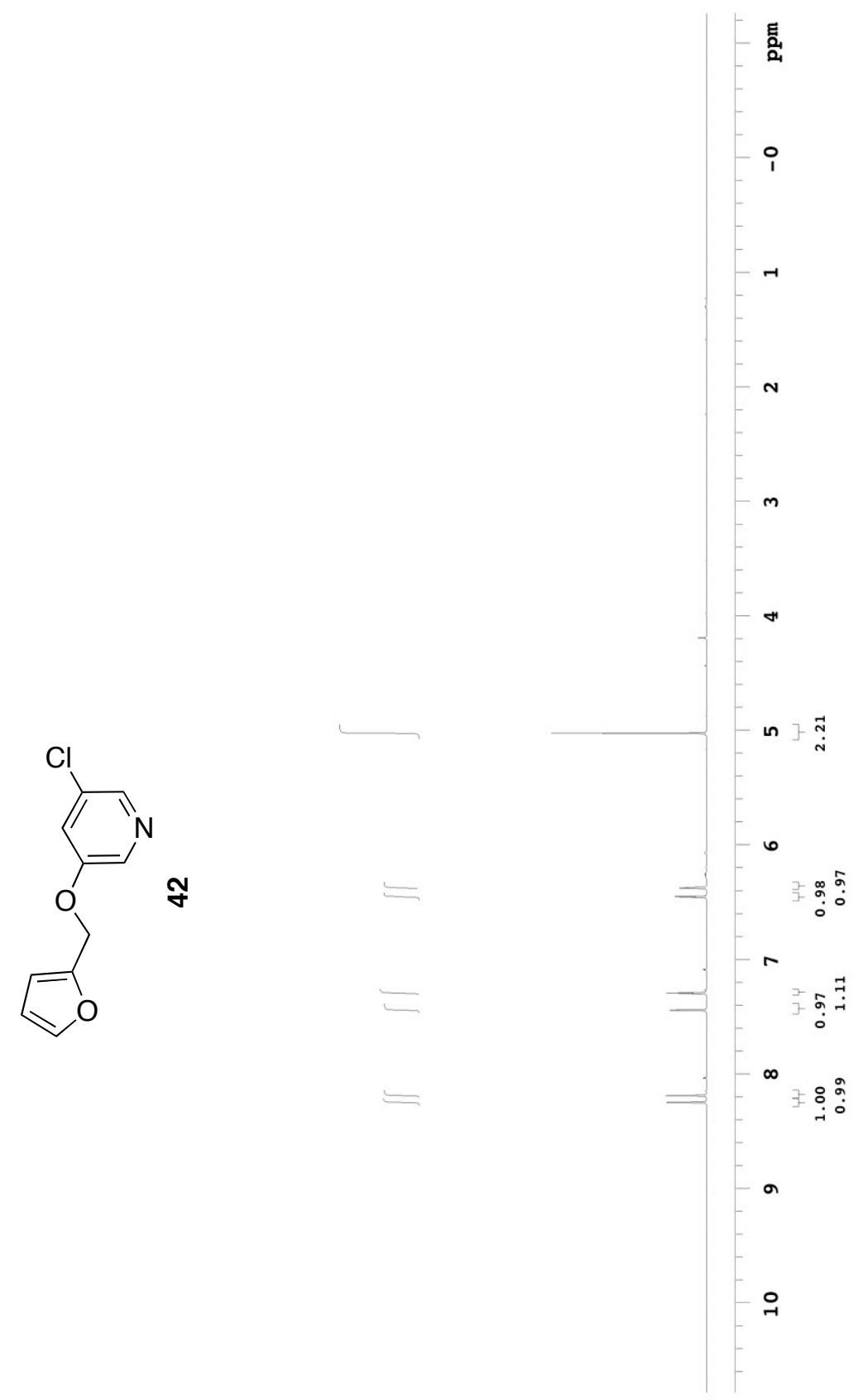




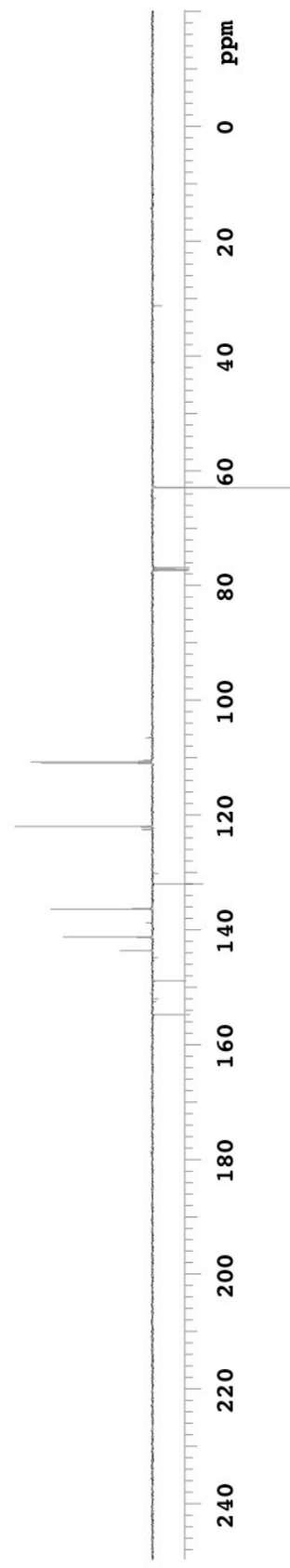




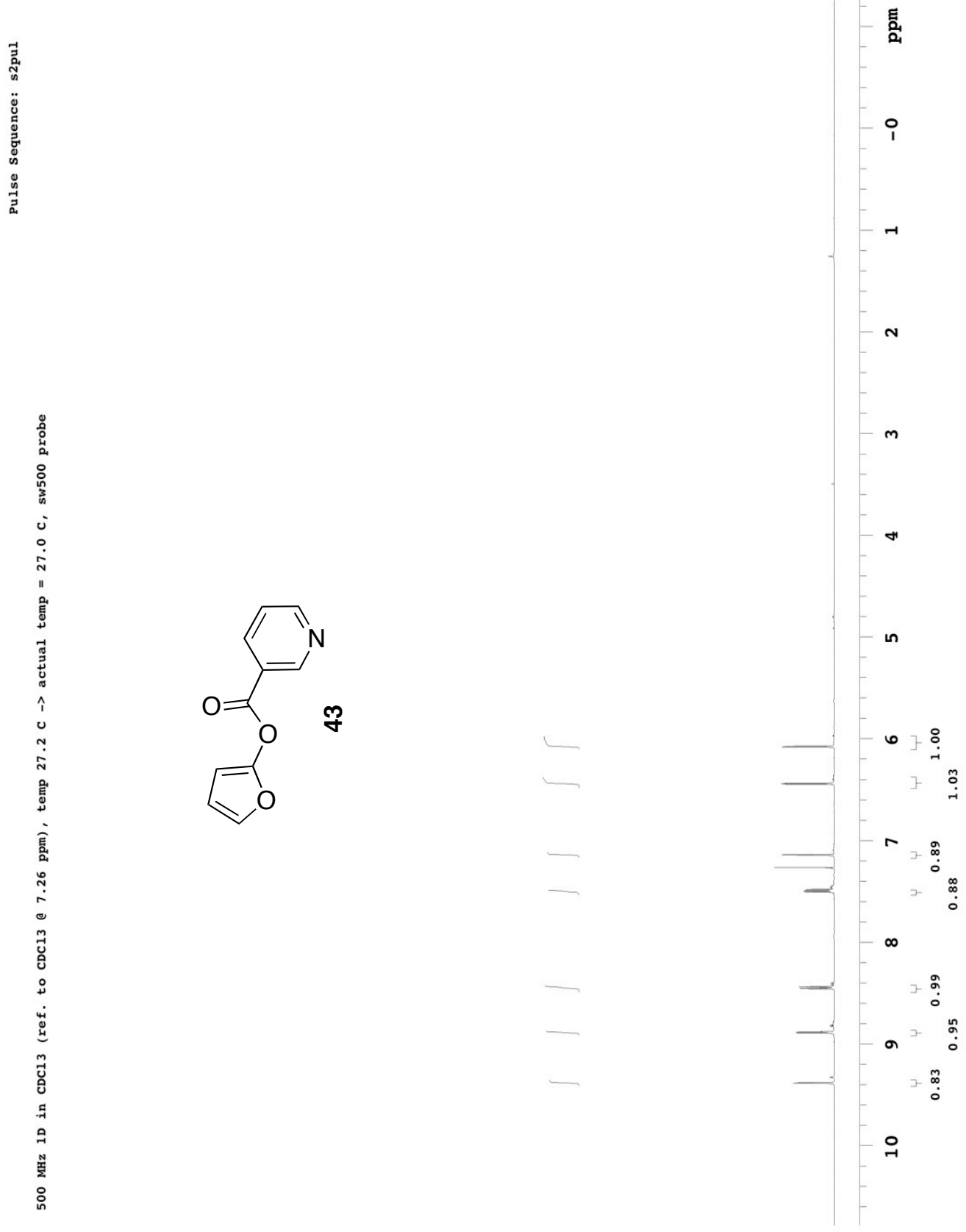




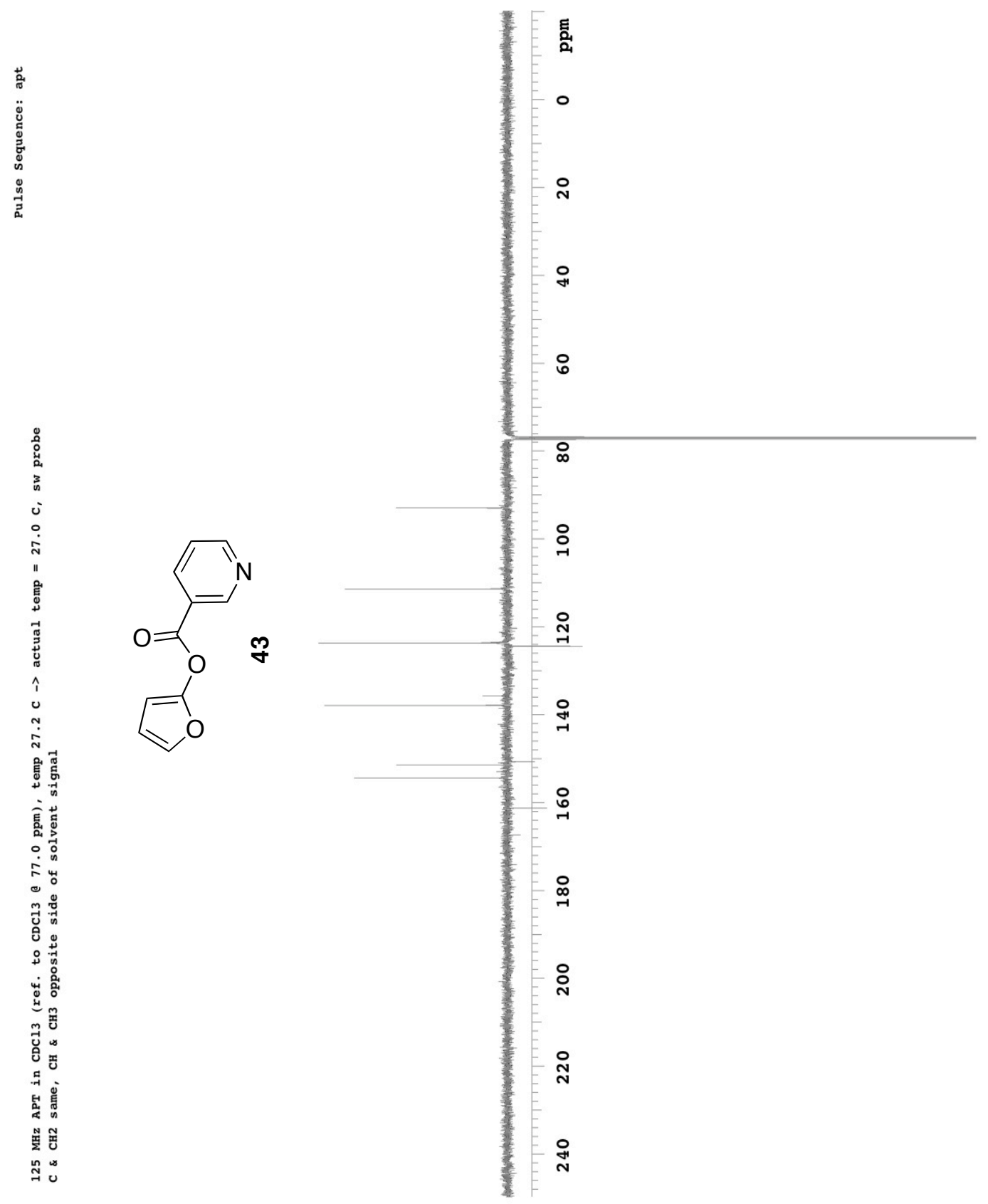




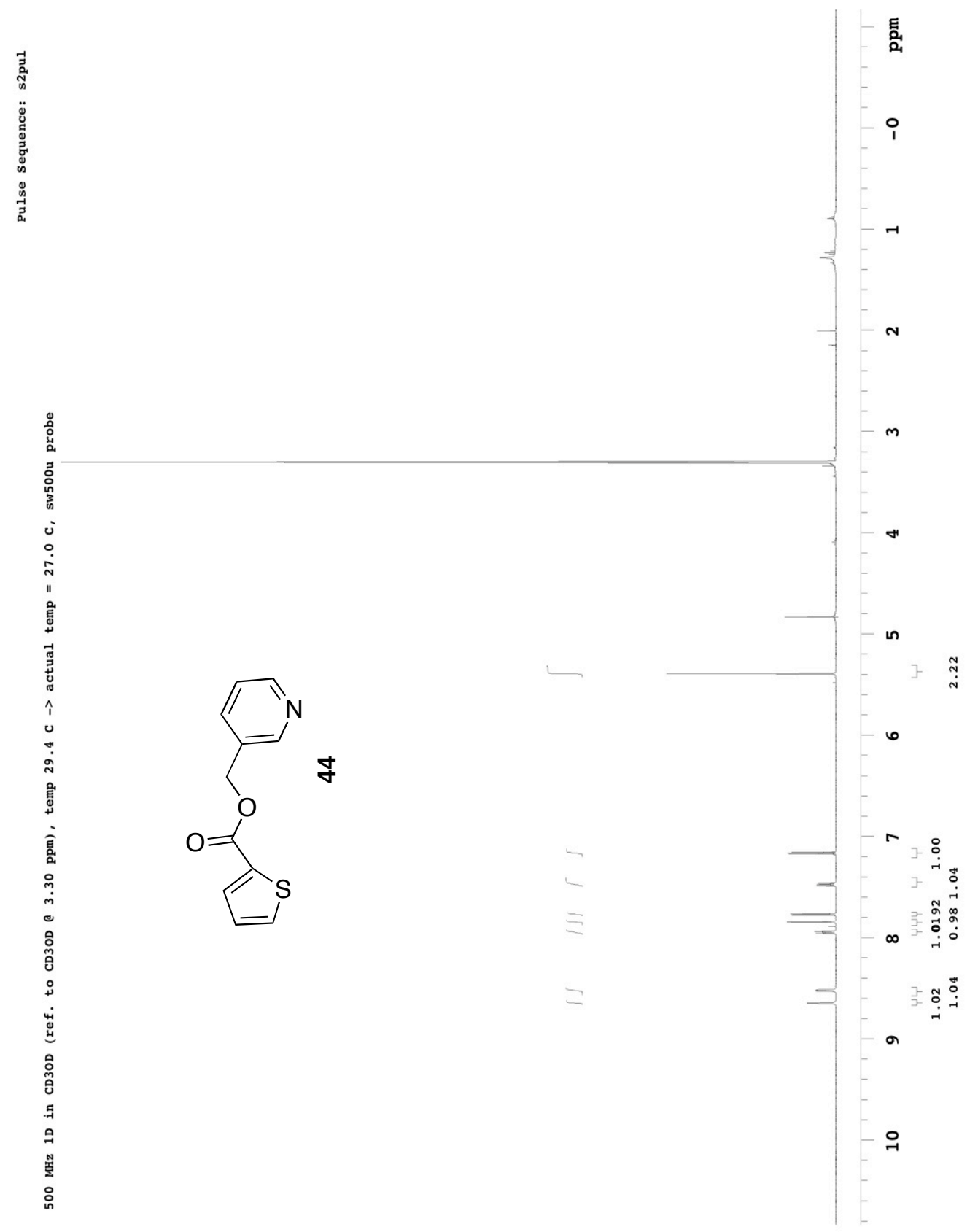




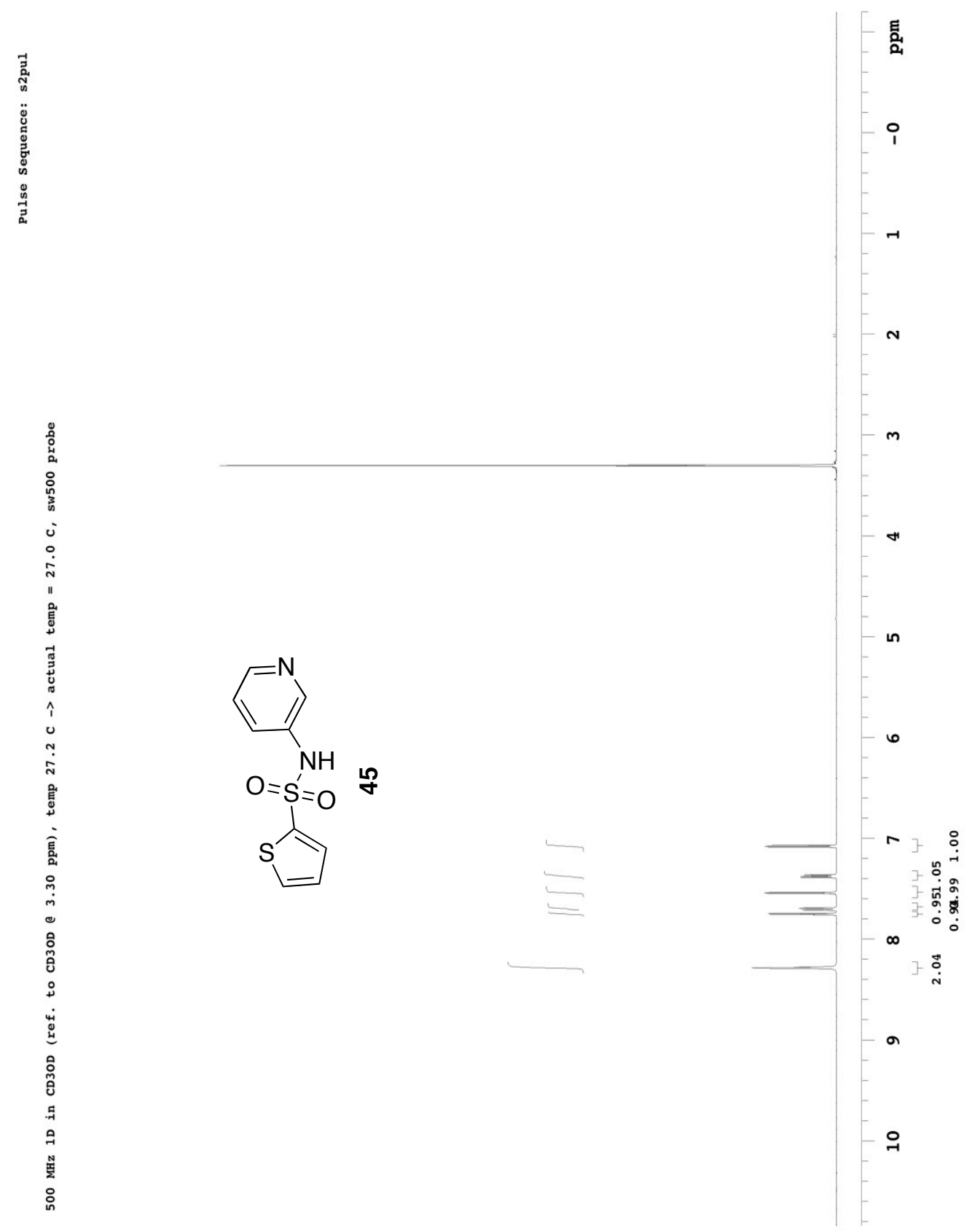




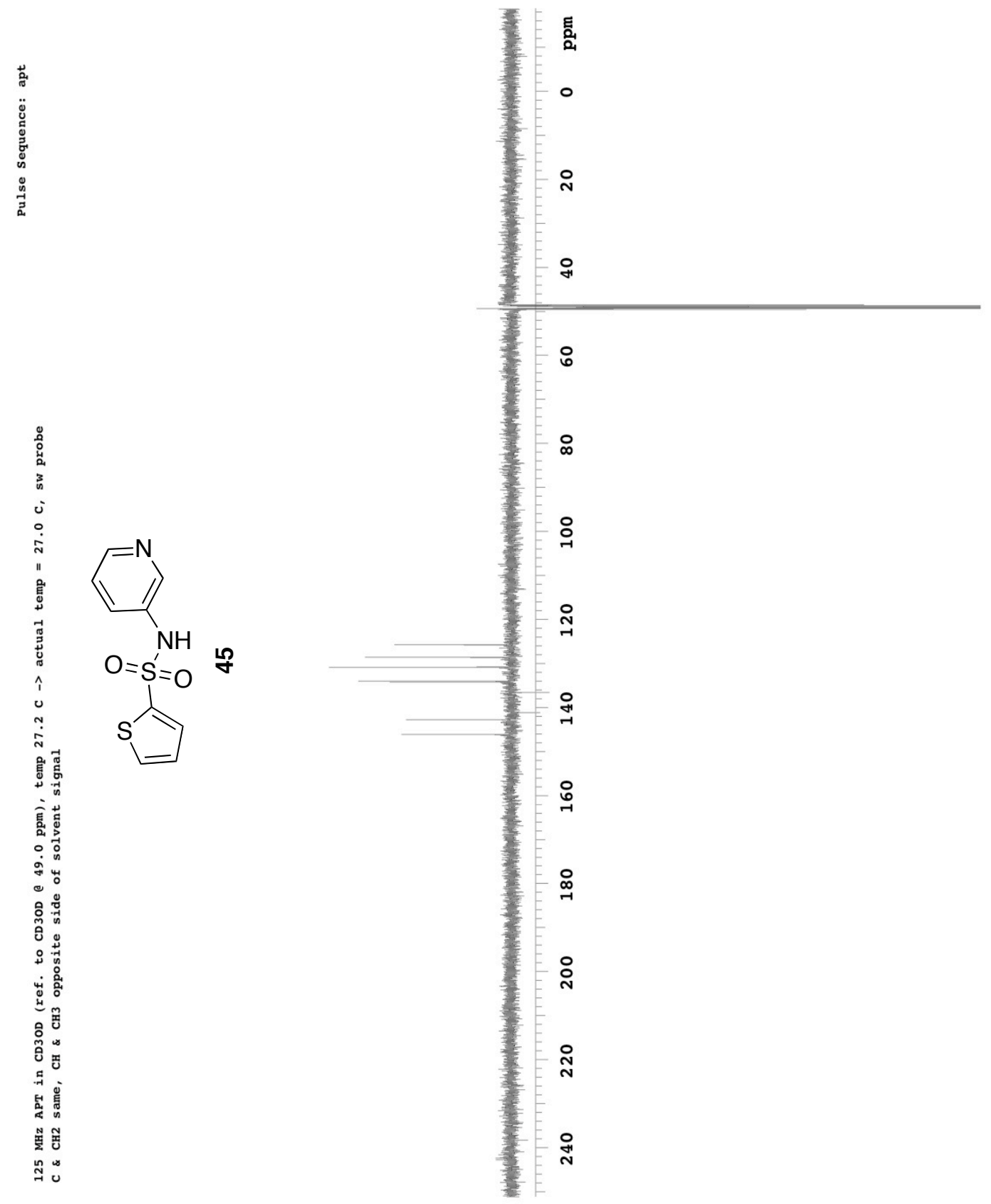




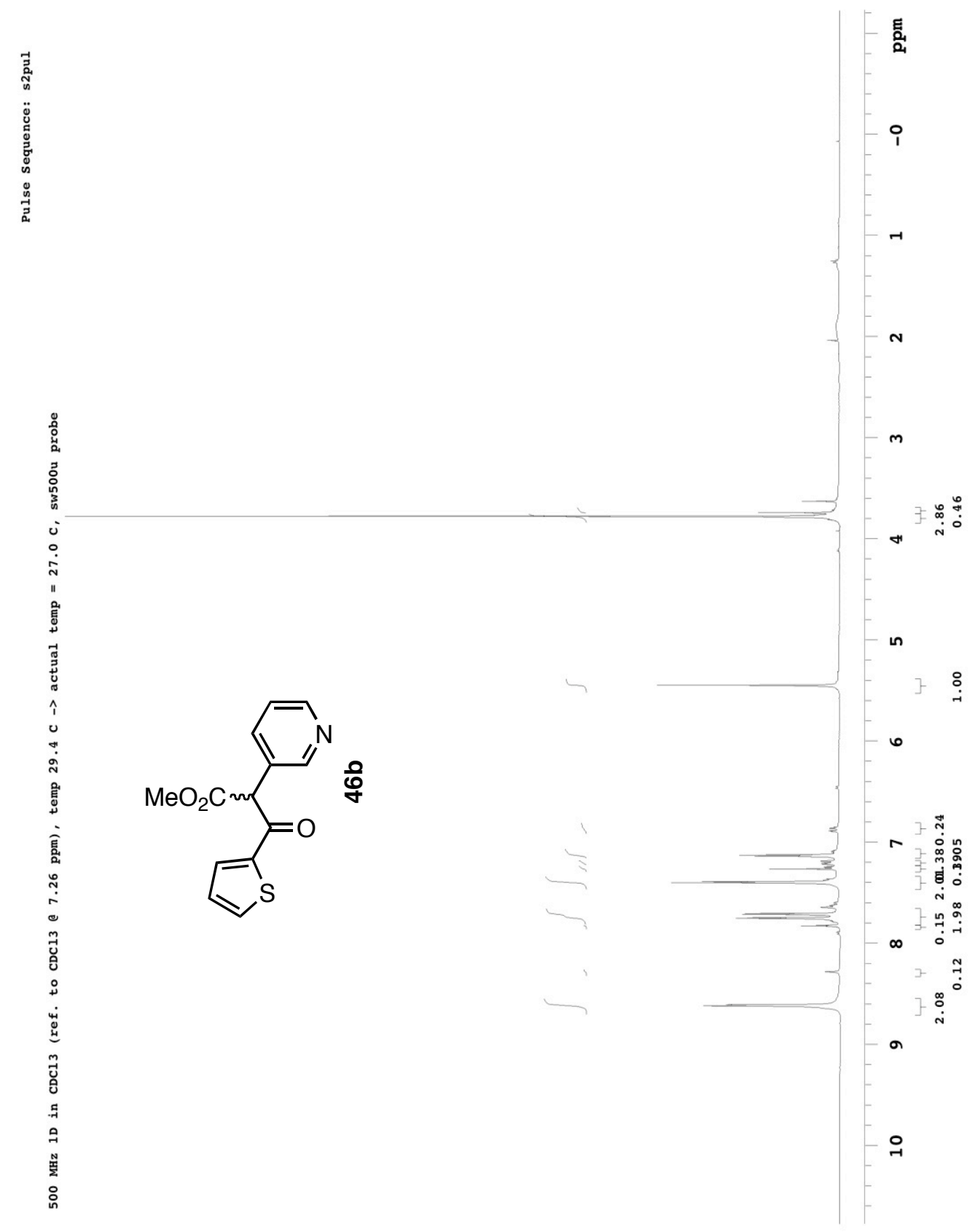




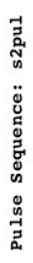

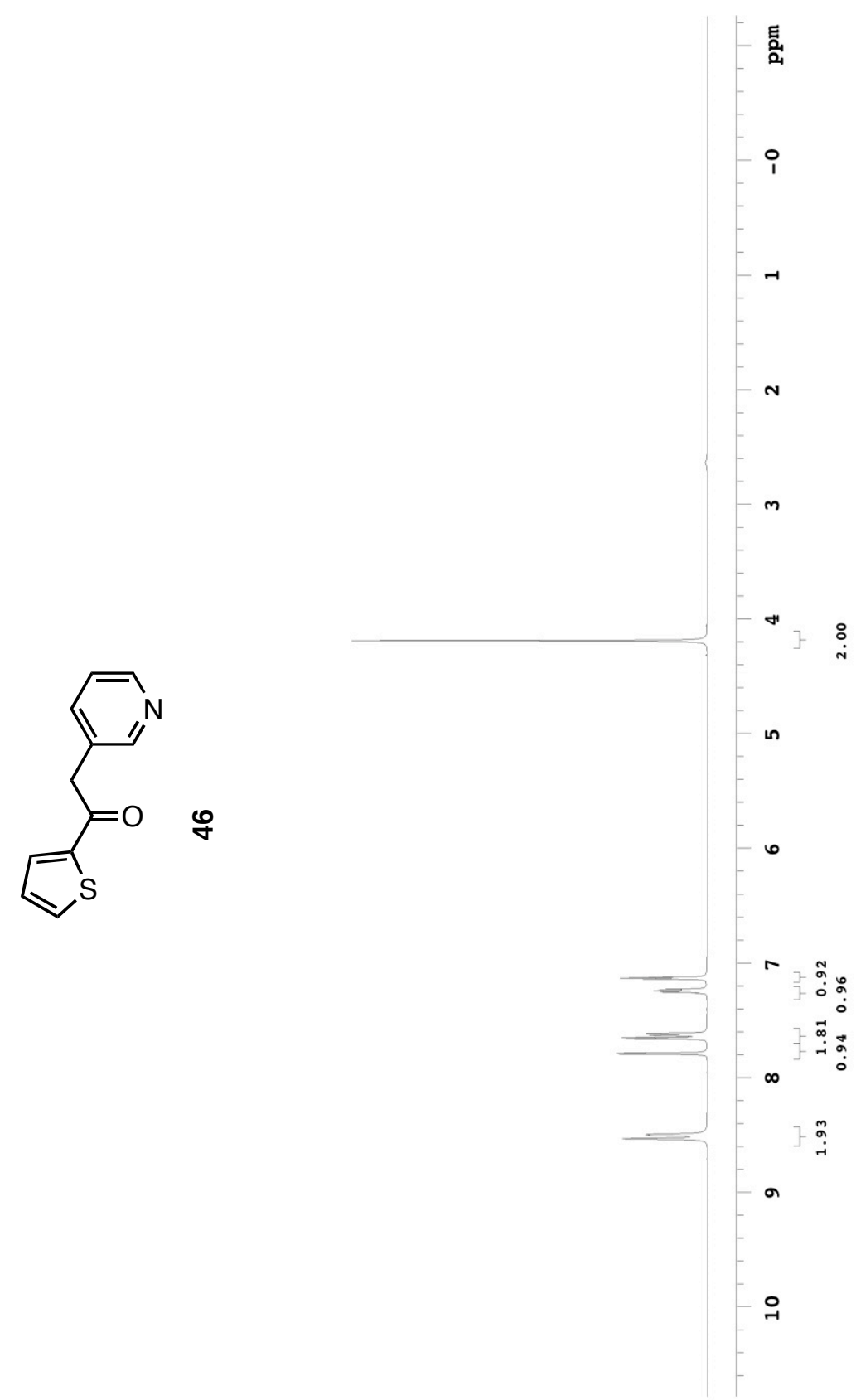




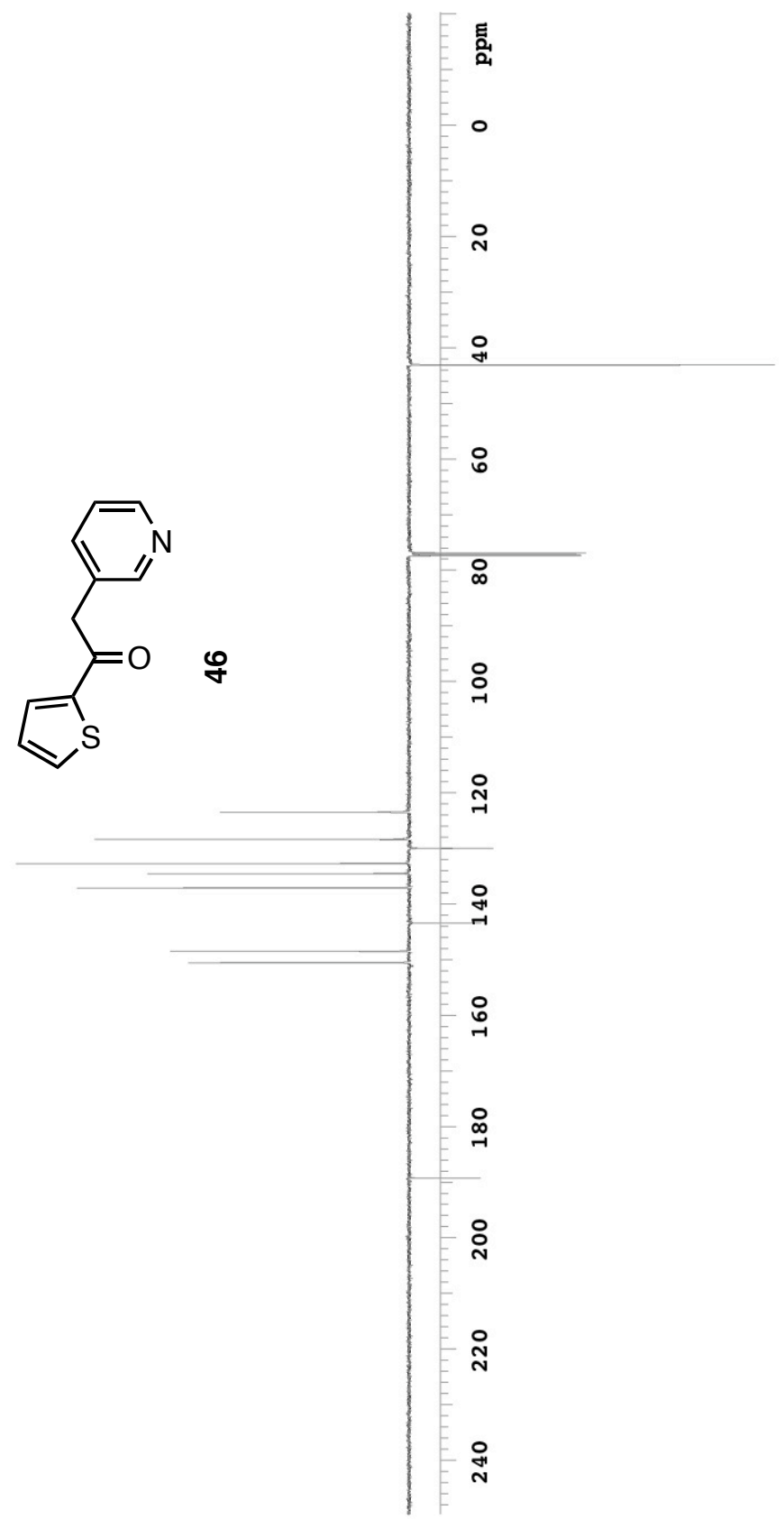




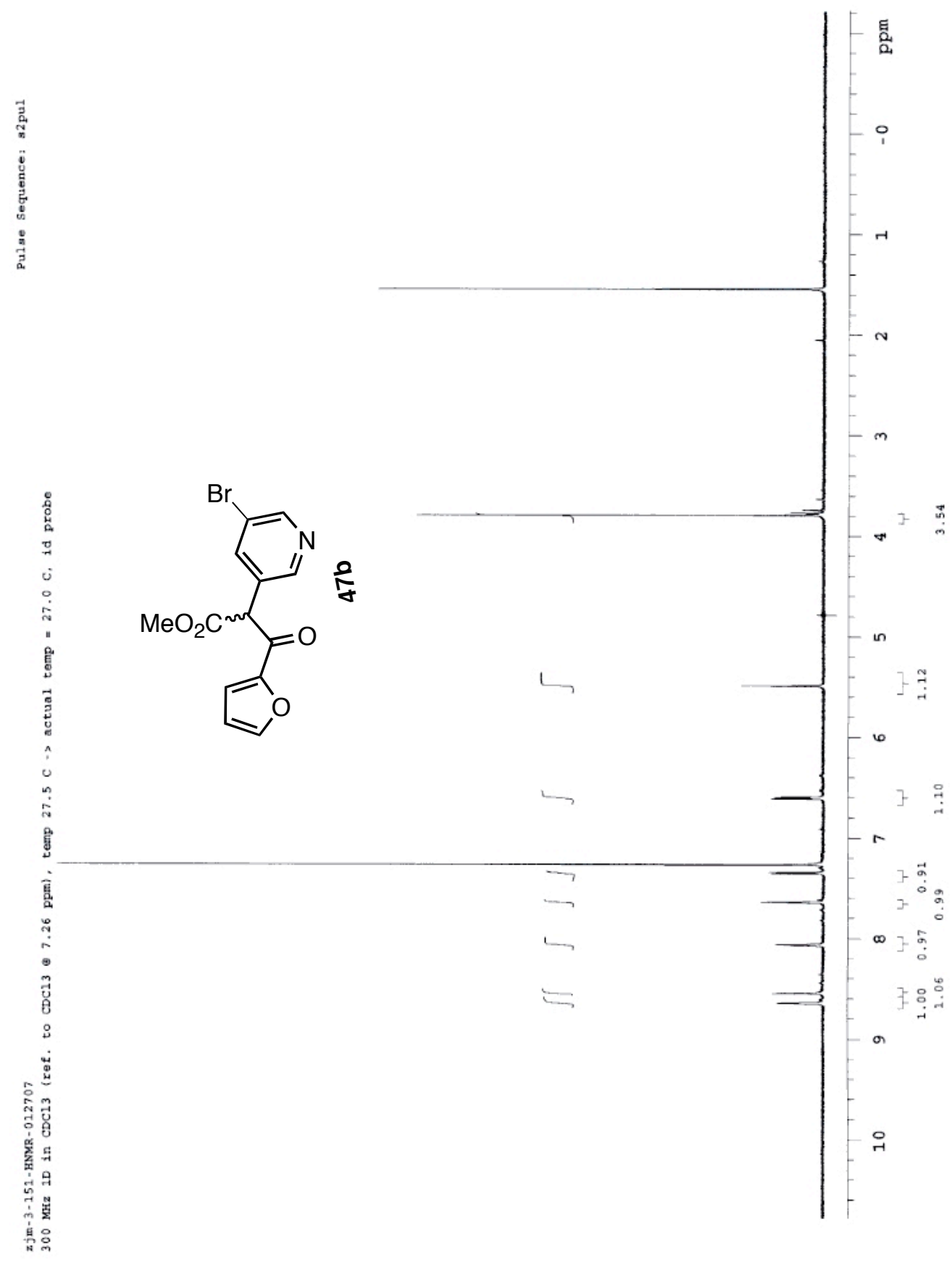




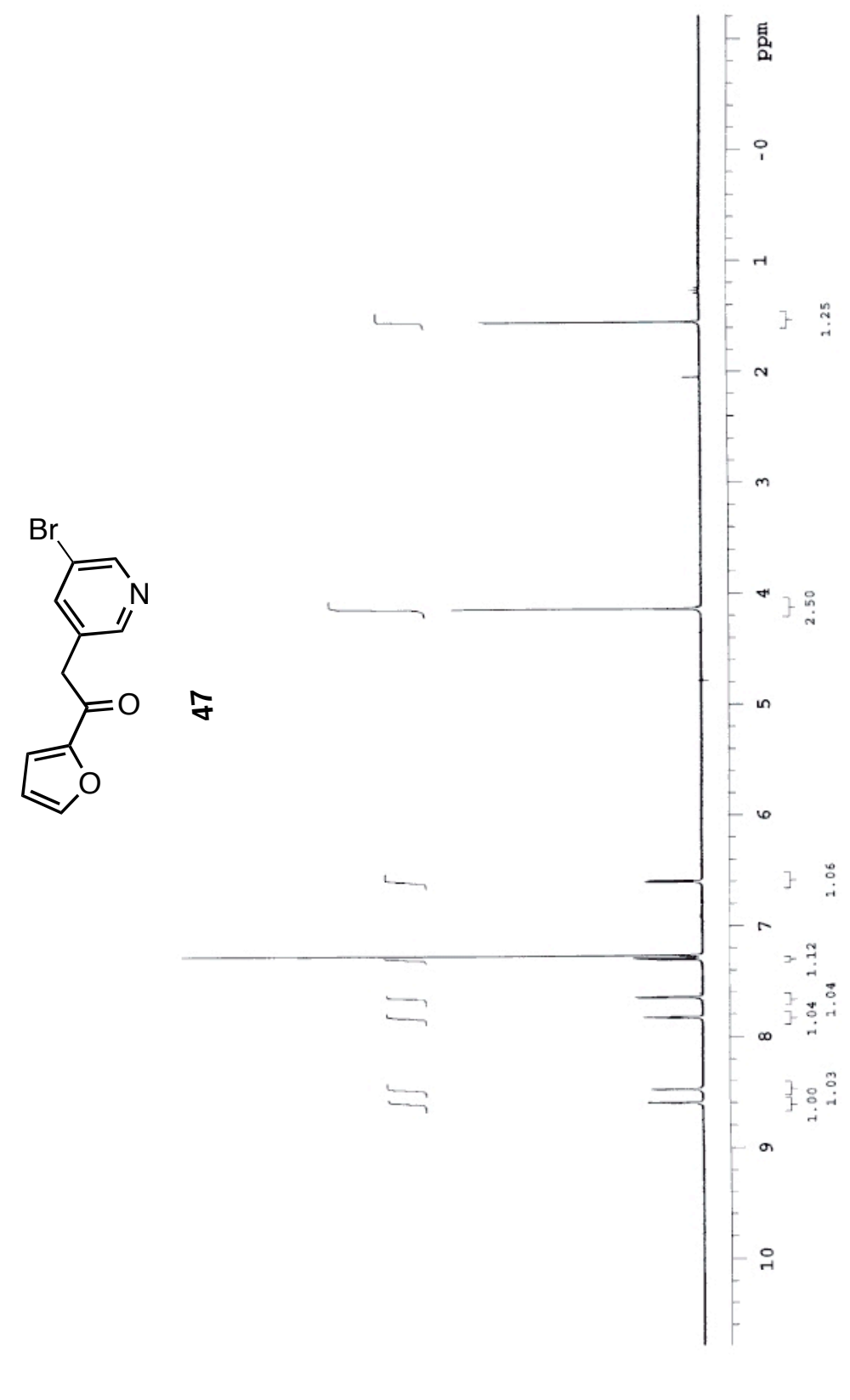



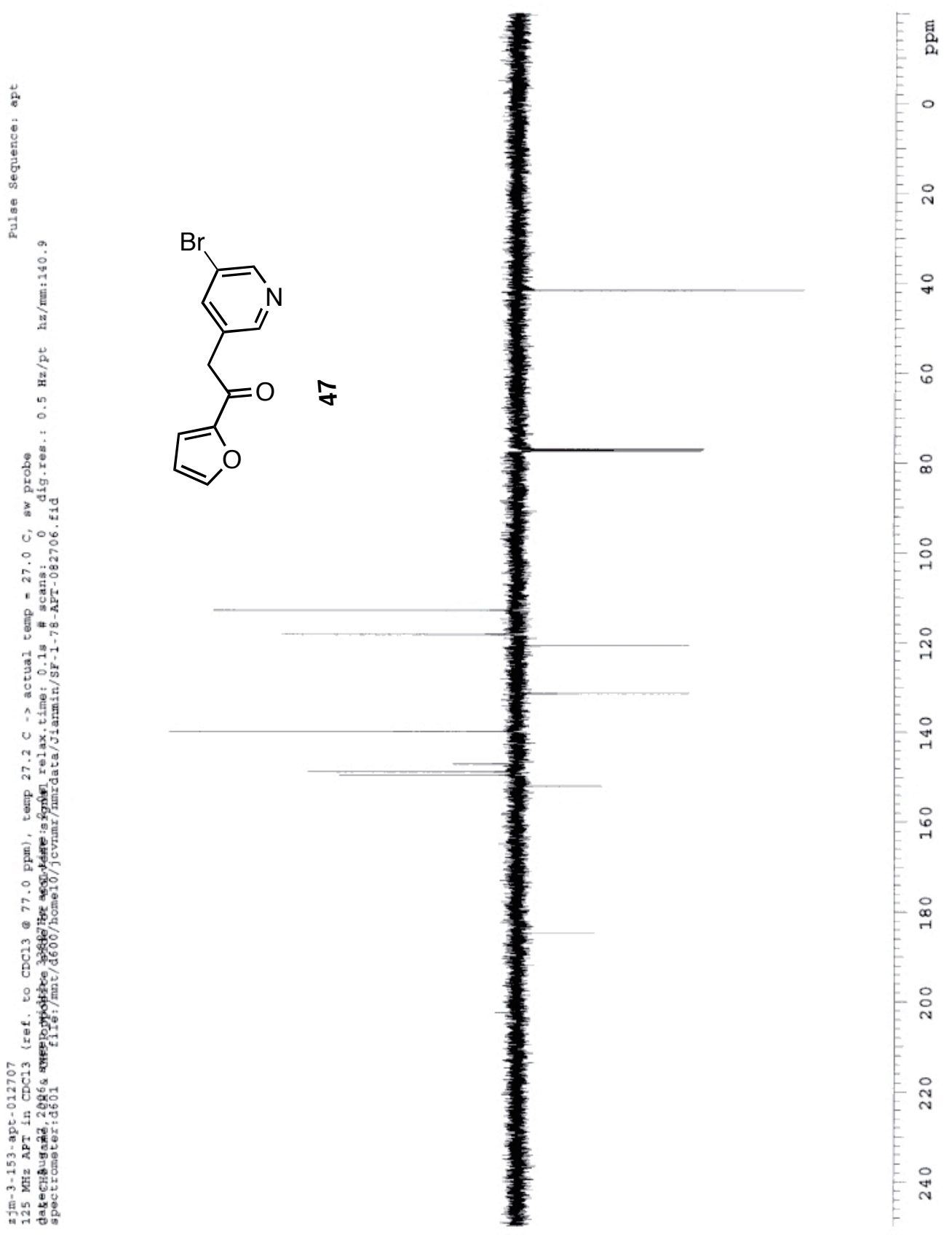


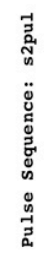

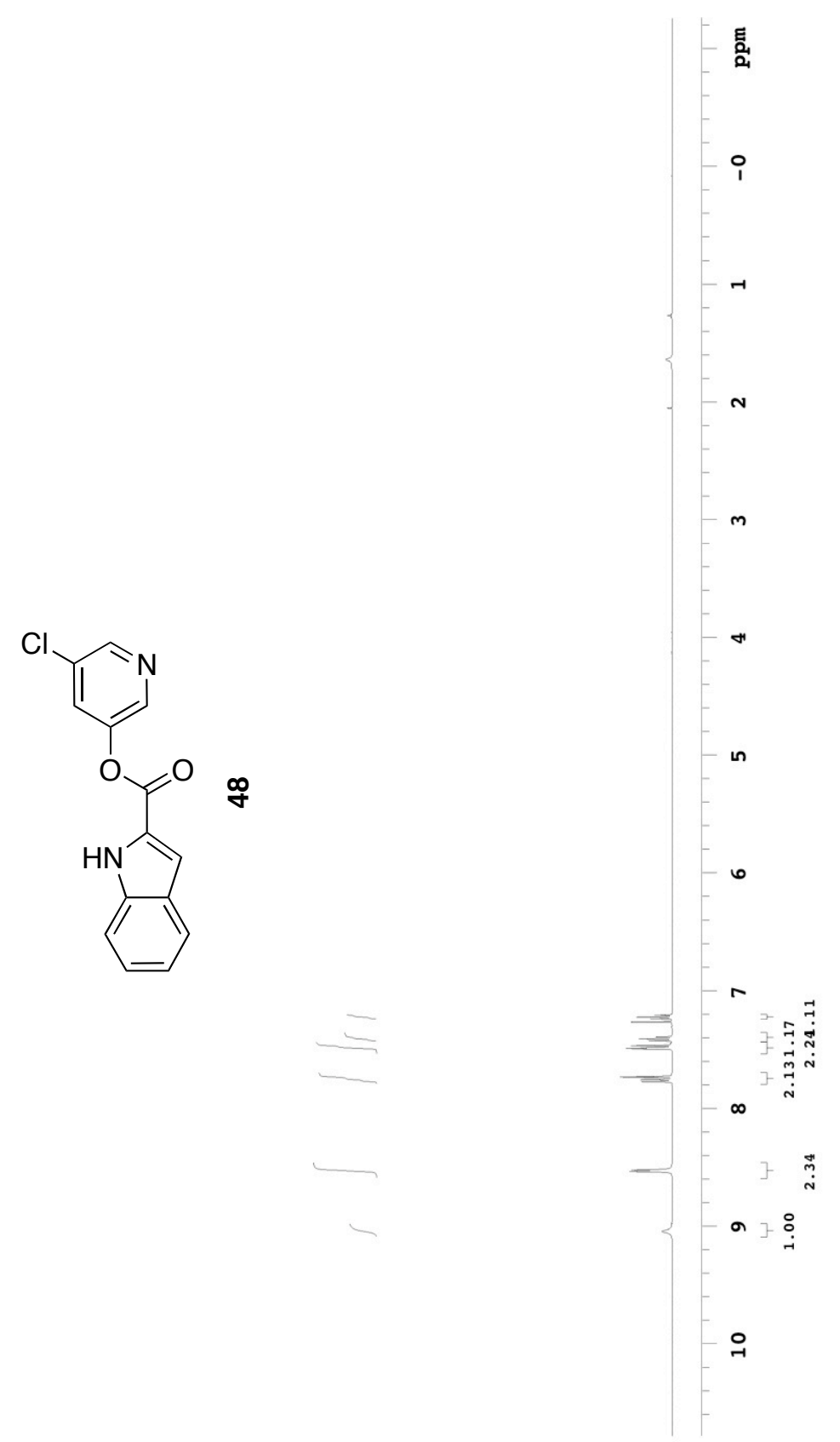




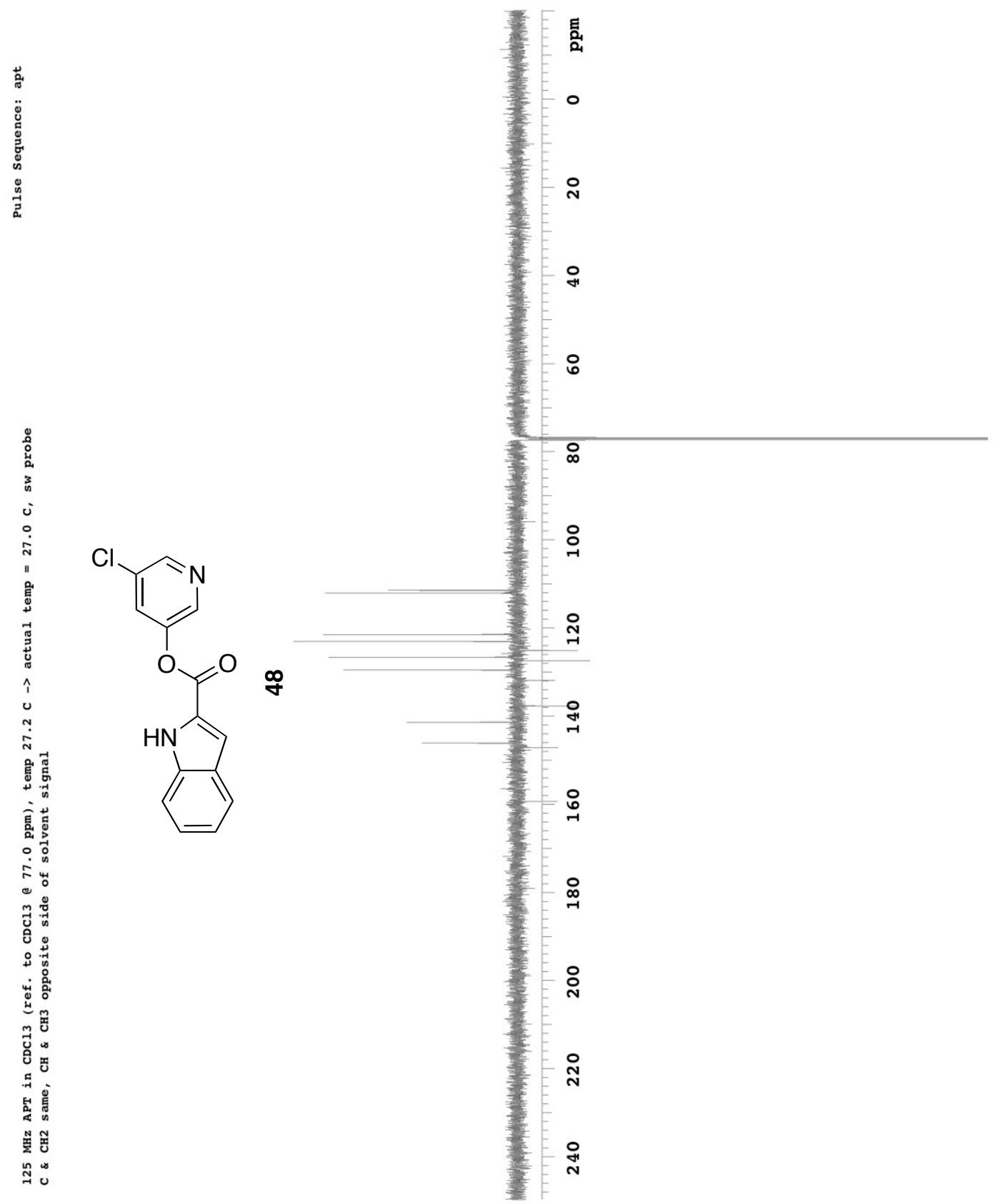




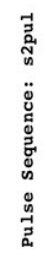

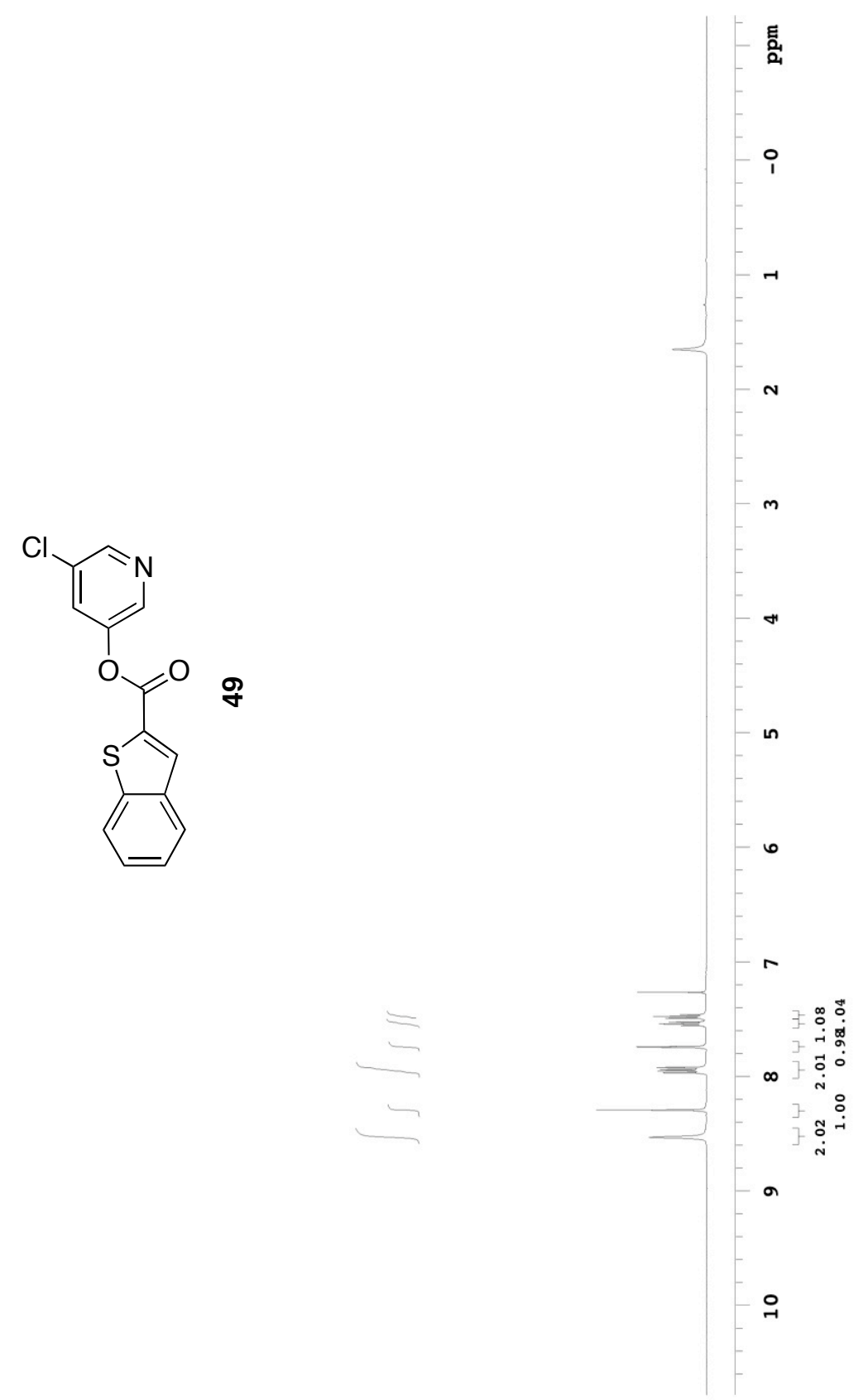




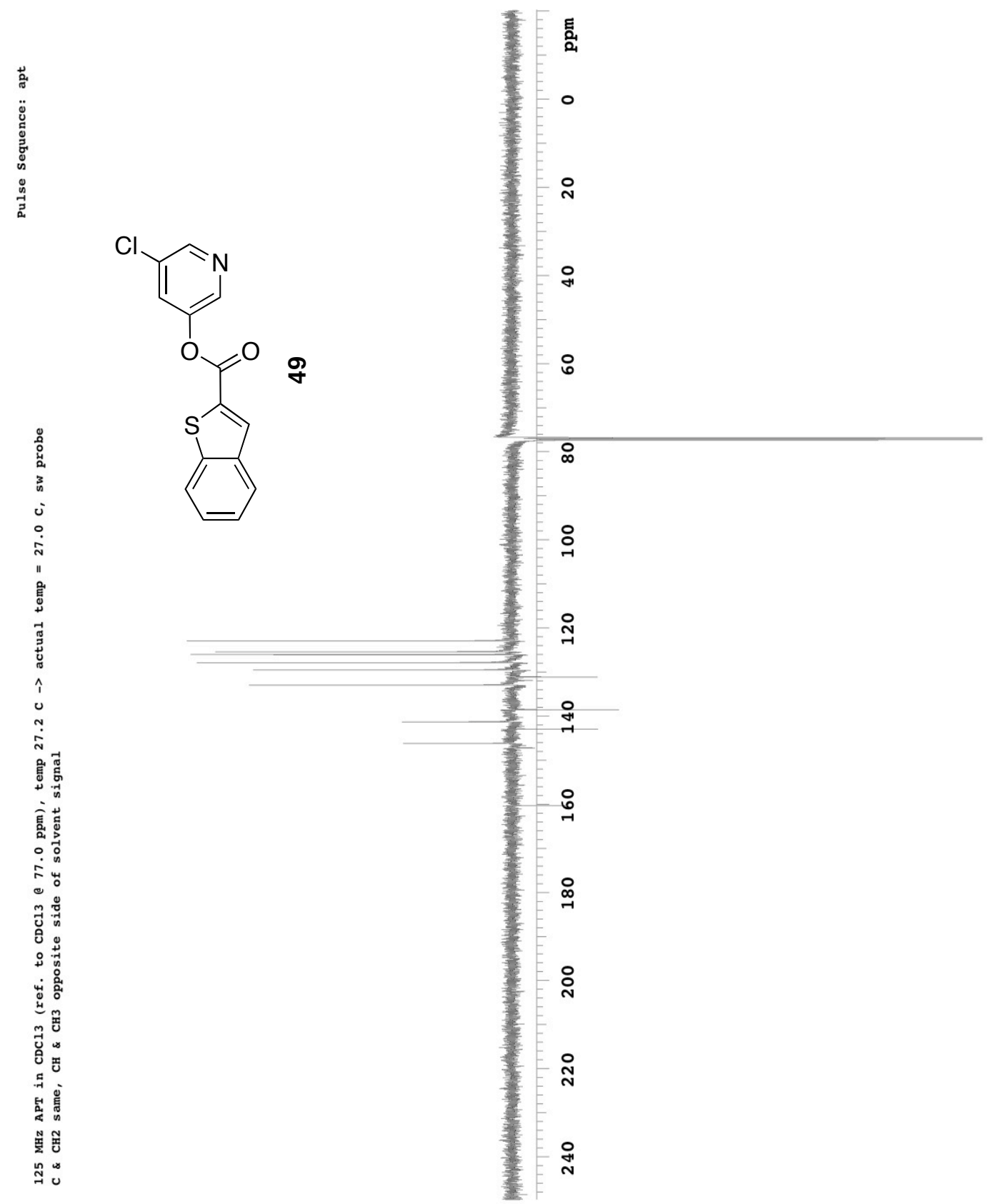




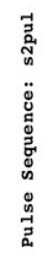

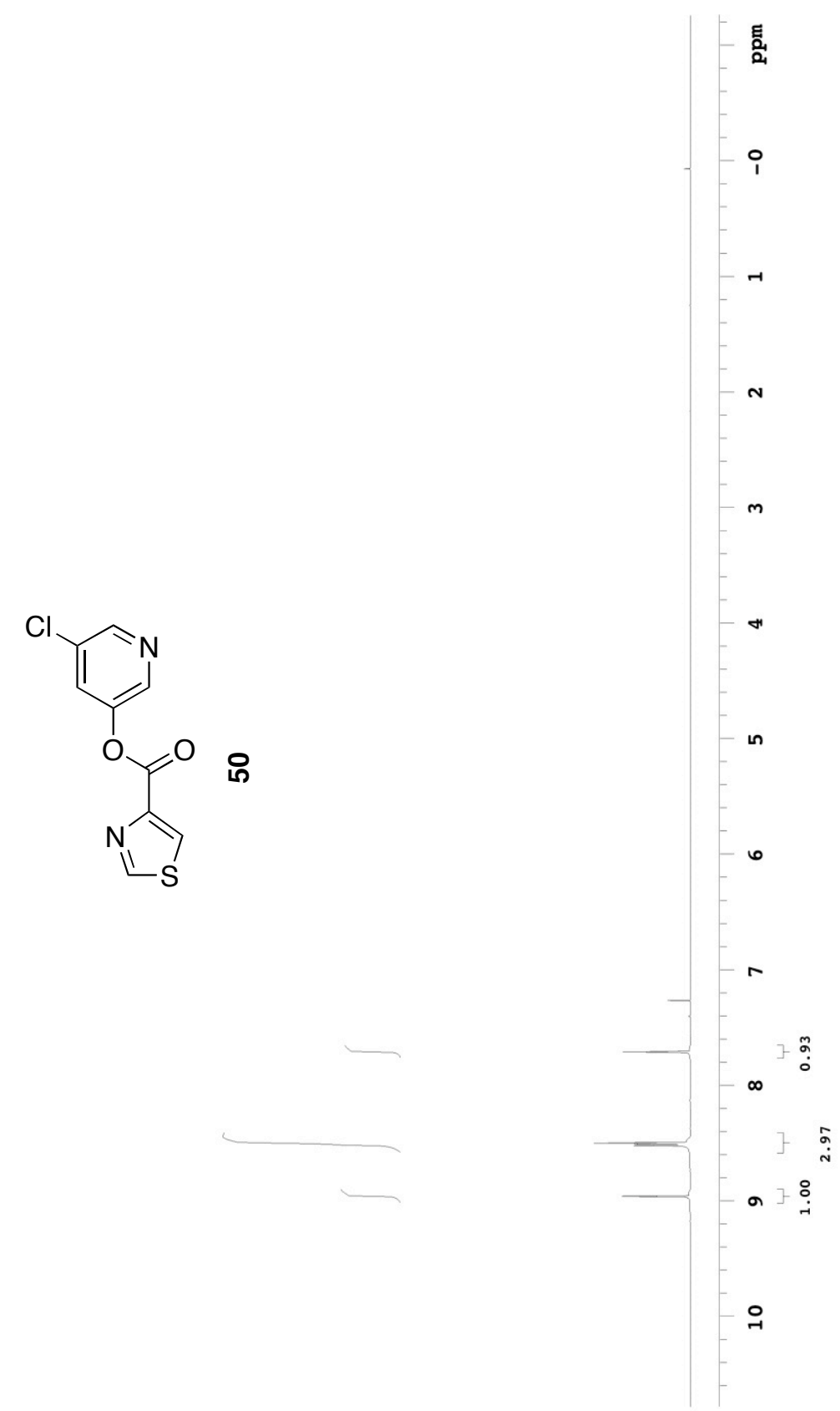




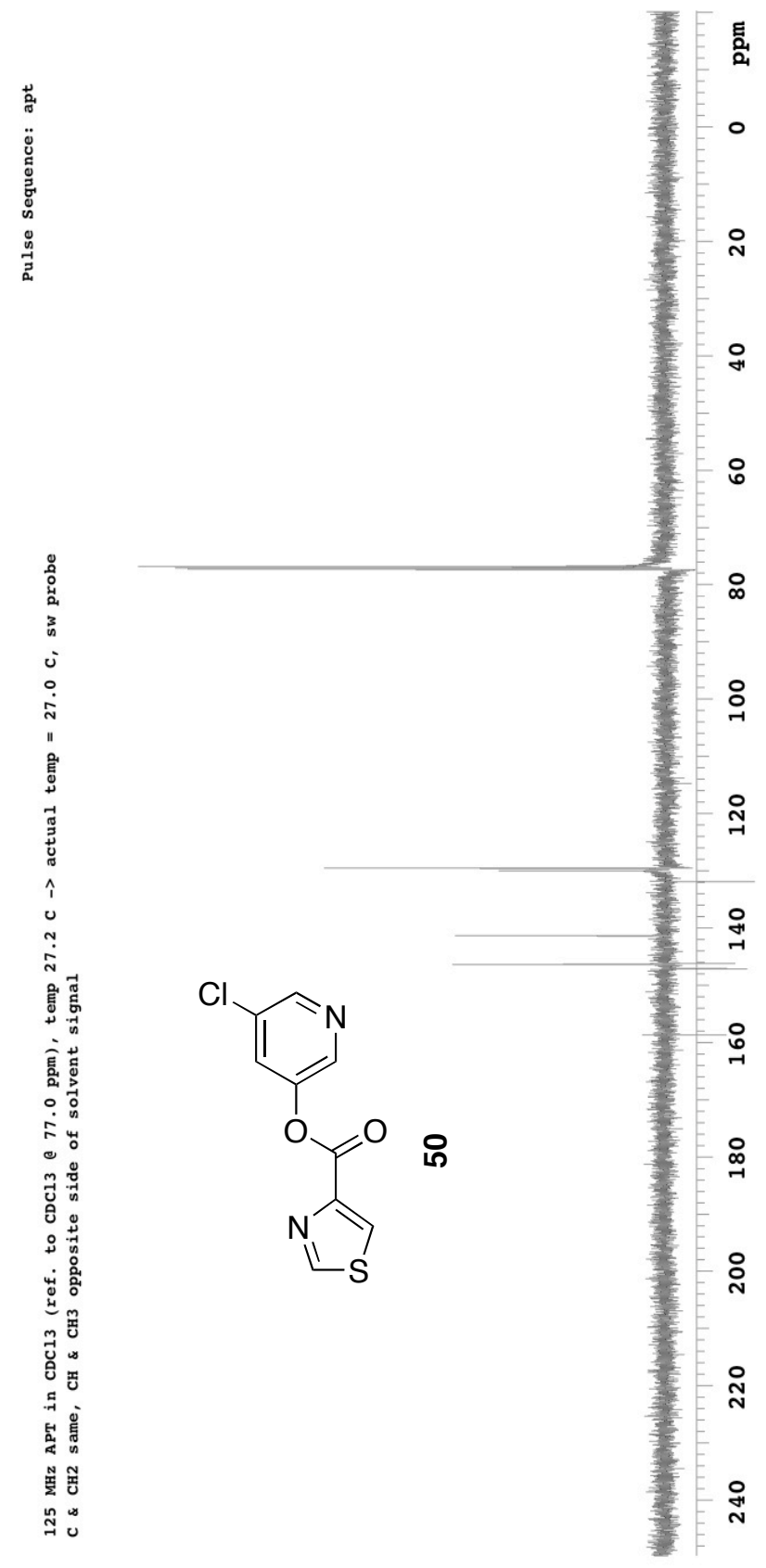




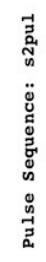

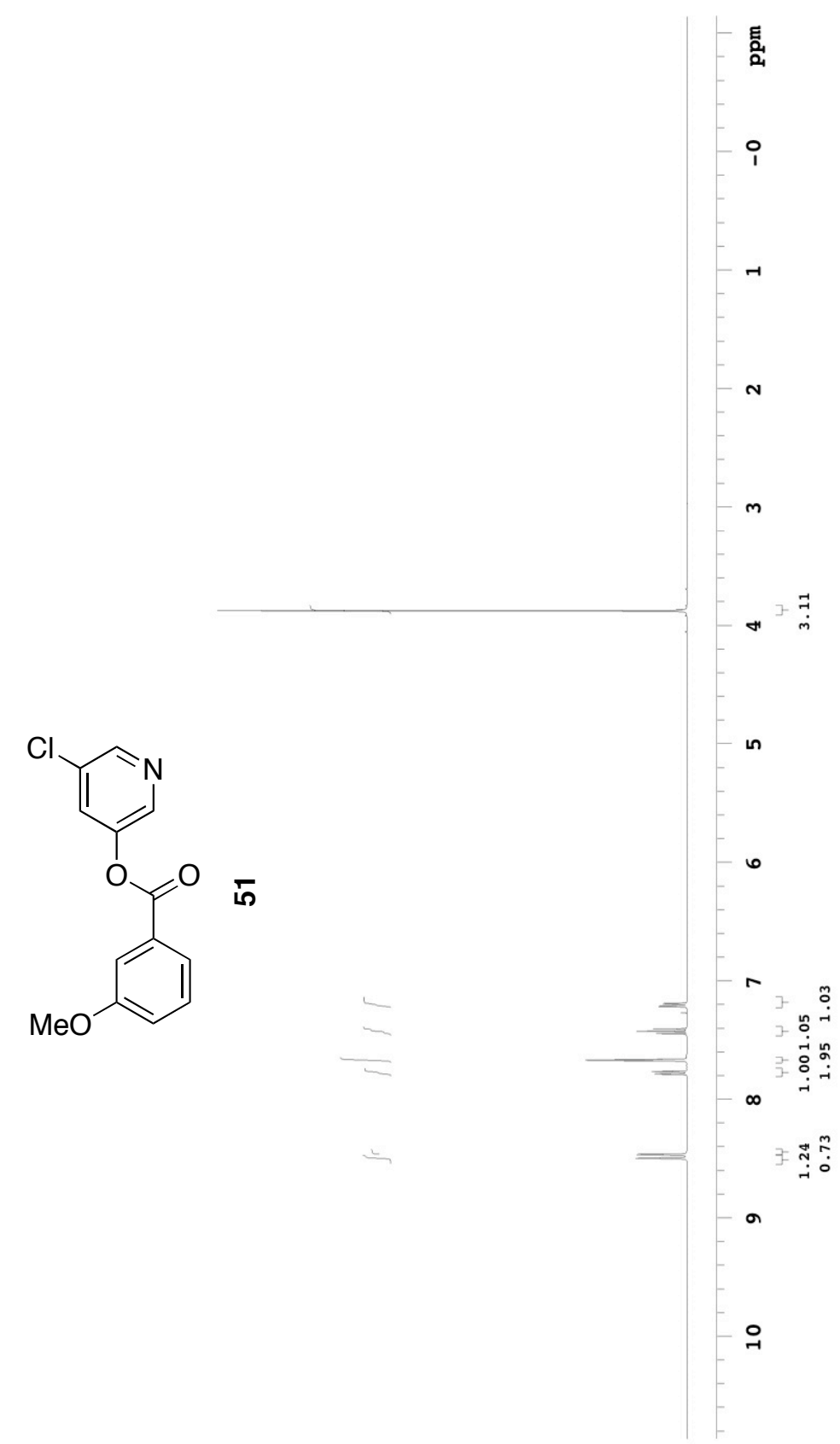




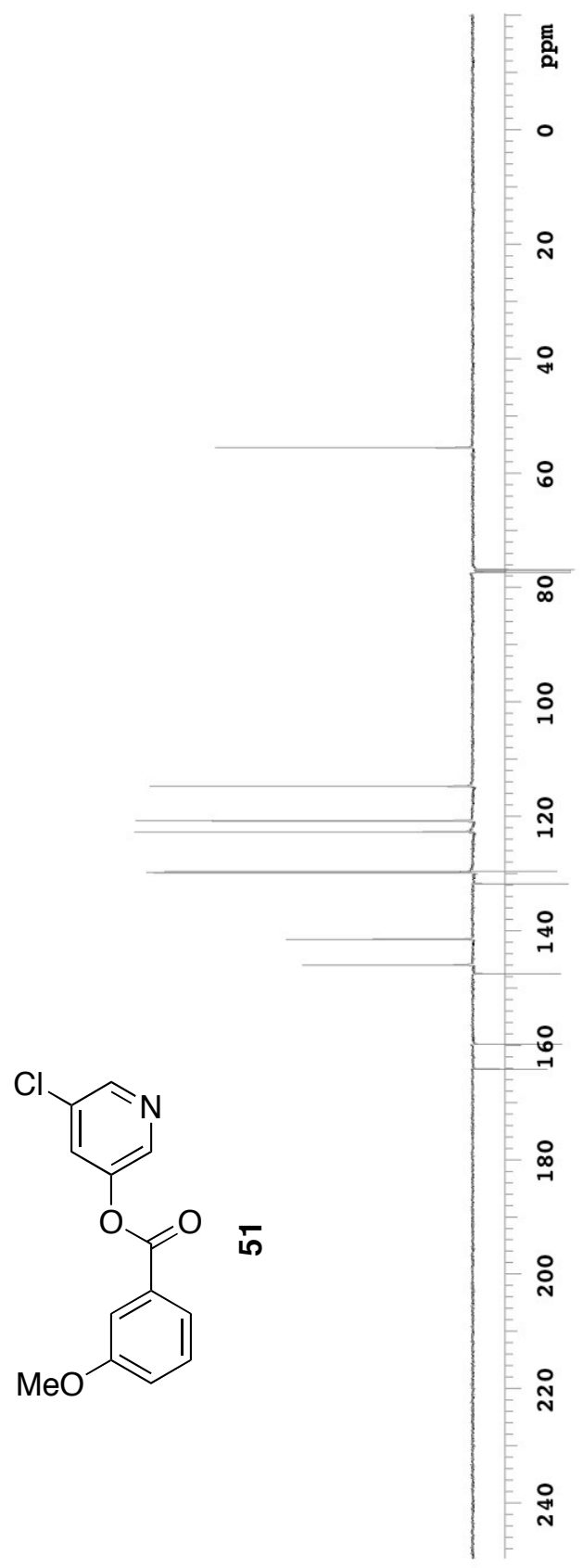




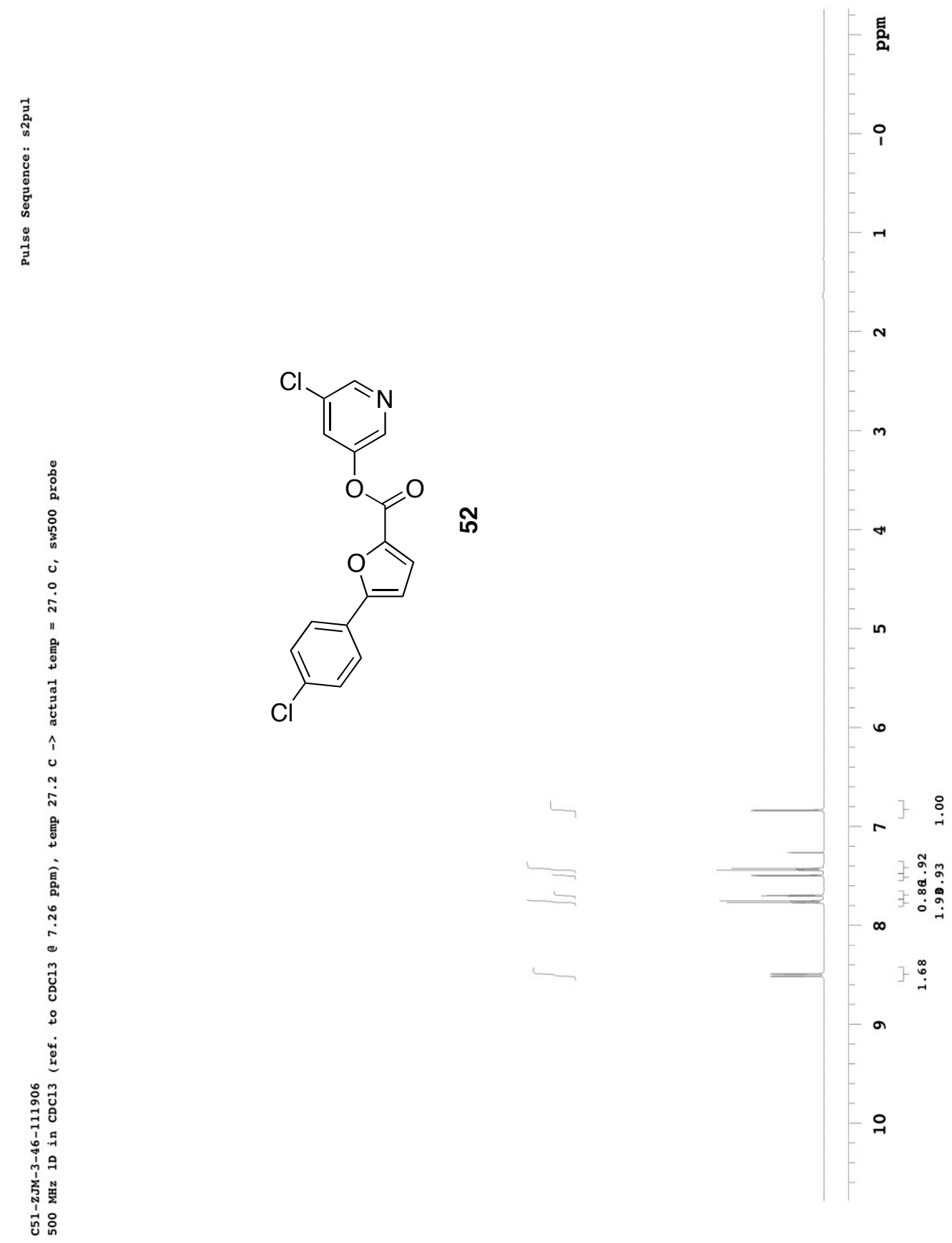




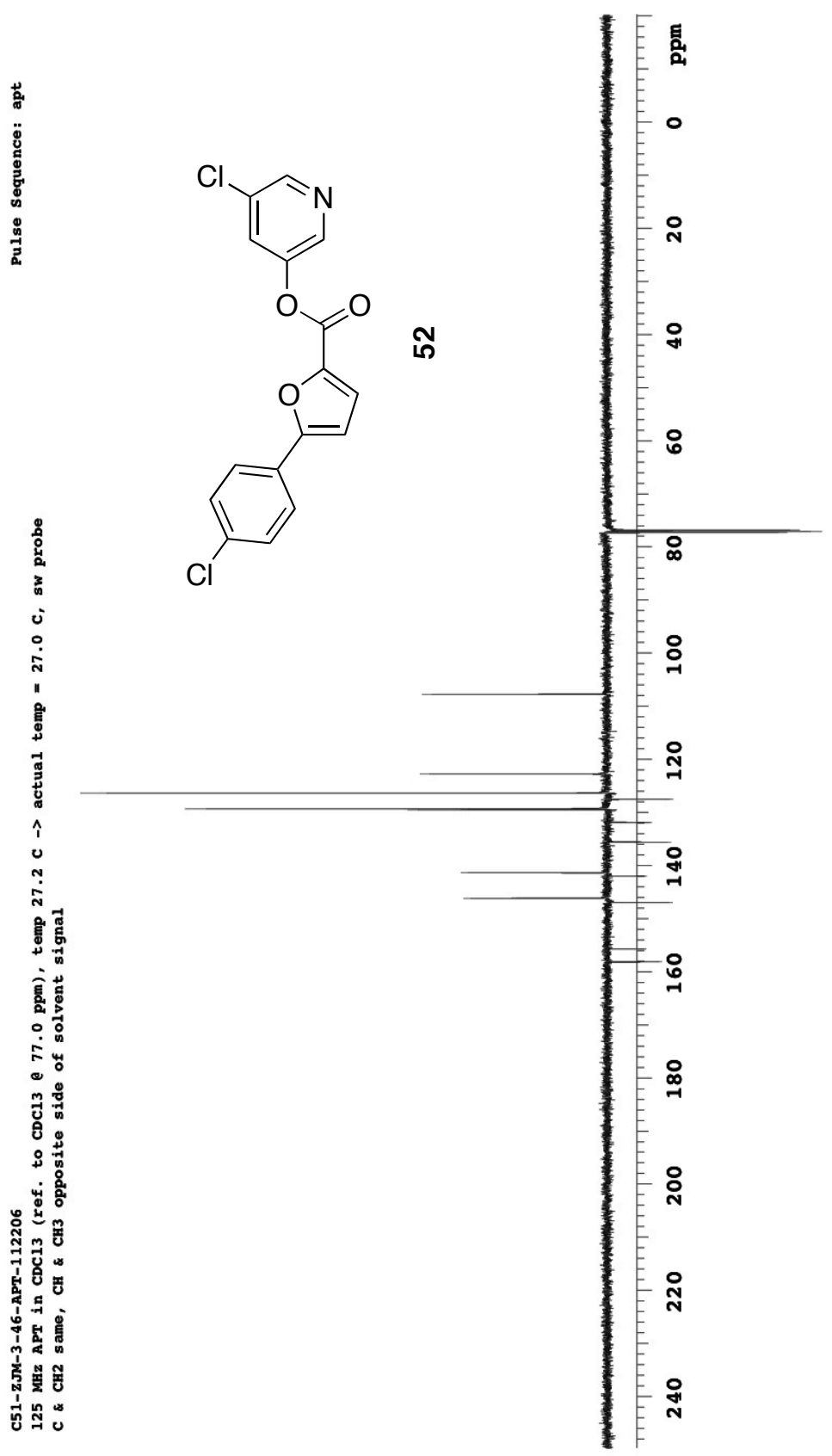




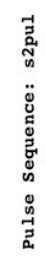

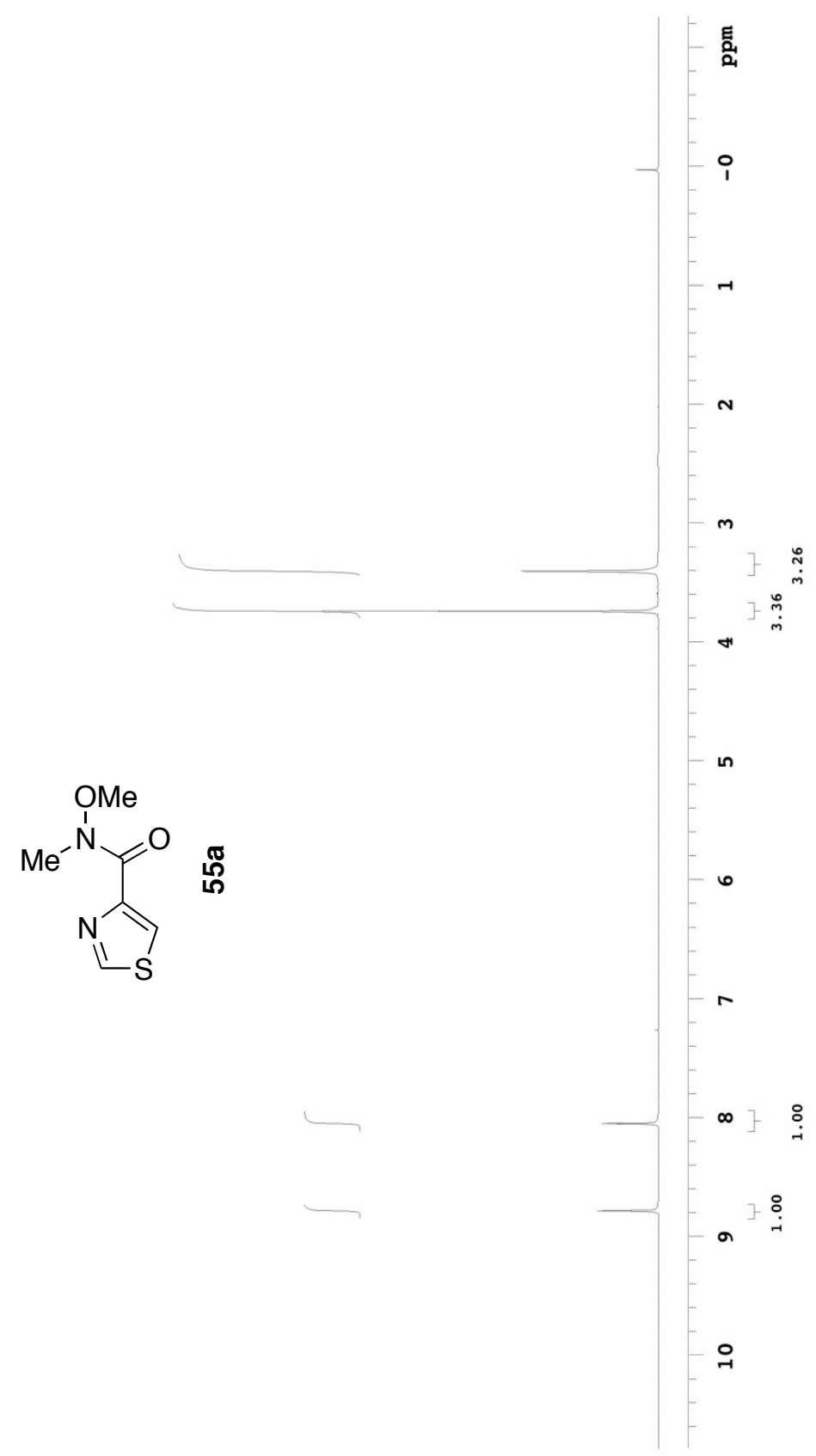




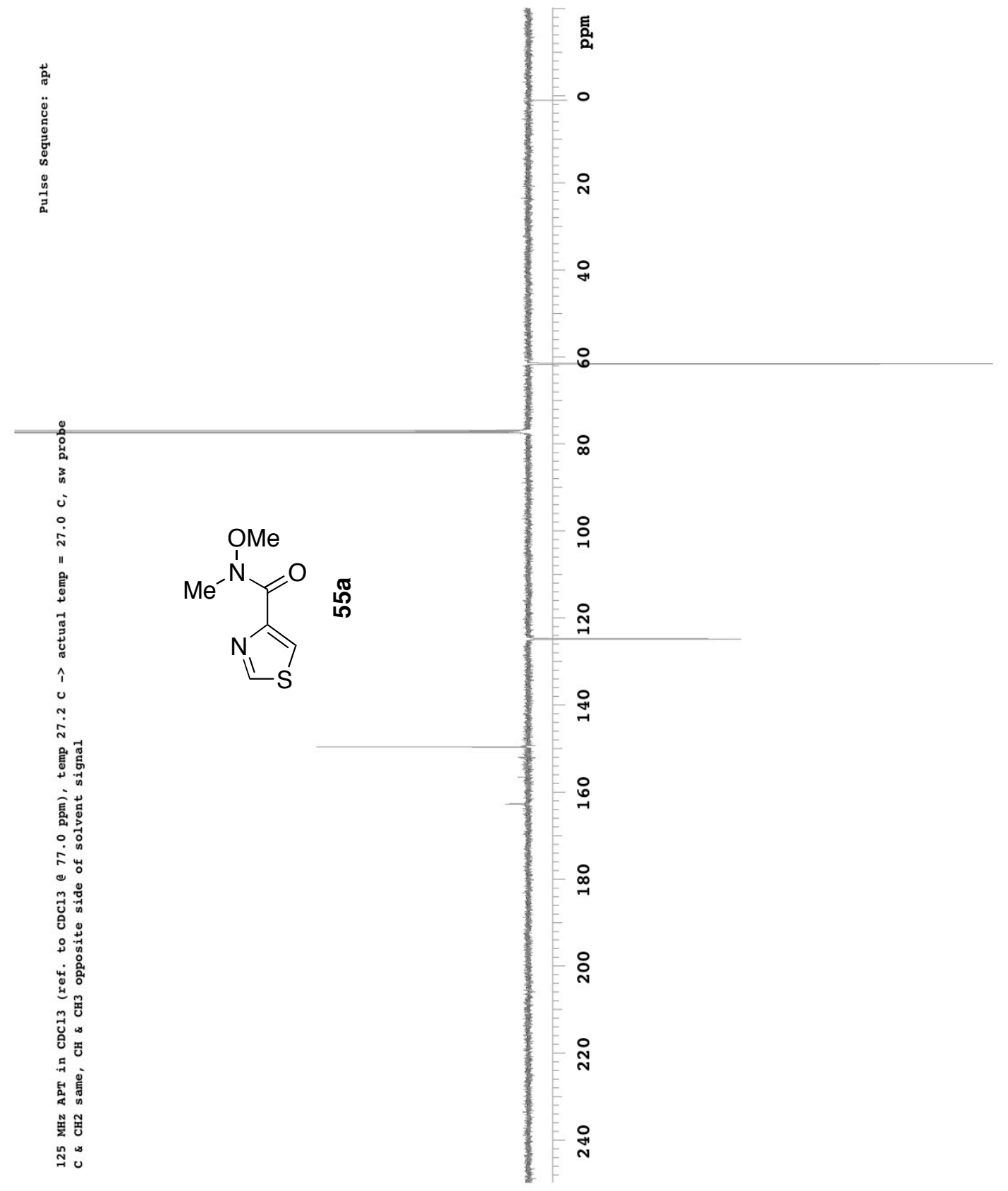




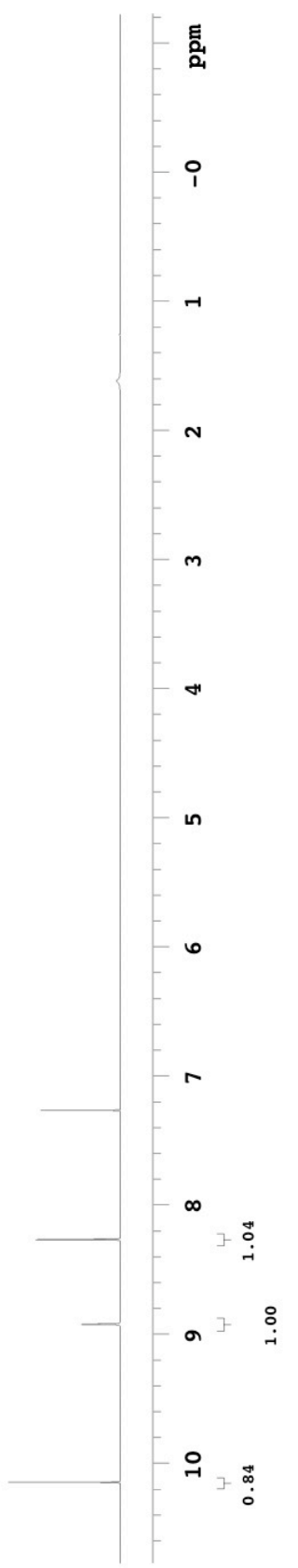




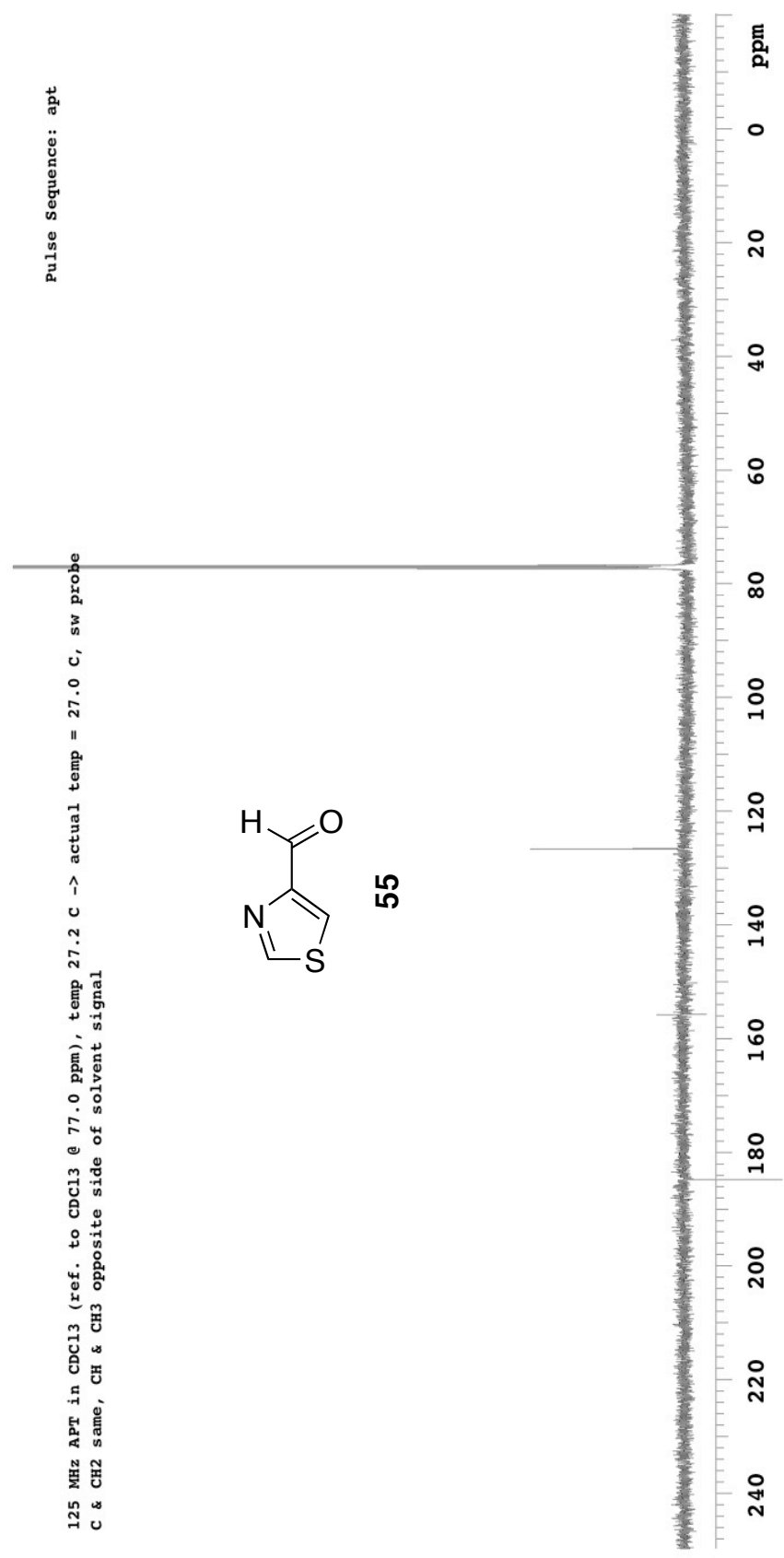




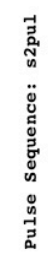

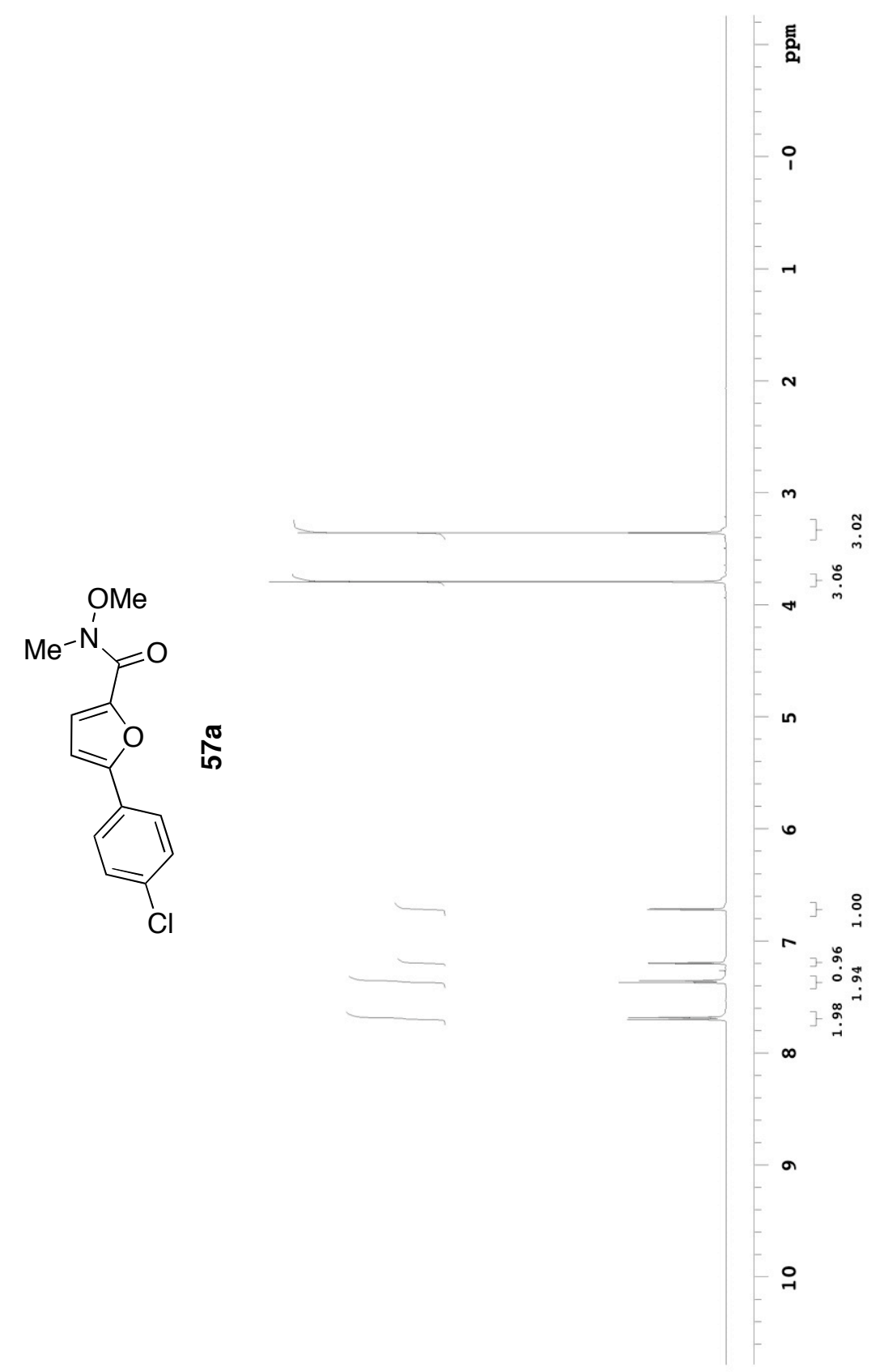




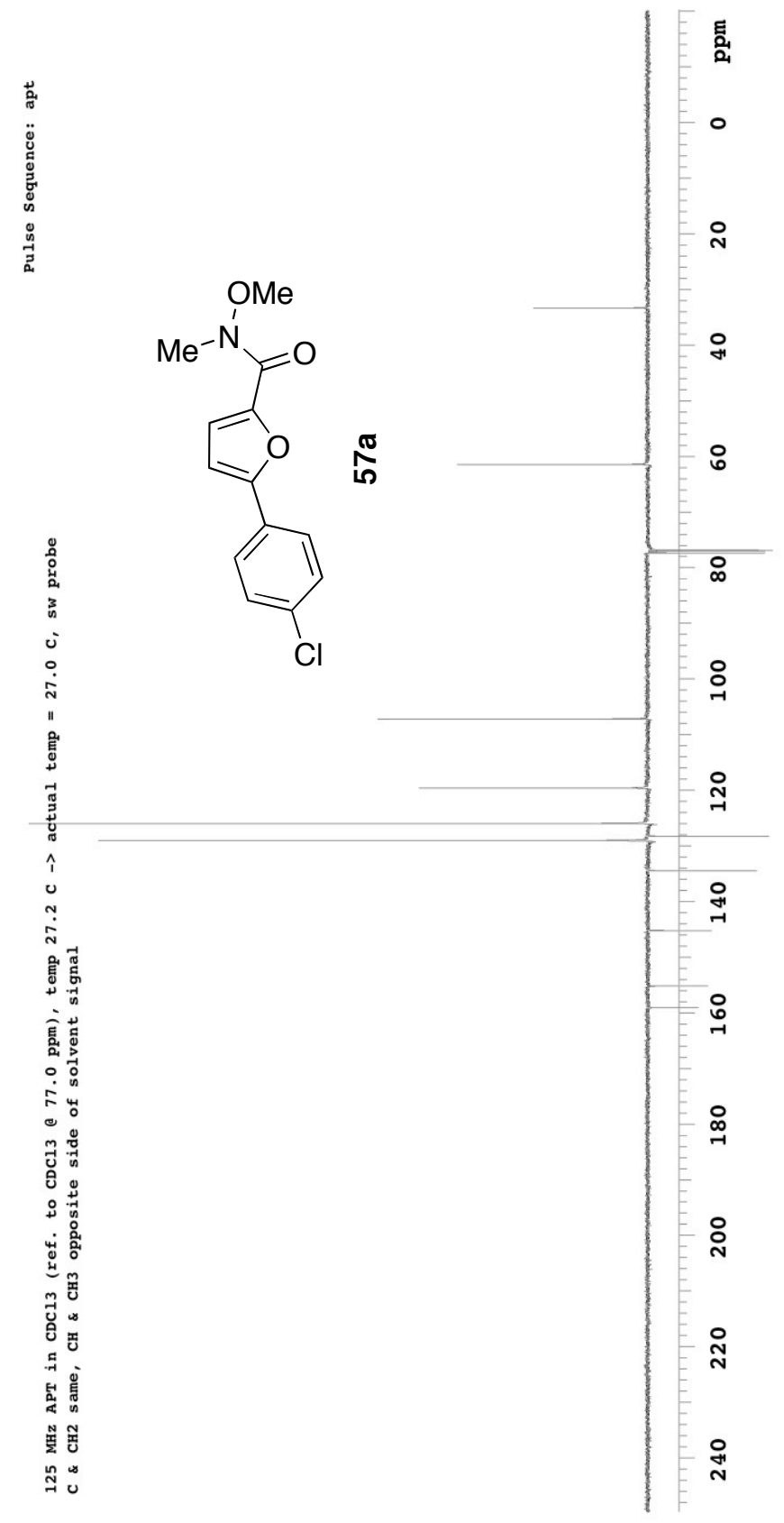




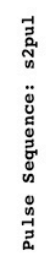

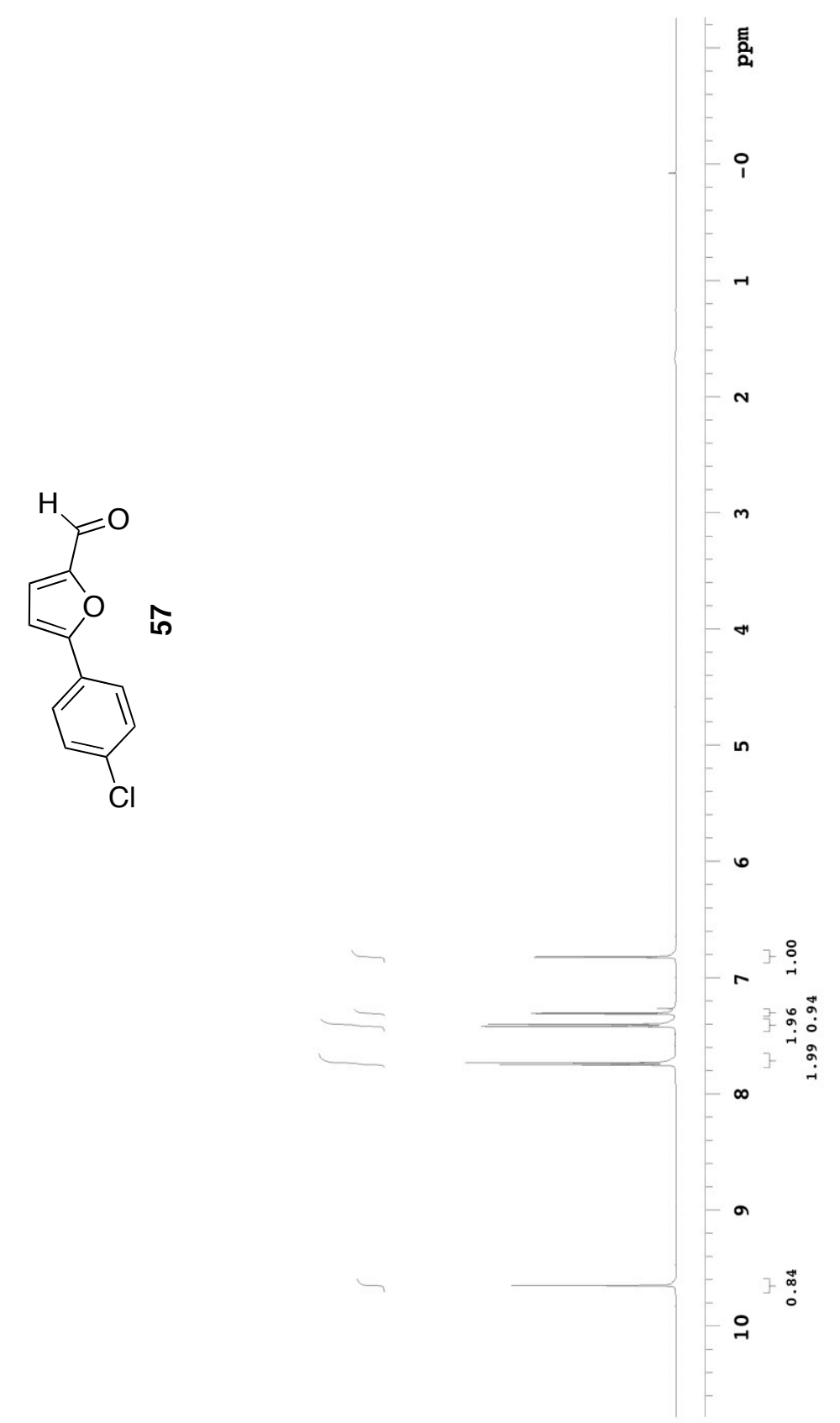




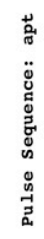

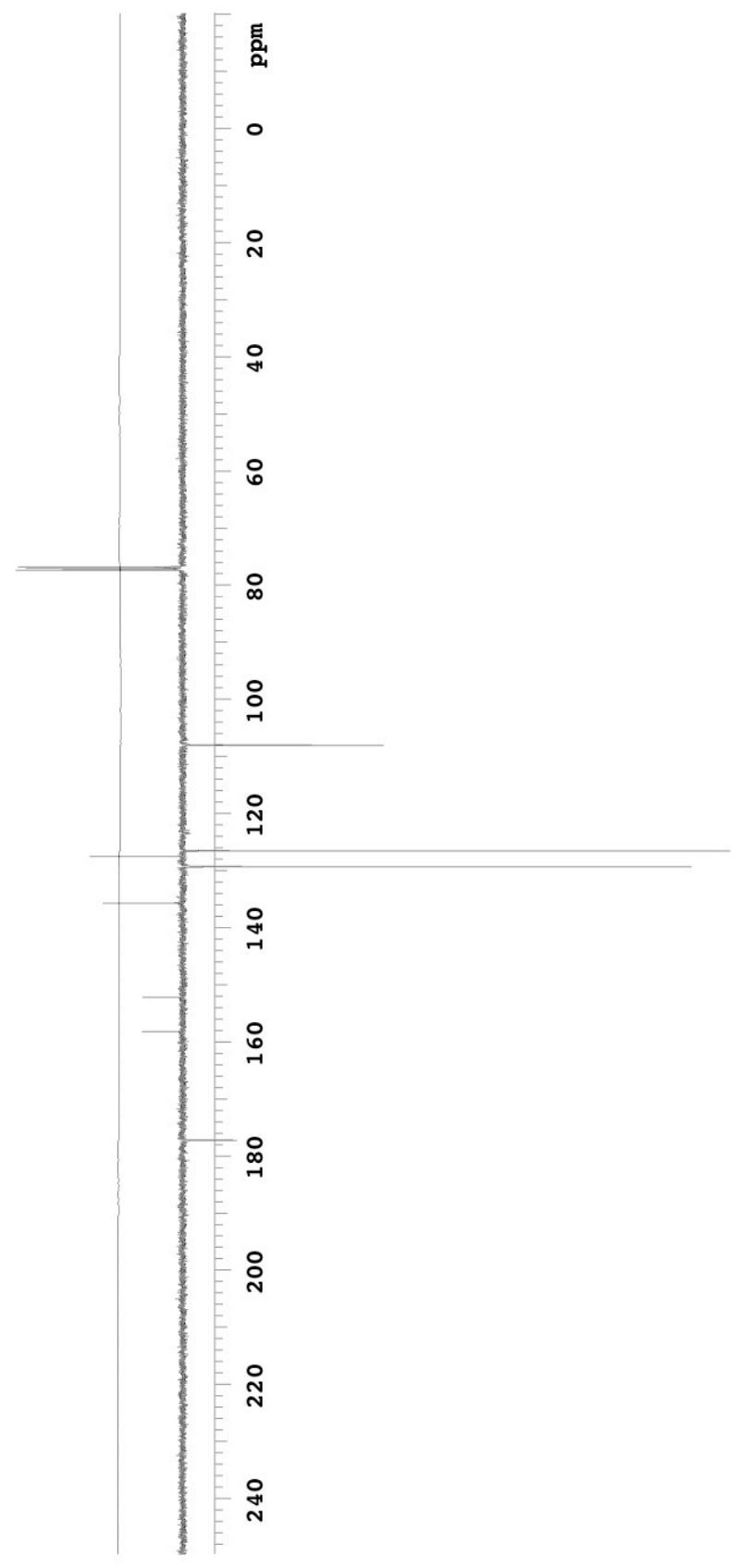

